\title{
Donut worry
}

Citation for published version (APA):

Schepers, R. (2018). Donut worry: the role of 5-HTTLPR genotype and ruminative thinking in emotional eating behaviour. [Doctoral Thesis, Maastricht University]. Maastricht University. https://doi.org/10.26481/dis.20180509rs

Document status and date:

Published: 01/01/2018

DOI:

10.26481/dis.20180509rs

Document Version:

Publisher's PDF, also known as Version of record

\section{Please check the document version of this publication:}

- A submitted manuscript is the version of the article upon submission and before peer-review. There can be important differences between the submitted version and the official published version of record.

People interested in the research are advised to contact the author for the final version of the publication, or visit the DOI to the publisher's website.

- The final author version and the galley proof are versions of the publication after peer review.

- The final published version features the final layout of the paper including the volume, issue and page numbers.

Link to publication

\footnotetext{
General rights rights.

- You may freely distribute the URL identifying the publication in the public portal. please follow below link for the End User Agreement:

www.umlib.nl/taverne-license

Take down policy

If you believe that this document breaches copyright please contact us at:

repository@maastrichtuniversity.nl

providing details and we will investigate your claim.
}

Copyright and moral rights for the publications made accessible in the public portal are retained by the authors and/or other copyright owners and it is a condition of accessing publications that users recognise and abide by the legal requirements associated with these

- Users may download and print one copy of any publication from the public portal for the purpose of private study or research.

- You may not further distribute the material or use it for any profit-making activity or commercial gain

If the publication is distributed under the terms of Article $25 \mathrm{fa}$ of the Dutch Copyright Act, indicated by the "Taverne" license above, 


\section{Donut worry}

The role of 5-HTTLPR genotype and ruminative thinking in emotional eating behaviour.

Robbie Schepers 
Kaft Illustratie: $\quad$ David Benton (Droidloot)

Kaft Ontwerp: $\quad$ Floor Vogels en Robbie Schepers

Layout: $\quad$ Floor Vogels

Druk: $\quad$ Ridderprint BV

ISBN: $\quad$ 978-94-6299-923-7

Dit werk is (mede)gefinancierd door de Nederlandse Organisatie voor Wetenschappelijk Onderzoek (NWO) onder de projectnaam: 'Gene by Cognition influences on emotional eating; a moderating role for ruminative thinking?' projectnummer 057-13-004. 


\section{Donut worry}

The role of 5-HTTLPR genotype and ruminative thinking in emotional eating behaviour.

\section{PROEFSCHRIFT}

Ter verkrijging van de graad van doctor aan de Universiteit Maastricht, op gezag van de Rector Magnificus, Prof. dr. Rianne M. Letschert, volgens het besluit van het College van Decanen, in het openbaar te verdedigen op woensdag 9 mei 2018 om 16.00 uur.

door

Robbie Schepers 


\section{Promotor}

Prof. dr. C.R. Markus

\section{Copromotor}

Dr. E. H. H. Keulers

\section{Beoordelingscommissie}

Prof. dr. J.G. Ramaekers (voorzitter)

Prof. dr. A.A. van Elburg, Universiteit Utrecht

Dr. C. Nederkoorn

Dr. A. Roefs

Prof. dr. M.A.M. Smeets, Universiteit Utrecht 
Grab your coat and 8rab your hat, leave your worries on the doorstep

Just direct your feet to the sunny side of the street

Can't you hear that pitter-pat?

That happy tune is your step

Life can be so sweet, on the sunny side of the street

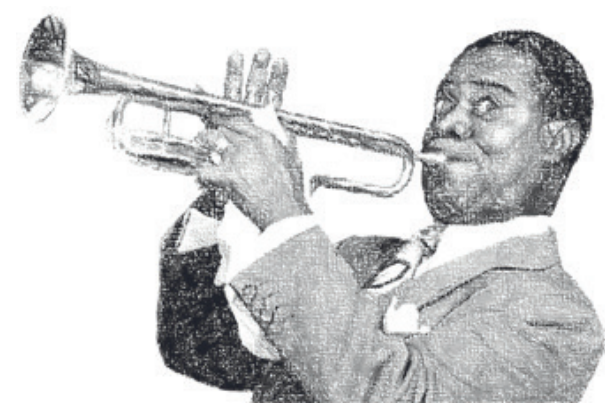





\section{Contents}

$\begin{array}{lll}\text { Chapter } 1 \text { General Introduction } & \text { Page } 9\end{array}$

Chapter 2 The interaction between 5-HTTLPR genotype and Page 31 ruminative thinking on body mass index

Chapter 3 Gene by cognition interaction on stress-induced Page 53 attention bias for food: effects of 5-HTTLPR and ruminative thinking

Chapter 4 The effect of 5-HTTLPR genotype and cognitive Page 77 rumination on long term cortisol reactivity measured in human hair.

Chapter 5 The interaction between 5-HTTLPR genotype and Page 91 Ruminative Thinking on Daily Stress and Food Intake a multilevel approach

Chapter 6 General Discussion

Page 113

References

Page 127

Summary

Page 147

Samenvatting

Page 153

Valorization Addendum

Page 159

Dankwoord

Page 165

Curriculum Vitae

Page 171

Publications

Page 175 



\section{Chapter 1}

\section{General Introduction}

\section{Published as:}

Schepers, R., \& Markus, C. R. (2015). Gene $\times$ cognition interaction on stress-induced eating: Effect of rumination. Psychoneuroendocrinology, 54, 4153. 
The worldwide epidemic of overweight is considered one of the greatest threats to human health. In recent years, the prevalence of clinical overweight or obesity has increased to 30 percent of the population in the US (Flegal et al., 2010) and in Europe (Berghofer et al., 2008). People with obesity have an overall poorer quality of health, a higher risk of developing diabetes (Mokdad et al., 2001) and a heightened risk of developing mood disorders (Dong, et al., 2004). Multiple factors have been proposed as contributors to the increased prevalence of obesity, of which a sedentary lifestyle and easy access to energy dense foods seem to be among the important contributors (Wing et al., 2001). Although most people in the Western world have easy access to energy dense foods, many do not suffer from obesity. Therefore individual differences in weight gain might be related to different levels of susceptibility to unhealthy eating styles. One of these well-known risky eating styles with regard to weight gain is: emotional eating, also called stress-induced eating.

Stress-induced eating refers to eating in response to stress and/or negative mood to fulfil emotional needs (to feed a feeling) rather than nutritional needs (to feed an empty stomach). This positive relationship between stress and increased food intake has been evidenced in several large populationwide association studies (Kivimaki et al, 2006; Mellbin \& Vuile, 1989; Ng \& Jeffrey, 2003). For instance, in their well-conducted large survey study ( $\mathrm{N=12110),} \mathrm{Ng}$ and Jeffery (2003) reported a clear positive association between perceived emotional stress and total energy and fat intake. Additionally, in a longitudinal cohort study in which children were monitored for three years (between the ages of 7 and 10), disproportionate weight gain was significantly associated with higher levels of psychosocial stress (Mellbin \& Vuile, 1989). A more specific form of stress, stress at the workplace, seems to predict weight gain as well, as indicated by a large longitudinal (5 year) study (Kivimaki et al., 2006). As the assessment of emotional eating differs between studies, some use dichotomous measures, quantitative measures 
or completely subjective measures, the prevalence of stress-induced eating is not definitively known, but seems to lie around approximately $40 \%$. In a survey on eating behaviour (Zellner et al., 2006), 37\% of women and 52\% of men reported to eat less when stressed, whereas $46 \%$ of women and only $17 \%$ of men reported to eat more under stress. Additionally, in a study related to the effects of examination stress $26 \%$ of participants reported eating less when stressed, whereas $36 \%$ reported consuming more during stressful periods (Epel et al., 2004). In Gibson's (2012) recent review, the results of multiple studies were combined to estimate the prevalence of stress-induced eating. Approximately $40 \%$ to $70 \%$ of people reported eating less under stress, whereas $30 \%$ to $50 \%$ of respondents reported eating more during stressful periods. In this same review, most studies reported that stress-induced eating occurred more frequently in females than in males. As the emphasis of this thesis lies on emotional eating as a possible factor contributing to obesity/weight gain, only the stress-induced increase of food intake will be explored/explained in the current thesis.

\section{Stress-induced eating with respect to particular foods}

Eating in response to stress may at first appear to contradict the normal response of a loss of appetite when facing threat. During acute stress the Hypothalamic-Pituitary-Adrenal-axis (HPA-axis) becomes more active; increasing the release of blood sugar and several glucocorticoids (including nor-adrenaline and corticotrophin-releasing hormones (CRH) that are known to suppress appetite (Torres \& Nowson, 2007). This effect of stress on appetite has often been demonstrated in animal studies (Arborelius et al, 1999; Marti, et al., 1994; Valles et al., 2000) and in a few human studies (for a review see: Takeda et al., 2004). However, whether stress increases energy intake appears to be significantly determined by the type of food that is available. In most animal studies, stress suppresses food intake when animals are only given chow. By contrast, stress has been found to increase food intake when animals have access to fatty and/or sweet foods (Dallman et al., 2003). 
This tendency to increase (rather than to suppress) energy intake during stress from high fat and/or sugary foods is a distinguished characteristic of emotional eating in humans, as found in a broad range of association, longitudinal and/or experimental studies (for an overview, see table 1). For instance supportive survey studies have been conducted across several countries, including the US (Kandiah et al., 2006), the UK (Cartwright et al., 2003) Sweden (Elfhag et al., 2008), Finland (Konttinen, 2010; Laitinen et al., 2002), France (De Lauzon et al., 2006) and China (Liu et al, 2007). Conflicting results have been reported as well though as two other large surveys could not see an increase in food intake caused by stress (Anschutz et al., 2009; Lluch et al., 2000). In addition to these observational association studies, experimental studies have provided sound evidence that people often eat more (sugary/ fatty products) during stressful times. For instance, in one study by Epel et al. (2001) women increasingly snacked on high-caloric sweet foods under stress exposure; a behaviour that has been interpreted as a function of their psychophysiological (cortisol) stress responsiveness. Numerous similar studies have found that people eat more after an experimental stressor in the lab (with a greater preference for sugary/fatty foods) (Born et al., 2010; Epel et al., 2004; Habhab et al., 2008; Rutters et al., 2009; Zellner et al., 2006). These experimental findings have been further supported by associative studies that established a strong link between daily stressors and an increased intake of fatty and/or sweet foods. In a study that followed women during a post graduate course for 15 weeks (including examination), higher cortisol levels appeared to predict weight gain (in BMI) due to a greater intake of calories from fats and carbohydrates (Roberts et al., 2014). Newman et al. (2007) found comparable results, indicating that women's increased snacking under daily stress is a function of cortisol stress responsiveness. Additionally, a survey of 457 women found a relationship between self-reported daily stress and the tendency to eat more calories from palatable (high fat/sweet) foods (Groesz et al., 2012).

Although the formerly stated studies clearly established stress-induced eating 
as a prevalent eating style, the reasons for certain individuals to eat more high fat/sugary foods under stress than others remain unresolved. Consequently, numerous studies from different scientific fields have attempted to identify meaningful risk factors for emotional (stress-induced) overeating, ranging from heritability and biological factors to cognitive-behavioural risk factors.

\section{Heritability}

Obesity has been found to be heritable; over 100 genes have been associated with this condition (Yang et al., 2007). It has been suggested that genes may influence obesity particularly in terms of promoting a behavioural trait to eat without hunger (Faith et al., 2006; Fisher et al., 2007). Twin studies have indicated the heritability of stress-induced eating for instance, a Swedish study showed a heritability of $60 \%$ for stress-induced eating (Tholin et al., 2005), a British/Finnish study reported a lower heritability of 9-45\% (Keskitalo et al., 2008) and a Korean study revealed a heritability of $25 \%$ (Sung et al., 2010). As the effect sizes between these studies show great heterogeneity, the heritability of emotional eating remains debatable and it is more likely that genes are a contributing factor than the only determining factor. Hence, if genes contribute to the risk for obesity and/or stress-induced eating, they may do so engendering a specific vulnerability rather than serving as the main cause.

\section{Other biological factors}

Other biological explanations for individual differences in (stress induced) eating behaviour can be found in the rewarding effect of palatable foods. Highly palatable foods activate the brain's reward systems involving dopamine, endocannabinoid and opioid pathways in the limbic system (Cota et al., 2006). Individual differences in the activation of such brain reward areas could explain differences in vulnerabilities for emotional eating as; emotional eaters often exhibit an increased activation of these reward areas in anticipation of and/or after the consumption of a sweet milkshake when experiencing negative mood (Bohon et al., 2009). Additionally hormones 
also seem to play a role in the relation between stress and eating behaviour. Normally, the leptin hormone inhibits the drive to eat highly palatable foods when the body is satiated. However, when people have high levels of (stress-related) glucocorticoids, the body might develop a resistance to leptin (Bjorntorp, 2001), thereby diminishing the effectiveness of the satiety break in favour of the rewarding impact of high palatable foods. This mechanism could explain how the experience of (chronic) stress can lead to increased intake of highly palatable foods.

Table 1. An overview of studies examining the relation between stress and a preference for sweet and/or fatty foods.

\begin{tabular}{|c|c|c|c|c|}
\hline Design & Type of Stress & Author & Sample & $\begin{array}{l}\text { Food preference } \\
\text { during/after stress }\end{array}$ \\
\hline \multirow[t]{11}{*}{$\begin{array}{l}\text { Association } \\
\text { Study }\end{array}$} & Life stress & $\begin{array}{l}\text { Kandiah et al., } \\
2006 \\
\text { Cartwright et al., } \\
2003\end{array}$ & $\begin{array}{l}\text { Female College Students } \\
(\mathrm{N}=272) \\
\text { Schoolchildren }(\mathrm{N}=4320)\end{array}$ & $\begin{array}{l}\text { Sweet and/or fatty } \\
\text { foods } \\
\text { Fatty foods }\end{array}$ \\
\hline & & Elfhag et al., 2008 & $\begin{array}{l}\text { Families (Fathers, } \\
\text { Mothers and Children, } \\
\mathrm{N}=4707 \text { ) }\end{array}$ & $\begin{array}{l}\text { Sweet foods (Among } \\
\text { women and girls) }\end{array}$ \\
\hline & & $\begin{array}{l}\text { Konttinen et al., } \\
2010\end{array}$ & $\begin{array}{l}\text { Men and women } \\
\text { between ages } 25 \text { and } 64 \\
(\mathrm{~N}=3714)\end{array}$ & Sweet foods \\
\hline & & $\begin{array}{l}\text { Laitinen, Ek \& } \\
\text { Sovio, } 2002\end{array}$ & $\begin{array}{l}\text { Adult men and women } \\
(\mathrm{N}=5150)\end{array}$ & $\begin{array}{l}\text { Sweet and/or fatty } \\
\text { foods }\end{array}$ \\
\hline & & $\begin{array}{l}\text { De Lauzon et al., } \\
2004\end{array}$ & $\begin{array}{l}\text { Adult men and women } \\
(\mathrm{N}=737)\end{array}$ & Energy dense foods \\
\hline & & Ng \& Jeffrey, 2003 & $\begin{array}{l}\text { Adult male and female } \\
\text { workers }(\mathrm{N}=12110)\end{array}$ & Fatty foods \\
\hline & & $\begin{array}{l}\text { Oliver \& Wardle, } \\
1999\end{array}$ & $\begin{array}{l}\text { Male and female } \\
\text { students }(\mathrm{N}=212)\end{array}$ & $\begin{array}{l}\text { Sweet and/or fatty } \\
\text { foods }\end{array}$ \\
\hline & & $\begin{array}{l}\text { Anschutz et al., } \\
2009\end{array}$ & Female students $(\mathrm{N}=475)$ & $\begin{array}{l}\text { No significant } \\
\text { preference }\end{array}$ \\
\hline & & Lluch et al., 2000 & $\begin{array}{l}\text { Men, Women and } \\
\text { Children }(\mathrm{N}=1320)\end{array}$ & $\begin{array}{l}\text { No significant } \\
\text { preference }\end{array}$ \\
\hline & & $\begin{array}{l}\text { Nguyen-Michel et } \\
\text { al., } 2008\end{array}$ & Latino Children $(\mathrm{N}=617)$ & $\begin{array}{l}\text { Sweet and/or and } \\
\text { salty, energy dense } \\
\text { foods }\end{array}$ \\
\hline & & $\begin{array}{l}\text { Cartwright et al., } \\
2003\end{array}$ & Children $(\mathrm{N}=4320)$ & Fatty foods \\
\hline
\end{tabular}




\begin{tabular}{|c|c|c|c|c|}
\hline & & $\begin{array}{l}\text { Wallis \& } \\
\text { Hetherington, } \\
2009\end{array}$ & $\begin{array}{l}\text { Adult female students } \\
(\mathrm{N}=89)\end{array}$ & $\begin{array}{l}\text { Sweet and/or fatty } \\
\text { foods }\end{array}$ \\
\hline & & Liu et al., 2007 & $\begin{array}{l}\text { College students } \\
(\mathrm{N}=2579)\end{array}$ & Fatty foods \\
\hline & & $\begin{array}{l}\text { Steptoe \& Lipsey, } \\
1998\end{array}$ & $\begin{array}{l}\text { Nurses and teachers } \\
(\mathrm{N}=44)\end{array}$ & $\begin{array}{l}\text { Sweet and/or fatty } \\
\text { foods }\end{array}$ \\
\hline & $\begin{array}{l}\text { Life stress and } \\
\text { chronic stress }\end{array}$ & Groesz et al., 2012 & Adult females $(\mathrm{N}=457)$ & $\begin{array}{l}\text { Highly palatable } \\
\text { foods }\end{array}$ \\
\hline & $\begin{array}{l}\text { Life stress and } \\
\text { workload }\end{array}$ & $\begin{array}{l}\text { McCann et al., } \\
1990\end{array}$ & $\begin{array}{l}\text { Adult male and female } \\
\text { workers }(\mathrm{N}=14)\end{array}$ & Fatty foods \\
\hline & Exam stress & $\begin{array}{l}\text { Michaud et al., } \\
1990\end{array}$ & $\begin{array}{l}\text { High School students } \\
(\mathrm{N}=225)\end{array}$ & Fatty foods \\
\hline & & Pollard et al., 1995 & $\begin{array}{l}\text { Male and female } \\
\text { students }(\mathrm{N}=179)\end{array}$ & $\begin{array}{l}\text { No significant } \\
\text { preference }\end{array}$ \\
\hline & & $\begin{array}{l}\text { O' Conner \& } \\
\text { O'Conner, } 2004\end{array}$ & $\begin{array}{l}\text { Adult female students } \\
(\mathrm{N}=131)\end{array}$ & $\begin{array}{l}\text { Sweet and/or fatty } \\
\text { snacks }\end{array}$ \\
\hline & & $\begin{array}{l}\text { Capello \& } \\
\text { Markus, } 2014\end{array}$ & Adult students $(\mathrm{N}=87)$ & Sweet snacks \\
\hline & Work stress & $\begin{array}{l}\text { Wardle et al., } \\
2000\end{array}$ & $\begin{array}{l}\text { Department store } \\
\text { employees }(\mathrm{N}=71)\end{array}$ & $\begin{array}{l}\text { Sweet and/or fatty } \\
\text { foods }\end{array}$ \\
\hline & $\begin{array}{l}\text { Surgery } \\
\text { anxiety }\end{array}$ & Bellisle et al., 1990 & Hernia Patients $(\mathrm{N}=12)$ & $\begin{array}{l}\text { No significant } \\
\text { preference }\end{array}$ \\
\hline & Chronic stress & $\begin{array}{l}\text { Roberts et al., } \\
2014\end{array}$ & $\begin{array}{l}\text { Adult female students } \\
(\mathrm{N}=38)\end{array}$ & $\begin{array}{l}\text { Fatty and } \\
\text { carbohydrate rich } \\
\text { foods }\end{array}$ \\
\hline Experiment & Acute stressor & Epel et al., 2001 & Adult women $(\mathrm{N}=59)$ & Sweet foods \\
\hline & & Oliver et al., 2000 & $\begin{array}{l}\text { Adult men and women } \\
(\mathrm{N}=68)\end{array}$ & $\begin{array}{l}\text { Sweet and/or fatty } \\
\text { foods }\end{array}$ \\
\hline & & Rutters et al., 2009 & $\begin{array}{l}\text { Adult men and women } \\
(\mathrm{N}=129)\end{array}$ & Sweet foods \\
\hline & & Born et al., 2010 & Adult females (N=9) & $\begin{array}{l}\text { Crispy foods and } \\
\text { foods with full taste }\end{array}$ \\
\hline & & Zellner et al., 2006 & $\begin{array}{l}\text { Adult female students } \\
(\mathrm{N}=34)\end{array}$ & Sweet and fatty foods \\
\hline & & $\begin{array}{l}\text { Grunberg \& } \\
\text { Straub, } 1992\end{array}$ & $\begin{array}{l}\text { Adult men and women } \\
(\mathrm{N}=54)\end{array}$ & $\begin{array}{l}\text { No significant } \\
\text { preference }\end{array}$ \\
\hline & & $\begin{array}{l}\text { Wallis \& } \\
\text { Hetherington, } \\
2009\end{array}$ & Adult females $(\mathrm{N}=26)$ & $\begin{array}{l}\text { No significant } \\
\text { preference }\end{array}$ \\
\hline & & Epel et al., 2004 & Adult females $(\mathrm{N}=59)$ & $\begin{array}{l}\text { Sweet and/or fatty } \\
\text { foods }\end{array}$ \\
\hline & & $\begin{array}{l}\text { Habhab et al., } \\
2008\end{array}$ & $\begin{array}{l}\text { Adult female students } \\
(\mathrm{N}=40)\end{array}$ & $\begin{array}{l}\text { Sweet and/or fatty } \\
\text { foods }\end{array}$ \\
\hline
\end{tabular}




\section{Cognitive factors}

Apart from biological explanations, several cognitive factors also have been proposed to explain emotional (stress-induced) overeating. For instance, the Escape Theory (Heatherton \& Baumeister, 1991) states that people tend to search for external (non-personal) stimuli to focus on when they experience an event that threatens their ego. Regarding stress-induced eating, this might mean that people may increasingly focus (i.e., as a type of escape) on food as a function of the negative impact of a stressor to shift their attention from their aversive self-awareness (known as the avoidance-distraction theory). Wallis and Hetherington (2004) found evidence for this theory. In their experiment, female participants who scored high on self-awareness questionnaires consumed more chocolate after an ego-threatening task than after a non-ego threating but equally cognitive demanding task. Ancillary, stress-induced eating might function as an emotional coping mechanism to reduce the negative affective influence of a stressor through the positive hedonic experience of tasting pleasant food (Schachter et al., 1968). Both assumptions (escape and coping) have received support from empirical findings (e.g., Spoor et al. 2007). An additional attempt to explain stressinduced overeating based on a cognitive mechanism concerns the adoption of a restrained eating style. This theory states that people who consciously and continuously attempt to restrict food intake to control weight (predominantly women) may become even more vulnerable to lose this control under stress or other emotionally-disrupting (demotivating) circumstances (Greeno \& Wing, 1994). Additionally, other explanations of vulnerabilities to (stressinduced) unhealthy eating behaviours include the reduced ability to inhibit behavioural responses (Nederkoorn et al., 2010) or attentional biases toward food cues (Shafran et al., 2007).

\section{Behavioural disinhibition and attention bias}

Particularly in Western societies in which (unhealthy) foods are everpresent, the ability to inhibit the temptation to eat is an important factor for weight gain prevention. In fact, numerous studies have shown that obese 
people do not employ this ability as effectively as do lean control groups (see Nederkoorn et al., 2010). More specifically, people with reduced behavioural inhibition capacities tend to eat more during a taste test (Guerrieri et al., 2007), and experimentally induced impulsivity leads to greater levels of food consumption in restrained eaters compared to non-restrained eaters (Guerrieri et al., 2009). The efficacy of inhibition capacity seems to be a good predictor of weight gain, according to a study conducted by Nederkoorn et al. (2010). This study reported greater weight gain over a year in participants with low compared to high inhibition capacity and an implicit preference for snack food.

Notwithstanding, the need to inhibit food intake, can only arise after becoming perceptually aware of the food. Attention to food cues seems to be important to the onset and the course of unhealthy eating behaviour as well. For instance, compared with lean individuals, obese individuals attend to food cues more rapidly and longer and show no difference in this Behaviour in fastened and unfastened states (Castelanos et al., 2009).

\section{Explanatory approach of this thesis}

Previously described research on the potential contribution of various biological, cognitive and behavioural factors has led to important new insights into the possible mechanisms and risk factors that are involved in emotional eating. However, when attempting to establish an overall concept, it still remains very difficult to incorporate all these findings in one model. The aim of the current thesis is to develop and test a new model in which in particular the interaction between two highly likely cognitive and biological risk-factors is used to explain emotional eating behaviour. Because stressinduced eating is highly related to the experience of emotional stress and/ or negative affect, it is fundamentally necessary to first determine individual differences in stress vulnerability when seeking sufficient explanatory answers. Based on current scientific knowledge two distinct factors were chosen as the basis of this model due to their significant roles in stress 
vulnerability, eating behaviour and their potential to exacerbate each other's effects. The biological stress vulnerability factor in this model is the carrying of a serotonin-vulnerable genotype; the cognitive stress vulnerability factor in this model is the tendency to ruminate about negative events. The following section will first describe how these biological and cognitive stress vulnerability factors are separately related to emotional eating behaviour. Subsequently a new model will be presented/described in which these vulnerability factors are combined in order to explain emotional eating behaviour. This model is then tested throughout the remaining chapters of the current thesis.

\section{Biological stress vulnerability: Serotonin and stress-induced eating}

When searching for biological explanations for individual differences in stress experience and stress-induced overeating, the brain serotonergic (5-HTergic) system is an excellent candidate as it is directly involved in the control of stress adaptation and eating behaviour (Markus, 2008). The serotonergic system (including serotonin or $5-\mathrm{HT}$ as its sole neurotransmitter) plays a role in many behaviours, including emotion, mood and cognition as well as in circadian and neuroendocrine rhythms, sexual activity and food intake (Lesch et al., 1997). However, the serotonergic system has been demonstrated to play a particular role in stress and stress-related mood disorders such as anxiety and depression (Graeff et al., 1996; Maes and Meltzer, 1995; van Praag, 2004). In the brain, the serotonergic system is important for the initiation and control of the neuroendocrine (HPA) mechanisms that are involved in stress activation and, thus, adaptation (e.g., Graeff et al., 1996; Linthorst, 2005; Markus, 2008). When a stressor is perceived, the HPA-axis is activated and releases (among other hormones) cortisol. Cortisol inhibits the activity of the HPA-axis as part of a negative feedback loop that enables the body to adapt to stress and to quickly return to a calm baseline state. The serotonergic system has a mediating role in this negative feedback loop and seems (among others) to facilitate the inhibiting effect of cortisol on the HPA-axis (see: Markus, 2008). Consequently, a reduced brain serotonergic 
function increases the risk for maladaptive stress coping and is generally recognized as one of the most important risk factors for the onset and the course of stress-related affective disorders such as depression (van Praag, 2004). Previous studies have shown that serotonin increases resistance to stress and thereby prevents a decline in positive mood (Deakin, 2013; Graeff et al., 1996). Consequently, most drugs that are used to treat stress-related mood disturbances act, at least partially, by causing changes to the brain's serotonergic system. These drugs block the cerebral reuptake of serotonin and, thus, counterbalance post-synaptic receptor sensitization (Stahl, 1998).

In addition to the potential involvement of serotonin in emotional eating through its influence on stress adaptation, serotonin is more directly involved in eating behaviour through its influence on food preferences and selection. In particular, serotonergic activity in the hypothalamic area of the brain has been found to predispose the selective intake of carbohydrate compared with protein foods. Whereas injections of 5-HT (or agonists of this neurotransmitter) in animal hypothalamic areas decrease the intake of carbohydrates compared with protein-rich foods, the reverse pattern is observed when animals are treated with 5-HT antagonists (Leibowitz and Alexander, 1998). In general, 5-HT agonists decrease the amount of food that animals eat in one meal and increase the time between meals (Leibowitz and Alexander, 1998). These effects of brain 5-HT on food selection, food size and inter meal time constitute part of a negative feedback loop to control its own function through the determination of carbohydrate intake. Because serotonin cannot pass through the blood-brain barrier, its synthesis within the brain depends on its sole precursor, tryptophan. Tryptophan is a large neutral amino acid (LNAA) that cannot be enzymatically synthesized by the body and, therefore, must enter the system through dietary sources. As with all LNAA's, tryptophan enters the brain through a transport carrier at the blood-brain barrier. Tryptophan shares this transport carrier with the other LNAA's, valine, tyrosine, isoleucine, leucine and phenylalanine. Therefore, the increased transport of tryptophan into the brain is proportional to 
the ratio of its concentration to the sum of concentrations of these other LNAA's in the plasma (i.e., the plasma Trp/LNAA ratio). Carbohydraterich foods have been found to increase the plasma Trp/LNAA ratio, thus giving tryptophan an advantage in the competition for access to the brain (Curzon, 1985; Fernstrom et al., 1971; Fernstrom et al., 1973; Wurtman, 1987). This increase in brain tryptophan is produced by the carbohydrate-induced elevation of glucose and insulin that causes the LNAA's, except tryptophan, to be transported into the skeletal muscles for conversion into protein (for an extensive review on this subject see: Markus, 2008). Thus, when people eat carbohydrate rich foods, their cerebral serotonin levels rise. This rise decreases the further intake of food and more specifically carbohydrates, thereby creating a negative feedback loop. When disturbances in this feedback loop arise, unhealthy eating behaviours might develop. Some evidence for this hypothesis can be found in studies on eating disorders. The administration of a serotonin antagonist increases caloric intake and feelings of hunger in human subjects (Silverstone \& Goodall, 1986). Wurtman and Wurtman (1980) proposed that people with obesity self-medicate, by eating carbohydrates to increase serotonin levels. They found that obese people often crave carbohydrates and feel better after eating them. In a controlled experiment, these obese people were found to eat fewer carbohydrates (in their choice of snacks and meals) when they were given a serotonergic drug. Furthermore, bulimic patients tend to overeat carbohydrates and show a lowered serotonin turnover, whereas anorexic patients show the opposite, having an increased serotonin turnover (Leibowitz \& Alexander, 1998).

\section{The serotonin transporter gene (5-HTTLPR)}

When determining the role of serotonin in stress vulnerability and stressinduced eating, it is important to examine individual differences in serotonin vulnerability, that is, differences in individuals' susceptibility to the impact of serotonin disturbances/alterations (see Jans et al., 2006). A major factor in serotonin vulnerability is the genetics that underlie the transport of serotonin. The serotonin transporter (5-HTT) is involved in the presynaptic 
re-uptake of serotonin, thereby altering (often ending) serotonergic transmission. The serotonin transporter is encoded by the SLC6A4 gene, which contains a polymorphism with short $(\mathrm{S})$ and long $(\mathrm{L})$ repeats in the 5-HTT-Linked Polymorphic Region (5-HTTLPR). The short allele (S-allele) of this gene has been associated with reduced 5-HTT-mRNA expression, reduced 5-HT binding and reduced 5-HT uptake (Heils et al., 1996). As previously described, serotonin is involved in stress resilience; therefore one might expect that carriers of the S-allele of the 5-HTTLPR show an increased vulnerability to stress. Caspi (2003) found that this gene moderated the effect of stress on depression. Consequently, numerous studies (both experimental and associative) have further explored the Gene (5-HTTLPR) $x$ Stress interaction on affective complaints and/or disturbances. The earliest systematic meta-studies concluded that the associations between 5-HTLPR, stress and depression could not be proven based on their examined data (Munafo et al., 2009; Risch et al., 2009). However shortly after these metaanalyses were published, other research groups conducted more extensive meta-analyses by additionally controlling for confounding heterogeneity in the examined studies. These studies did show effects of the 5-HTTLPRgenotype on depression by controlling for heterogeneity in either ancestry (Clarke et al., 2010) or methodology (Uher \& McGuffin, 2010). The debate about this effect is currently still active as two recent meta-analyses have convincingly demonstrated that carriers of the S-allele are more prone to develop symptoms of depression when experiencing stressful events (Karg et al., 2010; Sharply et al., 2014), while another recent meta-study could not find this effect (Culverhouse et al., 2017). Because of these heterogeneous findings it has recently been suggested that that the apparent effect 5-HTTLPR on stress- and depressive symptoms are not broadly generalizable but instead will become mostly relevant and profound in high stress prone subjects (e.g. Markus, 2008; Markus et al., 2012; Markus, 2013). Especially this combined possession of a biological (S-allele 5-HTTLPR) and cognitive stress vulnerability is an essential part of the proposed model of stress-induced emotional (over-) eating in the current thesis and will be further elaborated 
on at a later section of the introduction. First the individual role of 5-HTTLPR in biological stress responsiveness and eating behaviour will be described.

Numerous studies have examined the effect of 5-HTTLPR on stress experimentally. For instance, a recent meta-analysis (Miller et al., 2013) compared well-controlled experimental studies that examined cortisol stress responses as a function of 5-HTTLPR (including 1686 subjects) and revealed greater cortisol stress responsiveness in homozygous S-allele carriers. Consistent with these findings, ample brain imaging studies have shown that people who carry the S-allele 5-HTTLPR show greater activation of the brains' emotional arousal network (including the amygdala) in response to fearful stimuli (Hariri and Holmes, 2006; Murphy et al., 2013). Behavioural data have clearly revealed that S-allele carriers have an attentional bias towards negative emotional stimuli (Beevers et al., 2009; Markus \& De Raedt, 2011) and, hence, an increased risk for depressive symptoms in response to stressful life events (Karg et al., 2011; Miller et al., 2012; Sharpley, 2014).

\section{5-HTTLPR and neuroticism}

Behavioural, associative and imaging studies have clearly shown that S-allele carriers of the 5-HTTLPR gene are more prone to stress and, hence, the negative affective consequences of stress exposure and/or experiences. Because this genetic stress-vulnerability has also often been reported in wellconducted stress association studies, some researches have suggested that the S-allele 5-HTTLPR gene might directly relate to the stress susceptible personality trait neuroticism. Neuroticism is a personality trait that is often related to the proneness to frequently experience negative affect and to rate events as highly stressful (Shoji et al., 2010). Some previous studies have included trait neuroticism as a direct outcome measure of the 5-HTTLPR genotype. For instance, it has been shown that S-allele 5-HTTLPR carriers report higher neuroticism scores than do L/L carriers (Lesch et al., 1996). However, numerous studies have attempted to replicate these findings with mixed results. Although two meta-analyses supported an association 
between the S-allele and neuroticism (Schinka et al., 2004, Sen et al., 2004), three other meta-analyses failed to find reliable evidence of this association (Munafo et al., 2003, Munafo et al., 2005, Munafo et al., 2008). Consistent with previous statements that neuroticism is not a direct outcome of the S-allele (Middeldorp et al., 2007, Munafo et al., 2003, Willis-Owen et al., 2005), more recent studies have shown that neuroticism might have a moderating effect on the relationship between the 5-HTTLPR and stress experience and/or stress-related affective changes (Markus, 2013; Pluess et al., 2010; Verschoor \& Markus, 2011).

Based on the evidence that S-allele carriers of the 5-HTTLPR genotype have an increased proneness for reduced serotonin function and that serotonin is thus involved in stress and eating behaviour, an intriguing question is whether the possession of an S-allele of the 5-HTTLPR genotype may moderate the effects of stress on emotional eating. There only exist indirect support for this notion; including studies that showed an association between 5-HTTLPR and the risk of overweight/obesity (Erritzoe et al., 2010; Sookoian et al., 2007), one study revealing an interaction between S-allele 5-HTTLPR x neuroticism on body-mass index (Markus et al., 2012) and a study showing a positive relationship between 5-HTTLPR, past life events and the incidence of eating problems (Stoltenberg et al., 2010). There are also inconsistent indirect findings; for instance Sookoian and colleagues (2007) reported the direct association of the S-allele with (increased) caloric intake and bodyweight (Sookoian et al., 2007), but this result was not found by Hinney et al. (1997). The same inconsistencies have been found in studies that have related 5-HTTLPR to eating disorders. Some studies found a link between S-allele carriers and greater risk for eating disorders (Di Bella et al., 2000; Fumeron et al., 2001), whereas other studies were unable to replicate these results (Racine et al., 2009; Sundaramurthy et al., 2000). The fact that such direct associations between 5-HTTLPR and eating behaviour were not consistently replicated increases the likelihood that the 5-HTTLPR genotype is a significant contributing factor rather than the determining factor in 
stress-induced eating. Concluding, genes cannot be blamed for individuals' over-consumption of high palatable foods under stress, but might be able to put some genetic vulnerable individuals (carriers of S-allele 5-HTTLPR) at risk for stress related disturbances. Especially individuals that possess additional (cognitive) stress vulnerabilities might then be at greater risk to engage in stress compensating behaviours including emotional eating.

\section{Cognitive stress vulnerability: Rumination, stress and eating}

Stressors are not universal; what might be highly distressing for some individuals might be trivial for others. Losing a job might be perceived as a new challenge for one person, but a threatening and stressful event for another person. The evaluation of changes in one's own environment requires appraisal, indicating that the level of stress of an event is determined by the meaning and importance that a person assigns to it (Folkman \& Lazarus, 1988). In particular, when one addresses a certain situation as highly important, threatening and inescapable the stress response will be high, regardless of the objective characteristics of the situation. This dependence of stress on cognitive appraisal might offer an additional explanation for the mixed results in studies on the moderating influence of the 5-HTTLPR-gene on the effect of stress on depression. Among the studies that did not find this interaction, most only counted the number of stressful life events. However, numerous studies that also considered the impact of stressful life events reproduced Caspi's (2003) original Gene by Environment findings (see Markus, 2013). Therefore, it might be essential to account for the cognitiveemotional impact of stressful events to build a more conclusive model of stress-induced eating.

As previously described, the personality trait neuroticism is often used to describe a person's proneness to experience negative affect and to rate events as stressful (Shoji et al., 2010). For example, Gunthert et al., (1999) showed that compared to individuals with low neuroticism scores, individuals with high neuroticism scores reported more experiences of 
daily stressors, rated those stressors as more severe and were less able to cope with them. Neuroticism cannot be easily attributed as a cause of stressinduced eating because such a global personality dimension will not create stressful situations or directly cause eating. Rather, neuroticism may make people more prone to remain focused and to mentally dwell on the negative event/experience by triggering the tendency for a ruminative thinking style (Watkins, 2008). Ruminative thinking is often defined as: uncontrollable perseverative thinking about past or present events, mostly focusing on negative affect (Kirkegaard Thomsen, 2006). This thinking pattern has been linked to a range of negative affects, particularly depression and anxiety (Kirkegaard Thomsen, 2006). Rumination is a particularly noteworthy factor when studying the consequences of stress vulnerability because it places the body in a continuous state of stress -and thus induces long-lasting elevated levels of stress hormones (cortisol)- even after the negative event has ended (Zoccola and Dickerson, 2012). In addition to such a continuous form of stress, this thinking pattern causes negative events to be more easily recognized, resulting in even more persistent psycho-physiological stress, as stated by the Perseverative Cognition Hypothesis (Brosschot et al., 2006).

The precise nature of rumination remains debated. Nolen-Hoeksema (2000) considered rumination to be a negative symptom. Even when it is used as a reflective strategy to resolve problems it is thought to cause negative thinking patterns that generate negative affect. Martin and Tesser (1996) proposed rumination as a positive mechanism for facilitating problem solving. Several other researchers have expected rumination to be a positive mechanism that can become negative when people are unable to change their negative emotional state into a more desired state (Pyszczynski \& Greenberg, 1987). Treynor (2003) showed evidence for both definitions of rumination (positive and negative affective effects), depending on how rumination was operationalized. Their psychometric analysis reconsidered the Ruminative Response Scale (RSS), a widely used questionnaire to assess the two dimensions of rumination, 'reflection' and 'brooding'. In their analysis, the 
items that loaded onto the 'reflection' factor were related to purposefully turning inwards to complete cognitive problem solving. The items that loaded onto the 'brooding' factor were those regarding a passive comparison between the current (undesired) situation and an unachieved desired state. Further analyses based on longitudinal data showed that the reflection factor was associated with less depressive symptoms over time, whereas it was associated more with concurrent symptoms of depression. These findings might suggest that the reflection factor of rumination is caused by negative affect or causes negative affect in the short term, whereas it decreases negative affect in the long term (perhaps through cognitive problem solving). The brooding factor of rumination was associated with depressive symptoms in both the short and the long-term, thereby suggesting that brooding is consistently a negative facet of rumination (Treynor et al., 2003). Rumination might be an important factor in stress-induced eating because it maintains the activity of the stress response even after the stimulus has disappeared. This continued activation continuously makes the body more vulnerable to (unhealthy) stress-reducing behaviours such as the consumption of emotionally comforting, high fat/sugary foods.

Rumination is associated with not only self-reports of stress but also with clear overt physical stress responses. In a recent study, students were followed for a 2-week period in which their cortisol levels and rumination were monitored. This study indicated that people who ruminate more frequently and/or more extensively in a certain period (compared to a personal baseline), show higher levels of cortisol in their system (compared with their personal baseline of cortisol levels) (McCullough et al., 2007). Similar results have been found in other research. For example, in Zoccola and Dickerson's (2012) review, the results of 15 studies on the effect of rumination on cortisol were examined. Most of the studies showed that people who tend to ruminate, also show higher cortisol responses to stressors or an overall higher baseline level of cortisol. These findings were inconsistent over the 15 studies, but this inconsistency might be attributable to the heterogeneity of definitions and 
research methods that the different studies employed.

The direct relationship between rumination and the 5-HTTLPR gene has not been extensively investigated, but several recent studies have examined this topic and found promising results. Tryptophan depletion is a technique that can be used to significantly lower serotonin levels in the brain through the ingestion of a tryptophan-free amino acid drink. This technique has been shown to increase rumination (Neumeister et al., 1997). Furthermore, it seems that the S-allele 5-HTTLPR carriers tend to ruminate more after experiencing stress than do L-allele carriers (Canli et al., 2007; Clasen et al., 2011). Beevers et al. (2010) did not reproduce this finding, although this study did not control for the occurrence of stressful events. Given that both rumination and serotonin are important in coping with stress, it is plausible that this is the reason the latter study did not find a relationship between genotype and rumination.

\section{The model: Genes $x$ Cognition on emotional eating}

Although genes and cognition can independently affect stress vulnerability and eating behaviours, the current hypothesis is that the combined possession of both vulnerability factors will further heighten individuals' vulnerability for the emotional rewarding and/or stress-reducing influence of high caloric sweet/fat foods. First, an event that is perceived as threatening will lead to enhanced 5-HT HPA-axis activation needed to support stress adaptation. However, when people repeatedly experience stress and negative affect as a function of a cognitive vulnerability (like rumination), the resulting longlasting increase in serotonergic and HPA activation (and stress hormones) may decrease 5-HT sensitization and HPA function, thereby unbalancing these stress systems and increasing the risk of stress-related affective disturbances (Markus, 2008; van Praag, 2005; Zoccola \& Dickerson, 2012). Particularly when combined with a genetic (S-allele of the 5-HTTLPR) vulnerability factor, this type of process might further exacerbate the negative effects of long-lasting stress experiences because this genotype causes greater brain 
5-HT sensitization (to compensate for decreased 5-HTT expression (David et al., 2005)) and HPA stress responsiveness (Karg et al., 2011; Miller et al., 2012; Sharply et al., 2014, see: Markus et al., 2012; Markus, 2013). Based on these findings and suggestions, it is likely that this combination of a cognitive (rumination) and a genetic (S-allele of the 5-HTTLPR) vulnerability also significantly increases the risk for stress-related eating disturbances, including emotional overeating of high caloric palatable foods.

\section{Aim and outline of the thesis}

The current thesis aimed to investigate whether carrying an S-allele 5-HTTLPR genotype in combination with a cognitive-ruminative thinking style lead to increased stress responsiveness, and consequently more profoundly increase the chance of developing an emotional eating style. Chapter 2 concerns a large $(n=827)$ association study examining whether the combination of carrying an S-allele and having a ruminative thinking style increases the risk for weight gain. It was expected that $\mathrm{S}$-allele carriers with the highest rumination scores would reveal greater prevalence of emotional eating and body weight (body mass index). Chapter 3 describes a laboratory experiment on the interaction between 5-HTTLPR and rumination on stress-induced reward for palatable foods using a visual food-cue attention task during exposure. It was expected that in particular high ruminative S-allele carriers reveal more attention for high palatable foods after a stress-inducing task. Chapter 4 describes a study on the interaction between 5-HTTLPR and rumination on the accumulation of scalp hair cortisol concentrations as a measure for differences in chronic (HPA) stress experiences. Chapter 5 entails a 5-HTTLPR x rumination study on daily real life stress experiences and energy intake for 6 weeks. It was expected that high ruminative $S / S$ carriers would show a greater decline in mood and increased intake of high caloric palatable food after experiencing daily stress. Finally, Chapter $\mathbf{6}$ concerns the discussion and conclusion of the findings described in the current thesis. 



\section{Chapter 2}

\section{The interaction between 5-HTTLPR genotype and Ruminative Thinking on Body Mass Index}

Published as:

Schepers, R., \& Markus, C. R. (2017b). The interaction between 5-HTTLPR genotype and ruminative thinking on BMI. British Journal of Nutrition, 118, 629-637 


\section{Abstract}

Negative affect or stress is often found to increase energy intake for high palatable caloric-rich foods and hence, weight gain. Reduced brain serotonin (5-HT) function is known to increase stress-vulnerability as well as the risk for eating-related disturbances. A short (S) allele polymorphism in the serotonin transporter gene (5-HTTLPR) is associated with a less efficient functioning brain serotonin system and therefore higher stress vulnerability. It has been suggested that this genotype may be directly linked to an increased risk for weight gain and/or obesity. However, a high amount of variability has been apparent in replicating such a direct gene on weight gain relationship. A most recent suggestion is that this gene by weight relationship might be moderated by an additional (cognitive) vulnerability factor involving repetitive negative thinking (rumination). Our objective was to investigate whether the S-allele of 5-HTTLPR contributes to weight gain particularly in high cognitive ruminating individuals. 827 Healthy young male and female college students (Age 21.3 \pm 3.0 years; BMI 16-41.7 kg/m2) were genotyped for the 5-HTTLPR polymorphism and assessed for Rumination (Event Related Ruminative Index) and body weight. In line with the hypothesis, a hierarchical regression model showed that higher BMI scores were observed in specifically high ruminating $\mathrm{S}^{\prime}$-carriers $\left(\mathrm{p}=0.031, \mathrm{f}^{2}=0.022\right)$. These results suggest that cognitive rumination may be a critical moderator of the association between 5-HTTLPR and body mass. 


\section{Introduction}

Currently one of the most alarming threats to human health is obesity. In the western world where high caloric food is highly available and ever present, the maintenance of a healthy eating style is very important. Especially during stress and/or negative affect, eating behaviours might change. While most people tend to eat less when experiencing stress, around $40 \%$ of people increase their food intake (Gibson, 2012) particularly for high sweet and/ or fatty foods (for a review see: (Schepers and Markus, 2015)). This stress or negative-affect induced (emotional) eating might be a contributing factor to the growing epidemic of obesity, as an association between emotional eating and BMI has often been reported (Anglé et al., 2009; Blair et al., 1990; van Strien et al., 1985a; van Strien et al., 1985b). The heterogeneity in eating behaviour during stress has not been fully explained yet, but has extensively been explored over the last years in different scientific fields. Numerous influencing factors for emotional eating have been found in the form of behavioural disinhibition (Guerrieri et al., 2007), attention bias (Shafran et al., 2007), restrained eating styles (Greeno and Wing, 1994), genetics (Keskitalo et al., 2008; Sung et al., 2010; Tholin et al., 2005) and heightened brain reward responses to food (Bohon et al., 2009). However, since emotional eating specifically occurs after stress experiences it might be important to investigate the influence of individual difference in stress vulnerability, its underlying bio-psychological mechanisms and hence, how this relates to the risk for emotional eating and hence weight gain.

A system that is related to stress vulnerability and thus, eating behaviour is the brain serotonergic (5-HT) system. Dysfunction of the brain serotonergic system is associated with vulnerability towards stress and an increase in caloric intake specifically for palatable carbohydrate-rich foods (Markus, 2008). Dysfunction of the 5-HT system is found to be promoted by a genetic factor. This commonly recognized genotype involves a functional 
polymorphism in the length of the 5-HT transporter-linked transcriptional promotor region (5-HTTLPR), resulting in a short (S) and a long (L) repeat sequence. The S-allele is associated with less mRNA expression, less 5-HT binding and lower 5-HT availability (Heils et al., 1996). Ample evidence from numerous studies and/or meta-analyses now clearly reveals that the S-allele 5-HTTLPR gene significantly increases stress responsiveness and/or the negative affective consequences of stress exposure. For instance, people carrying the S-allele 5-HTTLPR are shown to; 1) have greater activation of the emotional brain network to fearful stimuli(Hariri and Holmes, 2006; Murphy et al., 2013), 2) increased behavioural and neuroendocrine stress responses (Gotlib et al., 2008; Markus and De Raedt, 2011; Markus and Firk, 2009; Mueller et al., 2010), and 3) an increased risk for depressive symptoms in response to stressful life events (Karg et al., 2011; Miller et al., 2013). We should state a note of caution that there is still some debate about the interaction between 5-HTTLPR genotype and stress on the development of depression, as some meta-analyses were not able to show this effect(Culverhouse et al., 2017; Risch et al., 2009), while other meta-analyses were successful in finding this interaction (Clarke et al., 2010; Karg et al., 2011; Sharpley et al., 2014).

Apart from a greater risk to experience stress and therefore (potentially) depression, S-allele carriers also show increased vulnerabilities for obesity (Erritzoe et al., 2010; Sookoian et al., 2007), anxiety (Graeff et al., 1996) and eating disorders (Di Bella et al., 2000; Fumeron et al., 2001; Rozenblat et al., 2017). Consequently, such vulnerabilities may make these genotype-carriers also more vulnerable for stress-induced emotional eating. However direct bodyweight or eating disorders by gene associations are not always found (Hinney et al., 1997; Racine et al., 2009; Sundaramurthy et al., 2000)suggesting that the role of 5-HTTLPR in emotional eating is more contributing than deterministic.

The evaluation of changes in one's environment requires appraisal, indicating that the level of stress perceived is determined by the meaning and level of 
importance a person assigns to it (Folkman and Lazarus, 1988). This appraisal therefore might play an important part in emotional eating behaviour, especially in individuals with a genetic stress vulnerability. Recently several studies showed support for this hypothesis while neuroticism, a personality trait that promotes the intensity and frequency of stressful events (Affleck et al., 1994; Bolger and Schilling, 1991; Bolger and Zuckerman, 1995; David and Suls, 1999; Gunthert et al., 1999; Larsen and Ketelaar, 1991), moderated the effect of 5-HTTLPR on bodyweight (Markus and Capello, 2012). However in following studies, neuroticism and genotype did not interact on emotional eating behaviour after academic stress (Capello and Markus, 2014a) or an experimental stressor (Capello and Markus, 2014b). Having a neurotic personality does not directly cause stress, it however does promote ruminative thinking (Lam et al., 2003; Watkins, 2008). Ruminative thinking is usually defined as uncontrollable perseverative thinking about past or present events. Different definitions exist but most refer to rumination as a negative aspect (brooding) while some also propose positive forms of rumination (reflective) (Watkins, 2008). In the current study, unless stated otherwise, rumination will be defined as a negative trait (brooding) while it is known to put the body in a state of long lasting cortisol levels even after the stressor disappeared (Zoccola and Dickerson, 2012). Complimentary evidence for the cognitive stress vulnerability that ruminative thinking poses can be found in the fact that it plays an important role in depression (Rood et al., 2010) and eating disorders (Birmingham and Firoz, 2006) and is a solid predictor for negative affect in healthy subjects (Roelofs et al., 2008). One of the few studies concerning rumination's relation to emotional eating even found that rumination was a mediator for the effect of daily stress on food intake among obese adults (Kubiak et al., 2008).

In the current study a model is proposed in which biological and cognitive stress vulnerabilities interact on emotional eating behaviour (for a review see; (Schepers and Markus, 2015)). When a stressor is perceived, this is expected to lead to an increased 5-HT and hypothalamic-pituitary-adrenal 
axis (HPA) activation as a form of stress adaptation (Dickerson and Kemeny, 2004). However if a person is inclined to ruminate about negative events the stress response will be prolonged, these long periods of 5-HT and HPA activation can lead to desensitization of these systems, thereby increasing the risk of developing stress related and/or affective disorders (Jans et al., 2007; van Praag, 2004; Zoccola and Dickerson, 2012). Especially in combination with a genetic stress vulnerability (5-HTTLPR) this effect might intensify because this genotype already causes greater brain 5-HT sensitization (David et al., 2005) and HPA stress responsiveness (Miller et al., 2013). Based on these findings it is highly likely that individuals with a combination of these cognitive and biological stress vulnerabilities will be more susceptible to develop stress related disturbances, like emotional eating. Therefore, in the current study we expected the S-allele to contribute to weight gain exclusively among individuals with a tendency to ruminate about negative events.

\section{Methods}

\section{Participants}

Through email and flyers students from different faculties of University Maastricht were invited to participate in the study, they were told the experiment entailed filling in an on-line questionnaire package at home (once) and afterwards visiting the lab to provide a buccal sample for 5-HTTLPR genotyping. The digital questionnaire package was offered as an on-line survey set on the digital research platform 'EMIUM' and contained questions about general information (age, weight, height, health, family history of health, eating habits etc.) and standardized questionnaires regarding depression, emotional eating and rumination (see below). The sample size was based on feasibility of recruitment (see statistics for a sensitivity analysis), in total, $\mathrm{n}=827$ students responded, of which $\mathrm{n}=602$ were female, the mean age of this sample was 21.28 years $(\mathrm{SD}=2.99)$. Our sample consisted largely out of female participants because we mainly recruited 
from faculties with a high preponderance of female students (Psychology and Neuroscience and Health, Medicine and Life Sciences -faculties). A total of 32 participants were removed from analysis because of: failed genotyping $(\mathrm{N}=6)$, incomplete questionnaire responses $(\mathrm{N}=10)$ or being diagnosed with an affective or eating disorder $(\mathrm{N}=16)$. The study was approved by the ethical committee of the faculty of Psychology and Neuroscience of Maastricht University and all participants were paid for participation.

\section{Body Mass Index}

When participants visited the lab for buccal sample extraction, their weight and height was measured to calculate their Body-mass index (BMI) as weight/ height2 $(\mathrm{kg} / \mathrm{m} 2)$ as a relative measure of body weight.

\section{Rumination}

To assess the tendency to ruminate about negative events we used the Event Related Rumination Inventory (ERRI) (Cann et al., 2011). This inventory contains 20 questions concerning rumination after experiencing negative life events and most importantly, discerns deliberate rumination (reflective) from intrusive rumination (brooding). The psychometric properties of this questionnaire have been found to be solid (Cann et al., 2011). Both scales (deliberate and intrusive) contain 10 items on a 4 point scale ranging from 0 (never) to 3 (often), resulting in a total score per scale ranging from 0 to 40 . For the analysis of this study the Intrusive Rumination Scale was used as a measure of Rumination (unless stated otherwise).

\section{Emotional Eating Behaviour}

To measure emotional eating, the Three Factor Eating Questionnaire R-18 (TFEQ-R18) was used. This questionnaire includes 18 items for measuring different eating behaviour styles across three scales (cognitive restrained, uncontrolled eating and emotional eating). The validity and reliability of this questionnaire are sound (Karlsson et al., 2000). The Emotional Eating Scale contains 3 items which can be answered on a 4 point scale ranging from 
'mostly true' to 'definitely false'. These raw scores are transformed to a total score for Emotional Eating ranging from 0 to 100 (Karlsson et al., 2000).

\section{Depressive symptoms}

The Beck Depression Inventory (BDI) was used to measure symptoms of depression through 21 standardized questions (Beck et al., 1961). The BDI has been studied extensively and has been shown as a reliable and valid measure for the severity of depressive symptoms (Beck et al., 1988).

\section{Genotyping}

Participants provided a buccal sample for genotyping triallelic variants of 5-HTTLPR (Wendland et al., 2006). The triallelic variants were classified as: $\mathrm{S}^{\prime}$-carrier $\left(\mathrm{S} / \mathrm{S}, \mathrm{S} / \mathrm{Lg}, \mathrm{Lg} / \mathrm{Lg}, \mathrm{S} / \mathrm{L}, \mathrm{S} / \mathrm{La}\right.$ and $\mathrm{La} / \mathrm{Lg}$ ) or $\mathrm{L}^{\prime} / \mathrm{L}^{\prime}$-carrier (La/ La). Exclusively for the calculation of the Hardy Weinberg equilibrium the triallelic variants were classified with a separate heterogeneous category: S'/S' (S/S, S/Lg and Lg/Lg), S/L (S/La and La/Lg) and L'/L' (La/La). 


\section{Statistical analysis}

Data were first examined for accuracy of data entry, missing values and normal distributions. Body Mass Index values were log transformed to create a more normal distribution, before transformation (Skewness=1.43, Kurtosis=4.952), after transformation (Skewness=0.759, Kurtosis=1.741). Hardy-Weinberg equilibrium (HWE) was determined on the DNA database $(\mathrm{N}=821)$ using $\chi$ 2-tests; revealing that the genotypes frequencies of $\mathrm{L}^{\prime} / \mathrm{L}^{\prime}(\mathrm{N}=214), \mathrm{S}^{\prime} / \mathrm{L}^{\prime}$ $(\mathrm{N}=413)$ and $\mathrm{S}^{\prime} / \mathrm{S}^{\prime}(\mathrm{N}=194)$ did not significantly differ from the HWE $(\chi 2=$ 0.037, $\mathrm{p}=0.85$ ). To test for between-group differences of demographics, separate independent samples T-test were run with a Bonferroni correction; all statistics were conducted at a two-tailed significance level.

The main analyses were conducted by means of Hierarchical Multiple Regression Analyses (using IBM SPSS 24 for Windows). Analyses were conducted with Genotype ( $S^{\prime}$-carriers vs L'/L') and Rumination as betweensubjects factors on, Body Mass Index (BMI) and Depressive Symptoms (BDI). Three blocks were used, block 1 contained Genotype, block 2 Genotype and Rumination, block 3 Genotype, Rumination and their Interaction. To check if Intrusive and Deliberate Rumination related differently to 5-HTTLPR, BMI and Depressive Symptoms, the same 3 step model of the main analysis was repeated except (Intrusive) Rumination was changed with Deliberate Rumination. Additionally these analyses were once rerun controlling for sex differences in a traditional manner by adding sex as a covariate in the model. Secondly, based on recent criticism on this method of controlling for confounders in Gene x Environment research (Keller, 2014) we also reran the analysis using the method described by Keller, adding sex to the model as well as all possible two-way interactions with sex. 5-HTTLPR was coded as: $0=\mathrm{L}^{\prime} / \mathrm{L}^{\prime}, 1=\mathrm{S}^{\prime}$-carrier, Sex was coded as: $0=$ Male, $1=$ Female. Multicollinearity was no concern (average VIF $=1.48$, average Tolerance $=0.74$ ) and the errors appeared to be independent (Durbin-Watson value $=2.119$ ). Sensitivity analysis (using $G^{*}$ Power 3.1.9.2 for Windows) showed this test could detect 
effect sizes of minimally Cohen's $F^{2}=0.015(\alpha=0.05$, Power $=0.80, N=795$, Predictors $=4$ ).

To test if the hypothesized interaction between Genotype and Rumination on BMI were mediated by Emotional Eating we conducted a Moderated Mediation Analysis as described by Hayes (2013). The computational tool PROCESS (Hayes, 2013) was used testing Hayes' model 7 (see figure 1). Because we used a 5000 sample bootstrapping technique BMI was not logarithmized in this analysis. In this model Sex was added as a co-variate to control for any potential sex related confounding effects.

Figure 1. Path diagram for the hypothesized model tested with the Moderated Mediation Analysis.

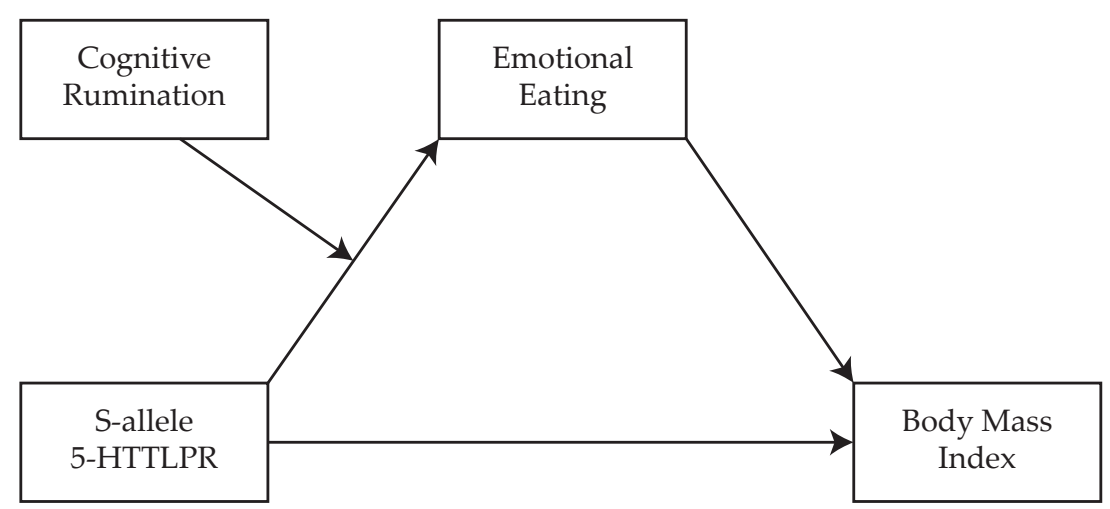




\section{Results}

\section{Demographics}

See table 2 for demographics, among these variables there were no a priori Genotype differences. There were Sex-related differences on four variables as Males showed higher BMI scores $(\mathrm{p}=0.002)$ and showed lower scores on Depressive Symptoms $(\mathrm{p}=0.005)$, Rumination $(\mathrm{p}<0.001)$ and Emotional Eating $(\mathrm{p}<0.001)$.

\section{5-HTTLPR and Rumination on BMI}

Table 3 reports the unstandardized (B) and standardized $(\beta)$ regression coefficients for the 3 blocks. Each block proved to be a better model over the preceding by significant increases of $R^{2}$ (in block $3 R^{2}=0.016$ ) In the last block an interaction between Genotype and Rumination significantly predicted variance in BMI $(\beta=0.280, p=0.033)$ as the association of Rumination with higher $B M I$ scores was greater among $S^{\prime}$-carriers than among $L^{\prime} / L^{\prime}$-carriers.

Table 2. Demographics and clinical characteristics (Means and standard deviations). Scores are grouped by 5-HTTLPR Genotype and $\operatorname{Sex}(\mathrm{N}=795)$.

\begin{tabular}{|c|c|c|c|c|c|c|c|c|}
\hline & \multicolumn{4}{|c|}{$S^{\prime} / S^{\prime}$} & \multicolumn{4}{|c|}{$\mathrm{L}^{\prime} / \mathrm{L}^{\prime}$} \\
\hline & \multicolumn{2}{|c|}{ Male } & \multicolumn{2}{|c|}{ Female } & \multicolumn{2}{|c|}{ Male } & \multicolumn{2}{|c|}{ Female } \\
\hline & Mean & SD & Mean & SD & Mean & SD & Mean & SD \\
\hline Age & 21.89 & 3.29 & 20.72 & 2.70 & 21.23 & 3.96 & 21.31 & 2.99 \\
\hline Body Mass Index* & 22.93 & 2.81 & 22.07 & 2.58 & 23.45 & 2.73 & 21.99 & 2.83 \\
\hline (Intrusive) Rumination (ERRI)* & 15.24 & 3.49 & 18.05 & 6.53 & 16.65 & 4.74 & 18.91 & 6.03 \\
\hline Deliberate Rumination (ERRI) & 19.07 & 5.16 & 20.48 & 6.31 & 19.91 & 6.59 & 20.25 & 6.23 \\
\hline Depressive Symptoms (BDI)* & 3.24 & 3.09 & 4.51 & 4.95 & 3.96 & 4.67 & 4.57 & 4.72 \\
\hline Emotional Eating (TFEQ)* & 15.02 & 22.55 & 31.72 & 27.26 & 15.20 & 18.50 & 23.74 & 26.72 \\
\hline
\end{tabular}

Note. ${ }^{*} \mathrm{p}<0.008$ (Bonferroni correction of $0.05 / 6$ ) for Sex differences, there were no significant effects of Genotype 
Table 3. Summary of Hierarchical Regression Analysis for (Logarithmized) Body Mass Index $(\mathrm{N}=795)$.

\begin{tabular}{|c|c|c|c|c|c|c|c|c|c|}
\hline \multirow[b]{2}{*}{ Variable } & \multicolumn{3}{|c|}{ Model 1} & \multicolumn{3}{|c|}{ Model 2} & \multicolumn{3}{|c|}{ Model 3} \\
\hline & B & SE B & $\beta$ & B & SE B & $\beta$ & B & SE B & $\beta$ \\
\hline Constant & 3.101 & 0.008 & & 3.138 & 0.015 & & 3.187 & 0.028 & \\
\hline Genotype & 0.003 & 0.010 & 0.012 & 0.003 & 0.010 & 0.010 & -0.062 & 0.032 & -0.225 \\
\hline Rumination & & & & -0.002 & 0.001 & $-0.100^{* *}$ & -0.005 & 0.001 & $-0.235^{* *}$ \\
\hline Genotype $x$ Rumination & & & & & & & 0.004 & 0.002 & $0.278^{*}$ \\
\hline $\mathbf{R}^{2}$ & 0.00 & & & 0.010 & & & 0.012 & & \\
\hline$F$ for change in $R^{2}$ & 0.117 & & & $8.070^{* *}$ & & & $4.555^{*}$ & & \\
\hline
\end{tabular}

Note. Genotype was represented as $\left(\mathrm{L}^{\prime} / \mathrm{L}^{\prime}=0, \mathrm{~S}^{\prime}\right.$-carrier $\left.=1\right) . \beta$ represents the standardized coefficient. ${ }^{*} \mathrm{p}<0.05 .{ }^{* *} \mathrm{p}<0.01$

\section{Moderated Mediation Analysis on BMI}

Table 4 reports the unstandardized (B) regression coefficients of the Moderated Mediation analysis. According to our additional hypothesis, the size of the indirect effect of Genotype on BMI through Emotional Eating depends on Rumination. As described by Hayes (2013), in such a model, interest is on estimation of conditional indirect effects, which is the value of the indirect effect conditioned on one or more values of the moderator. The test for statistical significance of this conditional indirect effect we used a $95 \%$ bootstrap confidence interval (BCI) as can be seen in Panel B. For the three different levels of Rumination all BCI's straddled zero, respectively for those low in Rumination ((-1SD), BCI $=-0.156$ to 0.108 ) for those scoring around the mean of Rumination ( $\mathrm{BCI}=-0.050$ to 0.1286 ) and for those high in Rumination ((+1SD) BCI= -0.0438 to 0.244$)$. As the indirect effect is equal and insignificant on all three levels of Rumination, it is not justified to assume that an indirect effect of Genotype on BMI through Emotional Eating is moderated by Rumination. 
Table 4. Moderated mediation analysis.

Panel A Regression results on Body Mass Index

\begin{tabular}{lcccc} 
Variable & $\mathbf{B}$ & $\mathbf{S E}$ & $\mathbf{t}$ & $\mathbf{p}$ \\
\hline Constant & 23.783 & 0,434 & 54.869 & $<0.001$ \\
Genotype & 0.219 & 0.004 & 5.639 & $<0.001$ \\
Rumination & 0.0524 & 0.226 & 0.232 & 0.816 \\
& & & & \\
Genotype x Rumination & -1.160 & 0.237 & -4.885 & $<0.001$ \\
\hline
\end{tabular}

Note. $\mathrm{N}=795$, Genotype was represented as $\left(\mathrm{L}^{\prime} / \mathrm{L}^{\prime}=0, \mathrm{~S}^{\prime}\right.$-carrier $\left.=1\right), \mathrm{R}^{2}=0.051, \mathrm{p}<0.001$.

Panel B Conditional Indirect effects and Index of Moderated Mediation for predicting Body Mass Index

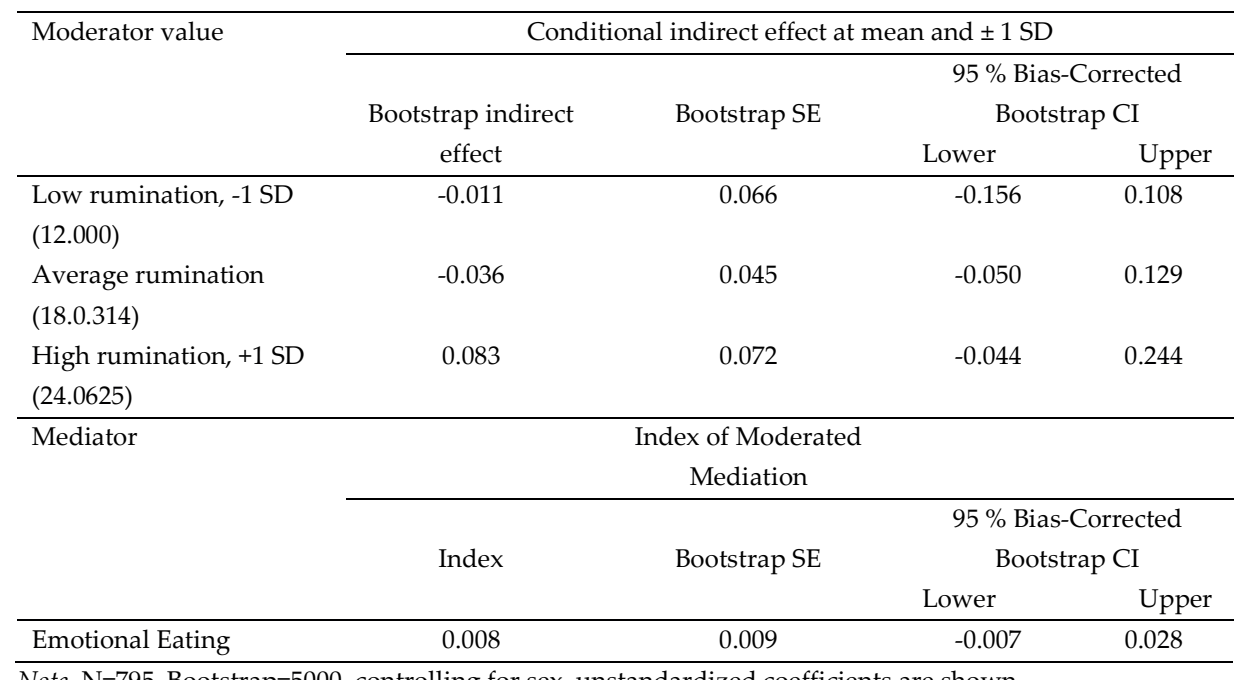

Note. $\mathrm{N}=795$, Bootstrap $=5000$, controlling for sex, unstandardized coefficients are shown. 


\section{5-HTTLPR and Rumination on Depressive Symptoms}

Only among the first three blocks, each block proved to be a better model over the preceding by significant increases of $R^{2}$ (in block $3 R^{2}=0.206$ ). Block 3 showed a significant interaction between Genotype and Rumination ( $\beta=0.330$, $\mathrm{p}<0.01)$, as the association of Rumination with higher BDI scores was greater among $S^{\prime}$-carriers than among $L^{\prime} / L^{\prime}$-carriers.

\section{Additional Analyses}

\section{5-HTTLPR and Deliberate Rumination on BMI}

To check if Intrusive and Deliberate Rumination related differently to 5-HTTLPR, Sex and BMI, the same 3 step model of the main analysis was repeated except (Intrusive) Rumination was changed with Deliberate Rumination. In block 1 Genotype could not significantly predict variance in $B M I(\beta=0.012, \mathrm{p}=0.733)$, in block 2 both Genotype ( $\beta=-0.012, \mathrm{p}=0.741)$ and Deliberate Rumination ( $\beta$ $=-0.023, \mathrm{p}=0.513$ ) could not significantly predict variance in $B M I$ and this block did not show a significant increase in $\mathrm{R}^{2}(\mathrm{~F}(1,792)=0.428, \mathrm{p}=0.513)$ compared to block 1. In block 3 Genotype $(\beta=-0.180, \mathrm{p}=0.132)$, Deliberate Rumination ( $\beta$ $=-0.077, \mathrm{p}=0.268)$ and a Genotype $x$ Deliberate Rumination-Interaction $(\beta=0.226$, $\mathrm{p}=0.093$ ) could not significantly predict variance in $B M I$ and this block did not show a significant increase in $\mathrm{R}^{2}(\mathrm{~F}(1,791)=2.825$, $\mathrm{p}=0.093)$ compared to block 2 .

\section{5-HTTLPR and Deliberate Rumination on Depressive Symptoms}

To check if Intrusive and Deliberate Rumination related differently to 5-HTTLPR, Sex and Depressive Symptoms, the same 3 step model of the main analysis was repeated except (Intrusive) Rumination was changed with Deliberate Rumination. Each block proved to be a better model over the preceding by significant increases of $R^{2}$ (in block $4 R^{2}=0.127$ ). Block 3 showed a significant interaction between Genotype and Deliberate Rumination $(\beta=0.357, \mathrm{p}<0.01)$ as the association of Deliberate Rumination with higher BDI scores was greater among $S^{\prime}$-carriers than among L'/L'-carriers. 


\section{Controlling for Sex differences}

The four previously mentioned hierarchical regression analyses were rerun with Sex as an added covariate. In all cases this did not change the earlier conclusions. (See table $5 \mathrm{a}$ for the results of controlling for Sex in the model of 5-HTTLPR and Rumination on BMI)

Table 5a. Regression results on BMI while controlling for Sex

\begin{tabular}{|c|c|c|c|c|}
\hline Variable & B & SE & $\beta$ & p \\
\hline Constant & 3.201 & 0.028 & & $<0.001$ \\
\hline Genotype & -0.062 & 0.031 & -0.225 & 0.051 \\
\hline Rumination & -0.004 & 0.001 & -0.216 & 0.003 \\
\hline Genotype $x$ Rumination & 0.004 & 0.002 & 0.280 & 0.031 \\
\hline Sex & -0.028 & 0.010 & 0.103 & 0.004 \\
\hline
\end{tabular}

\section{Controlling for Sex differences as proposed by Keller}

Additionally, these four hierarchical regression analyses were rerun controlling for Sex using the method as proposed by Keller (2014). This only changed conclusions for the model concerning 5-HTTLPR and Rumination on $B M I$ (see Table 5b). 
Table $5 \mathbf{b}$. Regression results on BMI while controlling for Sex as suggested by Keller

\begin{tabular}{lcccc} 
Variable & $\mathbf{B}$ & $\mathrm{SE}$ & $\boldsymbol{\beta}$ & $\mathbf{p}$ \\
\hline Constant & 3.254 & 0.040 & & $<0.001$ \\
Genotype & -0.079 & 0.033 & -0.289 & 0.017 \\
Rumination & -0.006 & 0.002 & -0.319 & 0.004 \\
Genotype x Rumination & 0.003 & 0.002 & 0.226 & 0.086 \\
Sex & -0.107 & 0.039 & -0.394 & 0.006 \\
Sex X Genotype & 0.041 & 0.022 & 0.169 & 0.065 \\
Sex X Rumination & 0.003 & 0.002 & 0.247 & 0.134 \\
\hline
\end{tabular}

Note. $\mathrm{N}=795$, Genotype was represented as $\left(\mathrm{L}^{\prime} / \mathrm{L}^{\prime}=0, \mathrm{~S}^{\prime}\right.$-carrier $\left.=1\right)$, Sex was represented as (Male $=0$, Female $=1$ )

\section{Discussion}

The aim of the current study was to explore whether the combined possession of a genetic (S-allele 5-HTTLPR) and a cognitive (Rumination) vulnerability for stress may increase the tendency for emotional eating and thereby promote weight gain. In support of the hypothesis, a high ruminative thinking style significantly increased Body Mass Index scores more in $S^{\prime}$-carriers than in L'/L' genotypes.

As described in the introduction, stress experiences are found to increase the risk for overeating, probably by way of 'self-medicating' from negative affect. Among the different mechanisms involved, both a cognitive (rumination) as well as a genetic (S-allele 5-HTTLPR) vulnerability are separately found to be involved. A cognitive ruminative thinking style is found to prolong stress experiences and responsiveness which, thereby may further increase the risk for destabilizing 5-HT and HPA systems involved in stress (Jans et al., 2007; van Praag, 2004; Zoccola and Dickerson, 2012). In addition, the S-allele of 5-HTTLPR is commonly found to enhance stress vulnerability most likely by decreasing 5-HT binding and availability, eventually leading to 
sensitized HPA and 5-HT responsiveness (Karg et al., 2011; Miller et al., 2013; Schepers and Markus, 2015). Both these factors not only appear to promote the experience of stress and/or the development of stress-related affective disorders, they also are both found to increase susceptibility for weight gain and/or reduced control of eating behaviour. For instance 5-HTTLPR genotype has been linked to increased bodyweight (Sookoian et al., 2007) and eating disorders (Di Bella et al., 2000) whereas high scores on rumination seemed to be a mediator for the effect of daily stress on the urge to eat (Kubiak et al., 2008). The focus of the current study was to explore whether the possession of both vulnerability factors in combination may profoundly enhance the risk of emotional eating and thereby weight gain.

In line with the hypothesis, current findings revealed an interaction between rumination and 5-HTTLPR on BMI as the positive association between rumination and BMI was greater among $\mathrm{S}^{\prime}$-carriers than among $\mathrm{L}^{\prime} / \mathrm{L}^{\prime}$ carriers. These findings elaborate on the former suggestions of a direct effect of 5-HTTLPR on bodyweight. Although multiple studies found an increased bodyweight by direct effect of carrying an S-allele (Fuemmeler et al., 2008; Lan et al., 2009; Peralta-Leal et al., 2012; Sookoian et al., 2007; Sookoian et al., 2008), these results are not consistent (Hinney et al., 1997; Iordanidou et al., 2010). Data from the present study suggest that 5-HTTLPR genotype has an effect on body mass but that this is conditional on the presence of ruminative thinking patterns. Comparable results have been found before where an effect of S-allele 5-HTTLPR on BMI was dependent on having a neurotic personality (Markus and Capello, 2012) or emotional eating prevalence was highest among S-allele carriers with high depressive symptoms (van Strien et al., 2010). These findings underline the importance of cognitive stress vulnerabilities as moderators on 5-HTTLPR related eating disturbances. We should however be cautious interpreting these results, while although the traditional method of controlling for sex by adding it as a covariate in the model did not change the conclusion of our analysis, using the recently suggested method of Keller (2014) however, adding sex and all of its possible 
interactions, caused the initial found interaction of genotype and rumination to lose statistical significance. Whether this change in significance is caused by a confounding effect of sex or by overfitting the model (as the initial effect already was of modest size $\mathrm{f}^{2}=0.022$ ), can't be discerned in this study. If in time Keller's proposed method of controlling for confounding effects in Gene X Environment studies becomes the new standard, larger samples sizes should be used to prevent overfitting and give definitive conclusions about the potential confounding effect of sex in 5-HTTLPR X Rumination interactions on BMI.

We expected that a combination of biological (S-allele 5-HTTLPR) and cognitive (rumination) stress vulnerabilities would increase the risk for weight gain through emotional eating behaviour. Surprisingly our Mediated Moderation analysis could not prove that the moderating effect of rumination on 5-HTTLPRs effect on body mass was mediated by scores on the emotional eating scale of the TFEQ. These findings correspond with earlier studies were an increased BMI among high neurotic S-allele-carriers was found (Markus and Capello, 2012), although this population did not show increased (selfreported) caloric intake during a stressful examination period (Capello and Markus, 2014a) or after an experimental stressor (Capello and Markus, 2014b). Contradictorily, mediating effects of emotional eating on BMI have been reported in the past as the effect of depressive symptoms on increased BMI was mediated by scores on an emotional eating questionnaire (Dutch Eating Behavior Questionnaire) (van Strien et al., 2016a; van Strien et al., 2016b). Conceivably the discrepancy between these results arises out of the heterogeneity of measuring emotional eating behaviour/tendency. Maybe the Three Factor Eating Questionnaire shows different sensitivities to measuring affect related changes in BMI caused by emotional eating, than the also commonly used Dutch Eating Behavior Questionnaire, or observations of affect related food intake.

In addition to exploring the effect of 5-HTTLPR and rumination on BMI, 
the current study also explored whether 5-HTTLPR and rumination have an interacting effect on depression. As both these factors are associated with clinical depression and depressive symptoms in healthy subjects (Karg et al., 2011; Papageorgiou and Wells, 2004; Rood et al., 2010; Sharpley et al., 2014), we expected and confirmed in our database that high ruminating $S^{\prime}$ carriers showed a greater incidence of depressive symptoms. We propose that in combination, the stress vulnerability caused by carrying an $S^{\prime}$-allele will be further exacerbated by the prolonging of stress responses caused by ruminative thinking (Schepers and Markus, 2015). While ruminative thinking occurs mostly in relation to the experience of stress (Allbaugh, 2013; Smith and Alloy, 2009) this corresponds well with findings that that although a few studies found a direct effect of 5-HTTLPR on depression (Collier et al., 1996; Hoefgen et al., 2005; Joiner et al., 2003) a great number of associations between 5-HTTLPR and depression relied on the occurrence of stressful life events (see: (Sharpley et al., 2014)). These findings once again underline the importance of cognitive stress vulnerabilities in the associations between 5-HTTLPR, stress and the development of depression.

As validation we further analysed the distinction of the two scales of the ERRI. While our main hypothesis was focused on rumination as a cognitive stress vulnerability we expected that exclusively the intrusive (brooding) scale of the ERRI as opposed to the deliberate (reflective) scale, would show an effect on depressive symptoms and body mass, as the intrusive scales focusses on the purely negative aspect of rumination while the deliberate scale is aimed at reflection. In our sample, scores on the two scales showed large overlap $(\mathrm{r}=0.5)$ and showed no different effects with regard to 5-HTTLPR, and depressive symptoms. These data correspond with previous reports of high correlations between the two ERRI scales (Allbaugh, 2013; Cann et al., 2011) and their similar associations with depressive symptoms (Allbaugh, 2013). Interestingly, there were differences in their effects on BMI and 5-HTTLPR genotype. As expected $S^{\prime}$-carriers with a high intrusive ruminative thinking style showed the highest BMI scores, whereas deliberate rumination showed 
no main or interaction effects on BMI. This finding validates the distinction of the two scales, while deliberate rumination shows no effect on body mass; intrusive rumination probably exacerbates the biological stress vulnerability effect of carrying an $S^{\prime}$-allele thereby increasing the tendency to cope with stress by overeating and thereby weight gain. In support, high scores on specifically the intrusive rumination scale of the ERRI have been linked to other negative coping styles in the form of behavioural disengagement and substance use (Cann et al., 2011) and a lower life satisfaction and loss of meaning in life (Triplett et al., 2012).

\section{Strengths, limitations and future directions}

Strengths of the current study were the inclusion of a sample of 5-HTTLPR genotyped individuals ( $\mathrm{N}=827)$ meeting HWE and taking in account the triallelic Lg's functional equivalency to the S-allele (Wendland et al., 2006). A limitation was the absence of insight in the amount of stress our participants had perceived, as described this might be a crucial factor in research related to 5-HTTLPR genotype and stress related affect and/or behaviour. A second limitation is the inability to discern cause from effect within the found associations. Both limitations could be controlled for in future (experimental) studies. Finally we would like to note that although we had a large sample $(\mathrm{N}=827)$ compared to a lot of similar studies in the field, recently there is still some debate on the ideal sample size for Gene X Environment research, some researchers even vowing for samples of thousands of subjects (Dick et al., 2015). Reproducibility of our findings is of great importance to draw irrefutable conclusions on 5-HTTLPR and ruminative thinking related body weight associations.

\section{Conclusion}

The current study is the first to show that the combined possession of a biological (S-allele 5-HTTLPR) and cognitive (ruminative thinking) -stress vulnerability increases the risk for weight gain. These findings elaborate on theories describing the influence of genes on eating behaviour by 
incorporating the moderating effect of ruminative thinking on the association between 5-HTTLPR and body mass. The present study thereby underlines the importance of accounting for cognitive factors when exploring genotypical influences on body mass and eating-related disturbances. 



\section{Chapter 3}

Gene by Cognition interaction on stressinduced attention bias for food: effects of 5-HTTLPR and Ruminative Thinking

Published as:

Schepers, R., \& Markus, C. R. (2017a). Gene by Cognition interaction on stress-induced attention bias for food: effects of 5-HTTLPR and Ruminative Thinking. Biological Psychology, 128, 21-28. 


\section{Abstract}

Stress is often found to increase the preference and intake of high caloric foods. This effect is known as emotional eating and is influenced by cognitive as well as biological stress vulnerabilities. An S-allele of the 5-HTTLPR gene has been linked to decreased (brain) serotonin efficiency, leading to decreased stress resilience and increased risks for negative affect and eating related disturbances. Recently it has been proposed that a cognitive ruminative thinking style can further exacerbate the effect of this gene by prolonging the already increased stress response, thereby potentially increasing the risk of compensating by overeating high palatable foods. This study was aimed at investigating whether there is an increased risk for emotional eating in high ruminative S/S-allele carriers reflected by an increased attention bias for high caloric foods during stress. From a large ( $\mathrm{N}=827)$ DNA database, participants $(\mathrm{N}=100)$ were selected based on genotype ( $\mathrm{S} / \mathrm{S}$ or $\mathrm{L} / \mathrm{L}$ ) and ruminative thinking style and performed an eye-tracking visual food-picture probe task before and after acute stress exposure. A significant Genotype $x$ Rumination $x$ Stressinteraction was found on attention bias for savoury food; indicating that a stress-induced attention bias for specifically high-caloric foods is moderated by a gene $x$ cognitive risk factor. Both a genetic (5-HTTLPR) and cognitive (ruminative thinking) stress vulnerability may mutually increase the risk for stress-related abnormal eating patterns. 


\section{Introduction}

Weight gain and obesity are a great health concern of the modern Western world, in both Europe (Berghöfer et al., 2008) and the US (Flegal et al., 2010) obesity has reached a prevalence of $30 \%$. Emotional eating, which is overeating during stress or negative affect seems to be an important factor in weight gain while it increases food intake of specifically high fat and/or sweet foods (Gibson, 2012; Greeno and Wing, 1994; Schepers and Markus, 2015). The cause of this unhealthy habit has not decisively been determined, although over the last years in both cognitive and biological scientific fields this topic has been explored extensively. For instance differences in behavioural disinhibition (Guerrieri et al., 2007), attention bias (Shafran et al., 2007), restrained eating styles (Greeno and Wing, 1994), heightened responses of reward areas of the brain towards food related cues (Bohon et al., 2009) and genetics (Keskitalo et al., 2008; Sung et al., 2010; Tholin et al., 2005) all seem to partly explain emotional eating. A system that is greatly involved in stress resilience and therefore might play an important part in emotional eating is the brain serotonergic (5-HT) system. Dysfunction of this neurotransmitter is associated with decreased stress resilience and increased intake of carbohydrate rich foods (Markus, 2008). The serotonin transporter gene contains a polymorphism (5-HTTLPR) that influences availability of serotonin transporters thereby influencing 5-HT efficacy. Carrying an $\mathrm{S}$-allele of this gene (opposed to an L-allele) causes increased hormonal and behavioural stress responsiveness (Gotlib et al., 2008; Markus and De Raedt, 2011; Markus and Firk, 2009; Mueller et al., 2010), greater brain responses to fearful stimuli (Hariri and Holmes, 2006; Murphy et al., 2013) and increased chances of affective disorders in response to stressful life events (Karg et al., 2011; Miller et al., 2013). There is indirect support for this gene's influence on emotional eating as an S-allele is associated with overweight and obesity (Erritzoe et al., 2010; Sookoian et al., 2007) and also seems to mediate the effect of stressful events on the incidence of eating disorders (Di Bella et al., 2000; Fumeron et al., 2001). However direct associations between this 
allele and bodyweight are not always reproduced (Hinney et al., 1997; Racine et al., 2009; Sundaramurthy et al., 2000), suggesting that its role in emotional eating is more contributing than deterministic. Ancillary to brain 5-HT function, stress vulnerability also depends on cognitive evaluation of (potential) stressful events (Folkman and Lazarus, 1988). A possible important interacting cognitive factor in 5-HTTLPR's effect on emotional eating is neuroticism. Neuroticism is a personality trait that influences the frequency and intensity of ratings of stressful events (Kendler et al., 2004; Luteijn and Bouman, 1988). This cognitive stress vulnerability seems to play a role in the effect of 5-HTTLPR on eating behaviour while particularly S/Scarriers who score high on neuroticism show an increased body mass index (BMI) (Markus and Capello, 2012). However a 5-HTTLPR by neuroticism interaction on food intake could not be found in response to a natural (Capello and Markus, 2014a) or experimental (Capello and Markus, 2014b) stressor. These data suggest that neuroticism does not directly influence the effect of 5-HTTLPR on eating behaviour, however it might play a role through promoting a ruminative thinking style (Lam et al., 2003; Watkins, 2008). Ruminative thinking is often defined as (uncontrollable) perseverative thinking about past or present negative events (Nolen-Hoeksema et al., 2008), even prolonging the biological stress response as the body remains in a state of elevated levels of stress hormones (cortisol) long after the stressor has disappeared (Zoccola and Dickerson, 2012). Consequently rumination is an important factor in depression (Rood et al., 2010) and eating disorders (Birmingham and Firoz, 2006), is a solid predictor for negative affect in healthy subjects (Roelofs et al., 2008) and is even found to mediate the effect of daily stress on food intake among obese adults (Kubiak et al., 2008). Recent insights propose that a specific combination of high ruminative thinking and carrying an S-allele of 5-HTTLPR might increase rewarding effects of high caloric palatable foods and hence, the risk of emotional eating (Schepers and Markus, 2015). The aim of the current study was to test whether this proposed increased risk of emotional eating among high ruminative S-carriers is reflected in an increased attention bias for high palatable foods during stress. 
Emotional eating usually is accompanied by a preference for high caloric sweet and/or fat foods (for a review see: Schepers \& Markus, 2015), consumption of specifically these food types are associated with activation of reward areas in the brain (Berridge, 1996; Small et al., 2003). Interestingly, seeing stimuli that are associated with reward when consumed can also already activate the brain reward areas, thereby drawing attention towards these stimuli and possibly induce craving (Carter and Tiffany, 1999). These so called 'attentional biases' have been found for multiple types of drugs, for instance: caffeine (Yeomans et al., 2005), tobacco (Bradley et al., 2007), alcohol (Townshend and Duka, 2001) and opiates (Lubman et al., 2000), but also for food cues, for instance particularly obese individuals show heightened vigilance for food related visual cues (Castellanos et al., 2009; Werthmann et al., 2011) and healthy women were found to show an increased attention for food cues and appetite after negative mood (Hepworth et al., 2010).

Based on these findings our aim was to examine the combined influence of 5-HTTLPR genotype and ruminative thinking on visual attention for food cues during acute stress. From a large genotype database (N=827), 97 homozygous $\mathrm{S}^{\prime}$-and L'-allele carriers with either high or low scores on a ruminative thinking scale were recruited and tested for visual attention for food cues using an eye-tracking paradigm before and after an acute laboratory stressor. We expected that high ruminative $S^{\prime}$-carriers would show increased stress responsiveness and thereby, show a greater attentional bias for high fat/sweet foods during stress. 


\section{Methods}

\section{Participants}

Potential participants were selected from an existing DNA database (see: Schepers \& Markus, 2017b) containing 827 university students from University Maastricht, genotyped for 5-HTTLPR and screened for factors including general health (weight and length, smoking and drinking habits, personal or family history of psychiatric disorders) and ruminative thinking (ERRI intrusive scale, see section Materials). For the current study only homozygous carriers of 5-HTTLPR were invited, because differences in stress responses are more pronounced within these groups then within heterogynous groups (Way and Taylor, 2010). Participants were also selected based on ruminative thinking, only including participants with scores in the extreme percentiles, participants with affective and/or eating related disorders were excluded. In total 221 students were invited for participation of which 97 (females/ males) responded. Among these participants were $47 \mathrm{~S} / \mathrm{S}$-carriers (28 low ruminators, 19 high ruminators) and $50 \mathrm{~L} / \mathrm{L}$ carriers (23 low ruminators, 27 high ruminators). These participants were between 18 and 45 years of age $(\mathrm{M}=20.73, \mathrm{SD}=3.36)$ and their $\mathrm{BMI}$ ranged from 17 to $27(\mathrm{M}=22.25, \mathrm{SD}=2.30)$, see table 6 for participant demographics. A total of 10 participants were removed for analysis because of: failed eye tracker calibrations $(\mathrm{N}=5)$, reports of feeling ill on the test day ( $\mathrm{N}=3$ ) and unwillingness to complete the stress induction task (MAST) $(\mathrm{N}=2)$.

\section{Rumination}

The Event Related Ruminative Index was used in the previously formed database to asses rumination. This questionnaire is divided in two scales (intrusive and deliberate rumination) and is thereby able to discern positive from negative aspects of rumination. This tool has been found to be reliable and valid (Cann et al., 2011). Both scales contain 10 items ranging on a four point scale, adding to a total score ranging from 0 to 40 . For the analysis of this study exclusively the Intrusive Rumination Scale was used as a measure 
of Rumination. A median split was used (on the former database, $\mathrm{N}=827$ ) to discern the high ruminators from the low ruminators, in this sample the median lay at 17 .

\section{Mood and Salivary Cortisol}

Total Mood Disturbance, Disturbance in mood was measured with a Dutch adaption of the short version of the Profile of Mood States-questionnaire (Wald and Mellenbergh, 1990). It contains 30 items (scores ranging from 0 to 4) measuring mood in five different scales (Vigour, Fatigue, Depression, Anxiety and Tension). Total Mood Disturbance (TMD) is calculated by adding the total Fatigue, Depression, Anxiety and Tension scores minus the Vigour score.

PANAS, Changes in positive and negative affect were measured by using the Positive And Negative Affect Scale-questionnaire (Peeters et al., 1999; Watson et al., 1988). This questionnaire contains 10 items for positive affect (e.g. interested, excited, proud) and 10 items for negative affect (e.g. nervous, upset, irritable). Total scores for both scales are a sum of the scores on their respected items which all range from 1 (not at all) to 5 (extremely).

Salivary Cortisol, Cortisol samples were obtained by using a Salivette sampling device (Sarstedt ${ }^{\circledR}$, Etten-Leur; the Netherlands). With this procedure, saliva was collected in small polyester swabs and stored ( $-25^{\circ}$ Celsius) immediately on collection. Salivary free cortisol levels were determined in duplicate by a commercially available luminescence immunoassay (IBL, Hamburg, Germany). Mean intra- and inter-assay coefficients of variation were less than $4 \%$ and $8 \%$ respectively.

\section{Visual attention task (eye-tracking)}

Eye-tracking was used to measure visual attention for food cues, utilizing a desktop mounted Eyelink 1000 with headrest (www.sr-research.com). Eye tracking has been proven to be an excellent method of detecting attention 
biases for stimuli related to: tobacco (Field et al., 2004), cannabis (Field et al., 2006) and food (Castellanos et al., 2009). The task used was a selfdeveloped adaption of a Posner cueing task comparable to the paradigm used by Castellanos et al. (2009) The task was programmed and run using Presentation (www.neurobs.com/). Each trial began with a fixation cross in the middle of the screen (for $1000 \mathrm{~ms}$ ) following, two images simultaneously appeared on either side of the screen for $2000 \mathrm{~ms}$, lastly a target (colon sign) would appear on the left or right side of the screen. Participants were asked to look freely on the screen except when the fixation cross appeared. Whenever a target appeared they determined if it was on the left or the right side of the screen by pressing corresponding buttons on a button box, this was done as fast and accurately as possible. Critical image pairs contained one food related image and an (non-food) object matched for colour, shape and complexity, for instance a stack of chocolates was paired with an equally big stack of dark wooden blocks. Non-critical image pairs (filler pairs) contained only image pairs of objects. Some images' colours were slightly manipulated with GIMP (https://www.gimp.org) to better match with its pair. The task was divided in 2 blocks with an approximate duration of 8 minutes each. The first block contained 20 image pairs with high caloric savoury food items (i.e. hamburger or pizza), 20 pairs with high caloric sweet food items (i.e. donut or ice cream), 20 pairs with low caloric foods (i.e. apple or carrot) and 60 filler pairs without any food items. The filler pairs were used to vary the task and de-emphasize the food related images. The second block contained the same image pairs as the first but mirrored (per pair the left and right images switched location). Between pairs image sizes could differ but all images were centred on the $\mathrm{Y}$-axis and the outer edges of the images were placed $1 \mathrm{~cm}$ from the outer edges of the screen on the $X$-axis. The order of image pairs was randomized, the order of target positions was semi-randomized while an equal amount of congruent (target following the location of the food-item) and incongruent (target following the non-food item) trials was prearranged. 


\section{Stress induction}

To induce short term acute stress, the Maastricht Acute Stress Test (MAST) was used. This task has shown great reliability and validity in inducing both cognitive and physiological stress responses by combining elements of the classic Trier Social Stress Test and the Cold Pressor Task (Smeets et al., 2012). During the five minute preparation phase instructions are presented on a computer monitor and read out loud by the experimenter. Participants are told there will be several trials in which they will have to submerge their hand in ice cold water ( $4^{\circ}$ Celcius) for a randomly chosen amount of time but never exceeding 90 seconds. In between these trials participants counted backwards in steps of 17 from 2043 as fast and accurately as possible, they were told that the duration of these inter-trials would be random but at least 45 seconds. Negative feedback was given by the experimenter if the participant made a mistake while counting or counted too slowly. In reality the duration of both the trials and inter-trials were not randomly decided but had a fixed duration, leading to a total time of 10 minutes for the completion of the MAST. During this task participants were also told that they would be videotaped and they were able to see themselves on a monitor through a direct camera-feed.

As a manipulation check, changes in mood were measured by questionnaires and salivary cortisol samples were used as a measure of physical stress. In the present study, after the last trial of the MAST, participants were told that they were halfway through the task and could now take a short break. During this break participants provided a saliva sample and reported their mood via questionnaire. Afterwards, they were told that there would not be a second part to the MAST.

\section{Procedure}

All experiments were conducted from 11.00 to 13.00 or 11.30 to 13.30 to control for shifts in attention for food by time of day. At arrival, participants first reported their mood and provided a saliva sample. Following, they 
were seated in front of the eye tracking equipment; the chair was adjusted to each person's height so the chinrest of the headrest would be at a constant $55 \mathrm{~cm}$ distance from the camera. Using a nine point calibration-program, the software was calibrated to each participant's individual eye movements up until an accuracy of at least $1^{\circ}$ was attained. After five practice trials the first block of experimental trials started, between the two blocks participants had a short break in which they could remove their head from the headrest. After completion of the eye-tracking task, participants were brought to a different room for the MAST, before and after stress induction they once again reported their mood and provided a saliva sample. Then, the eye-tracking task was completed for a second time after which the participant's mood was assessed again accompanied by a saliva sample.

\section{Data preparation}

Exclusively the eye-tracking data of the critical trials was analysed, only fixations within the regions of the interest were used. The regions of interest followed the shape of the presented stimuli. Fixations were defined as a gaze position that remained stable within $1^{\circ}$ for more than $100 \mathrm{~ms}$ (as shorter fixations might reflect anticipation). Two dependent variables were calculated with these data. Duration bias (as a measure of maintained attention) was calculated by dividing the total time spend fixating on a food picture divided by the total time spent fixating on either image. If this number exceeds 0.5 there is a preference for food items, scores below 0.5 signify a bias for non-food related items. Direction bias (the first orientation after stimulus presentation) was calculated by dividing the total number of first fixations on food pictures divided by the total number of trials in which the first fixation was on either image. Once more scores over 0.5 signify an attention bias for food pictures while scores under 0.5 signify an attentional bias for non-food related images.

For both measures of attention bias three separate calculations were made, one for each food type (high caloric savoury, high caloric sweet and 
low caloric).

\section{Statistical Analysis}

Data were first examined for accuracy of data entry, missing values and normal distributions. Genotype distribution of the original database ( $\mathrm{N}=827)$ was analysed using a $\chi^{2}$ test showing no difference with the Hardy-Weinberg equilibrium $\left(\chi^{2}=0.052, \mathrm{p}=0.82\right)$.

The main research questions were analysed using GLM ANOVA (SPSS 21 for Windows) with Genotype (S'/S'vs L'/L') and Rumination (High vs Low) as between-subjects factor and Stress (pre vs post-stress) as a within-subjects factor on Duration biases, Direction biases, cortisol changes and mood (POMS \& PANAS).

To test for differences in baseline mood and cortisol levels a Univariate GLM ANOVA was run with Genotype (S/S vs L/L) and Rumination (High vs Low) as between-subjects factors.

To test responsivity of mood and cortisol in relation to the stress induction, Repeated Measures ANOVA was used with Genotype ( $\left.\mathrm{S}^{\prime} / \mathrm{S}^{\prime}, \mathrm{L}^{\prime} / \mathrm{L}^{\prime}\right)$ and Rumination (High, Low) as within subjects-factors and Stress (-20 min., 0 min., $+20 \mathrm{~min}$. and $+40 \mathrm{~min}$. to onset of stress induction) as a between subjectsfactors. If sphericity assumptions were not met a Greenhouse Geisser correction was used, in that case corrected F-values and their corresponding degrees of freedom are reported. All statistics were conducted at a two-tailed significance level of $5 \%$ and data are reported as means \pm SD. 


\section{Results}

\section{Participant characteristics}

A priori analysis showed that the distributions of Genotype $\left(S^{\prime} / S^{\prime}, L^{\prime} / L^{\prime}\right)$ and Rumination did not significantly differ on a Chi Square Test $\left(\chi^{2}=1.38, p=0.24\right)$. This distribution was equal for both men $\left(\chi^{2}=1.53, \mathrm{p}=0.22\right)$ and women $\left(\chi^{2}=\right.$ 0.95, $\mathrm{p}=0.33$ ). Univariate ANOVA with Genotype and Rumination as withinsubjects factors did not reveal any significant main or interactions effects for either BMI or age.

Table 6. Demographics and clinical characteristics (Mean, SD) of participants (N=97). Scores are grouped by 5 -HTTLPR genotype $\left(S^{\prime} / S^{\prime}\right.$ or $\left.L^{\prime} / L^{\prime}\right)$ and ruminative thinking style (High or Low).

\begin{tabular}{lcccc}
\hline & \multicolumn{2}{c}{$\mathrm{S}^{\prime} / \mathrm{S}^{\prime}$} & \multicolumn{2}{c}{$\mathrm{L}^{\prime} / \mathrm{L}^{\prime}$} \\
\cline { 2 - 5 } & Low Rumination & High Rumination & Low Rumination & High Rumination \\
\hline Female / Male & $20 / 8$ & $18 / 1$ & $15 / 8$ & $22 / 5$ \\
Average Age & $20.14(1.67)$ & $20.74(2.35)$ & $21.87(5.75)$ & $20.37(2.32)$ \\
Average BMI & $22.06(2.40)$ & $22.19(2.38)$ & $23.04(2.32)$ & $21.82(2.09)$ \\
Average ERRI & $11.71(1.67)$ & $27.53(5.31)$ & $12.43(1.53)$ & $24.85(3.98)$ \\
\hline
\end{tabular}

Note. BMI $=$ Body Mass Index, ERRI $=$ Event Related Ruminative Index.

\section{Baseline Salivary Cortisol and Mood}

Salivary Cortisol. Univariate ANOVA with Genotype $\left(S^{\prime} / S^{\prime}, L^{\prime} / L^{\prime}\right)$ and Rumination (High, Low) as between subjects factors on Salivary Cortisol $(\mathrm{nmol} / \mathrm{l})$ at baseline did not reveal any significant main-or interaction effects.

Positive Mood (PANAS). Univariate ANOVA with Genotype $\left(S^{\prime} / S^{\prime}, L^{\prime} / L^{\prime}\right)$ and Rumination (High, Low) as between subjects factors on Positive Mood at baseline revealed a significant effect of Rumination, $\mathrm{F}(1,83)=16.689, p<0.001$ wherein high ruminators $(M=25.500, S D=5.679)$ scored lower than the low ruminators $(\mathrm{M}=30.605, \mathrm{SD}=6.268)$. There were no further effects of Genotype or Genotype X Rumination-interactions.

Negative Mood (PANAS). Univariate ANOVA with Genotype $\left(S^{\prime} / S^{\prime}, L^{\prime} / L^{\prime}\right)$ 
Figure 2a. Baseline Positive Affect

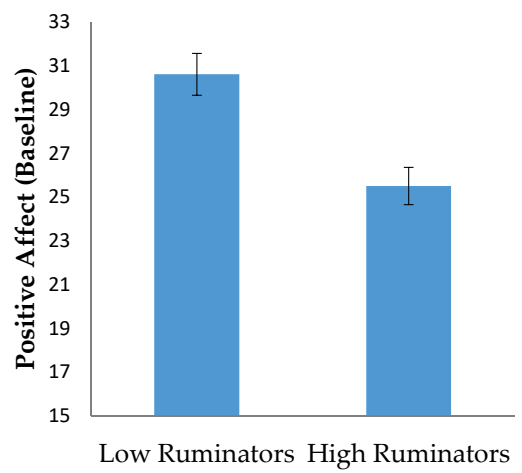

Figure 2a Mean Positive Affect scores as measured using the PANAS $20 \mathrm{~min}$. before stress induction. High ruminators scored significantly lower on Positive Affect $(p<0.001)$. The error bars represent the standard error of the mean.

Figure 2c. Baseline Total Mood Disturbance Low Ruminators High Ruminators

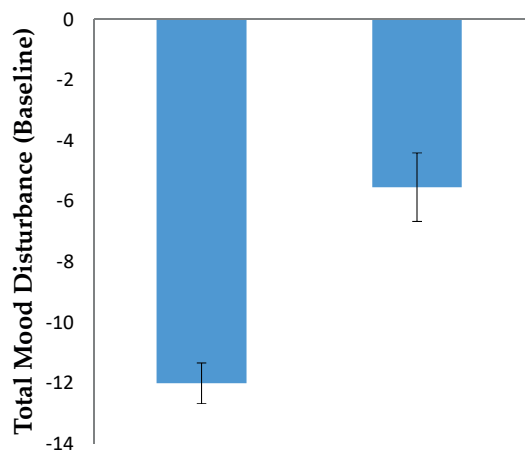

Figure 2c Mean Total Mood Disturbance scores as measured by the POMS $20 \mathrm{~min}$. before onset of stress induction. High ruminators scored significantly higher on Total Mood Disturbance $(\mathrm{p}<0.001)$. The error bars represent the standard error of the mean.
Figure 2b. Baseline Negative Affect

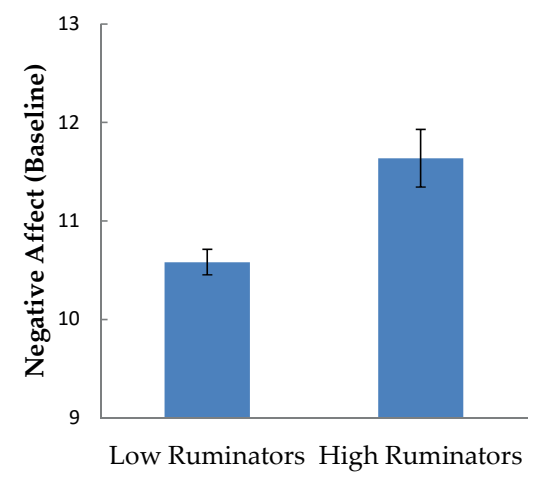

Figure 2b Mean Negative Affect scores as measured using the PANAS $20 \mathrm{~min}$. before stress induction. High ruminators scored significantly higher on Negative Affect $(p=0.001)$. The error bars represent the standard error of the mean. 
and Rumination (High, Low) as between subjects factors on Negative Mood at baseline revealed a significant effect of Rumination, $\mathrm{F}(1,83)=11.659, p=0.001$ wherein high ruminators $(\mathrm{M}=11.636, \mathrm{SD}=1.942)$ scored higher than the low ruminators $(\mathrm{M}=10.581, \mathrm{SD}=0.852)$. There were no further effects of Genotype or Genotype X Rumination-interactions.

Total Mood Disturbance (POMS). Univariate ANOVA with Genotype ( $S^{\prime} / S^{\prime}$, $\left.L^{\prime} / L^{\prime}\right)$ and Rumination (High, Low) as between subjects factors on TMD at baseline revealed a significant effect of Rumination, $\mathrm{F}(1,77)=24.321, p<0.001$ wherein high ruminators $(\mathrm{M}=-5.537, \mathrm{SD}=7.246)$ scored higher than the low ruminators ( $\mathrm{M}=-12.000, \mathrm{SD}=4.231)$. There were no further effects of Genotype or Genotype X Rumination-interactions. See figure 2 for baseline differences in affect.

\section{Salivary Cortisol Stress Response}

Repeated Measures ANOVA was used with Genotype $\left(\mathrm{S}^{\prime} / \mathrm{S}^{\prime}, \mathrm{L}^{\prime} / \mathrm{L}^{\prime}\right)$ and Rumination (High, Low) as within subjects-factors and Stress (-20 min., 0 min., $+20 \mathrm{~min}$. and $+40 \mathrm{~min}$. to onset of stress induction) as a between subjects-factors on Salivary Cortisol (nmol/l). An effect of Stress was found, F(1.742,80)=4.623, $p=0.015$. Further examination showed that compared to pre-stress induction (+0 min.), post-stress induction cortisol levels were significantly higher at +20 min., $\mathrm{F}(1,80)=12.386, p=0.001$ and +40 min., $\mathrm{F}(1,80)=7.781, p=0.007$, indicating a biological stress response to the MAST. There were no significant main or interaction effects of Genotype or Rumination. See figure 3.

\section{Mood Stress Response}

Repeated Measures ANOVA with Genotype $\left(S^{\prime} / S^{\prime}, L^{\prime} / L^{\prime}\right)$ and Rumination (High, Low) as between subjects-factors and Stress (-20 min., 0 min., +20min. and $+40 \mathrm{~min}$. to onset of stress induction) as a within subjects-factors on TMD revealed a significant effect of Stress, $F(3,67)=28.605, p<0.001$. Further examination showed that compared to pre-stress induction ( $+0 \mathrm{~min}$.), poststress TMD scores were significantly higher at $+20 \mathrm{~min}$., $\mathrm{F}(1,76)=46.44$, 
$p<0.001$ and +40 min., $F(1,79)=50.894, p<0.001$. There were no further main or interaction effects of Genotype or Rumination.

Repeated Measure ANOVA with Genotype $\left(S^{\prime} / S^{\prime}, L^{\prime} / L^{\prime}\right)$ and Rumination (High, Low) as between and Stress (-20 min., 0 min., +20min. and +40min. to onset of stress induction) as within-subjects factors on the Positive Scale of the PANAS showed a main effect of Stress, $F(3,79)=27.002, p<0.001$. Further analysis showed that compared to pre-stress induction $(+0 \mathrm{~min}$.), post-stress Positive Mood scores were significantly lower at $+20 \mathrm{~min}$., $\mathrm{F}(1,82)=30.166$, $p<0.001$ and +40 min., $F(1,82)=46.0 .19, p<0.001$. There were no further main or interaction effects of Genotype or Rumination. Similar analysis on the Negative Scale of the PANAS initially showed a main effect of Stress, F(1.560,79)=34.721, $p<0.001$ in which scores were significantly higher after (+20 min.) than before stress induction (+0 min.). However this effect depended on Rumination in the form of a Two-way interaction, $\mathrm{F}(1.560,79)=4.299, p=0.024$; as seen in figure 4; post-stress-induction (+20 min.) scores of high ruminators $(\mathrm{M}=15.279$, $\mathrm{SD}=5.115)$ were significantly higher than among low ruminators $(\mathrm{M}=12.286$, $\mathrm{SD}=2.949$ ).

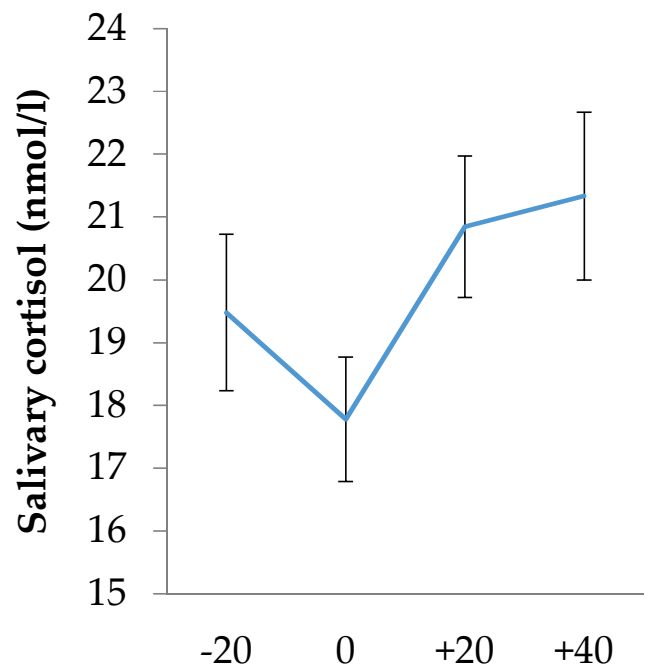

Figure 3 Mean salivary cortisol levels as a function of time (in minutes) after stress induction. Cortisol levels were significantly higher after stress induction (+20 $\mathrm{min}$.) than before $(+0$ $\min$.), $\mathrm{p}=0.001$. The error bars represent the standard error of the mean. 
Figure 4. PANAS changes

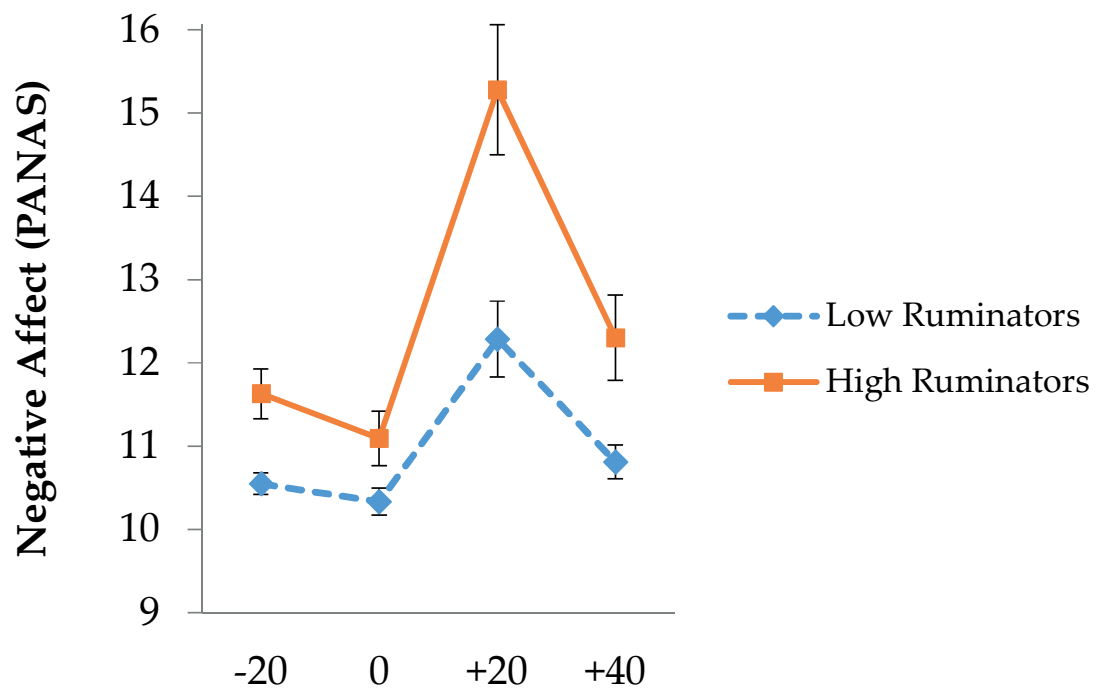

Figure 4 Mean scores of Negative Affect as a function of rumination (low, high) and time (in minutes) after stress induction. A two-way interaction between time and rumination showed that post stress (+20 min.) negative affect was significantly higher for high ruminators than low ruminators $(\mathrm{p}=0.024)$. The error bars represent the standard error of the mean.

\section{Duration biases (eye-tracking data)}

Savory food cues. Repeated Measures ANOVA with Genotype $\left(S^{\prime} / S^{\prime}, L^{\prime} / L^{\prime}\right)$ and Rumination (High, Low) as between and Stress (Pre and post Stress induction) as within-subjects factors on Duration Bias for savory food cues revealed a main effect of Stress, $\mathrm{F}(1,83)=4.690, p<0.033$, a Genotype X Stress-interaction, $\mathrm{F}(1,83)=10.616, p<0.002$ and a Genotype $X$ Rumination $X$ Stress-interaction, $\mathrm{F}(1,83)=4.017, p<0.048$. Post-hoc analysis revealed this 3 way-interaction was due to a Genotype $X$ Stress-interaction in exclusively the low Rumination group, $F(1,41)=10.695, p<0.002$. Further analysis showed that this interaction was caused by a significant effect of Stress exclusively in the $S^{\prime} / S^{\prime}$-group, $\mathrm{F}(1,22)=10.376, p=0.004$ as opposed to the $\mathrm{L}^{\prime} / \mathrm{L}^{\prime}$-group, $\mathrm{F}(1,19)=2.204, p=0.153$. As can be seen in Figure 5, a greater post-versus pre stress duration bias in $S^{\prime} / S^{\prime}$-over L'/L'-carriers was exclusively seen among low ruminators. 
Sweet food cues. Repeated Measures ANOVA with Genotype $\left(S^{\prime} / S^{\prime}, L^{\prime} / L^{\prime}\right)$ and Rumination (High, Low) as between and Stress (Pre, Post-Stress induction) as within-subjects factors on Duration Bias for sweet food cues revealed only a main effect of Stress, $\mathrm{F}(1,83)=37.415, p<0.001$ in which bias-scores were higher after $(\mathrm{M}=0.556, \mathrm{SD}=0.083)$ than before $(\mathrm{M}=0.512, \mathrm{SD}=0.066)$ stress induction. There were no further main or interaction effects.

Low caloric food cues. Repeated Measures ANOVA with Genotype $\left(S^{\prime} / S^{\prime}, L^{\prime} / L^{\prime}\right)$ and Rumination (High, Low) as between and Stress (Pre, Post-Stress induction) as within-subjects factors on Duration Bias for low caloric food cues revealed an effect of Stress, $\mathrm{F}(1,83)=6.710, p<0.011$ in which bias-scores were higher after $(\mathrm{M}=0.502, \mathrm{SD}=0.097)$ than before $(\mathrm{M}=0.480, \mathrm{SD}=0.061)$ stress induction. There were no further main or interaction effects.

Figure 5. Duration bias for savoury foods
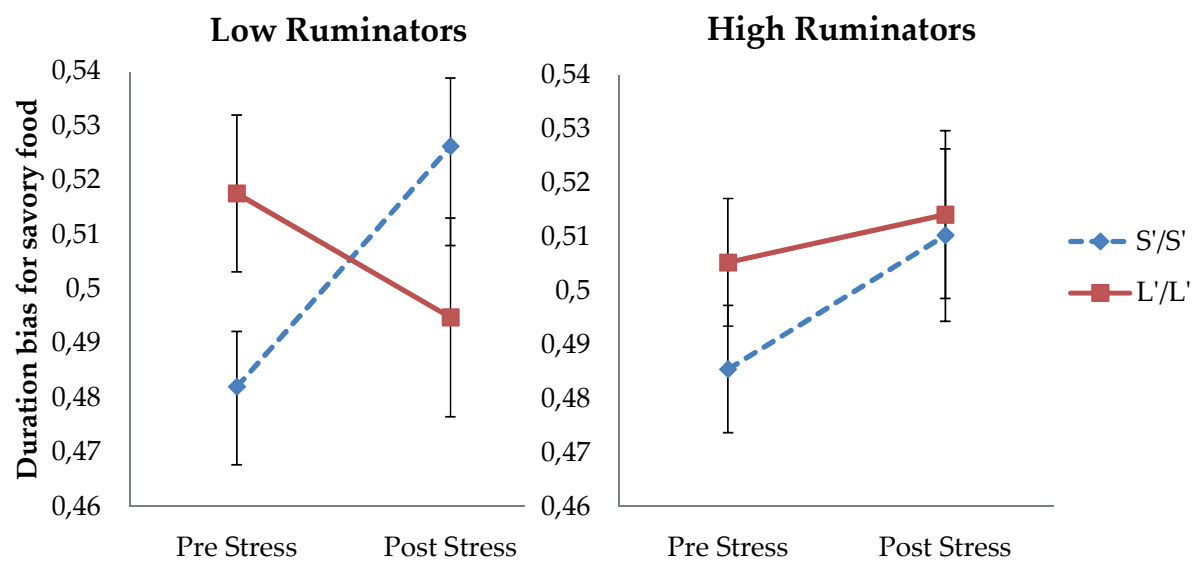

Figure 5 Eye-tracking data regarding mean duration bias for savoury high caloric foods as a function of Genotype $\left(S^{\prime} / S^{\prime}, L^{\prime} / L^{\prime}\right)$, Rumination (High, Low) and Stress (pre, post-stress induction). A three-way interaction between Genotype, Rumination and Stress was found $(\mathrm{p}<0.048)$ in which a greater post-versus pre stress duration bias in $S^{\prime} / S^{\prime}$-over $L^{\prime} / L^{\prime}$-carriers was exclusively seen among low ruminators $(p<0.002)$. 
Figure 6. Direction bias for savoury foods
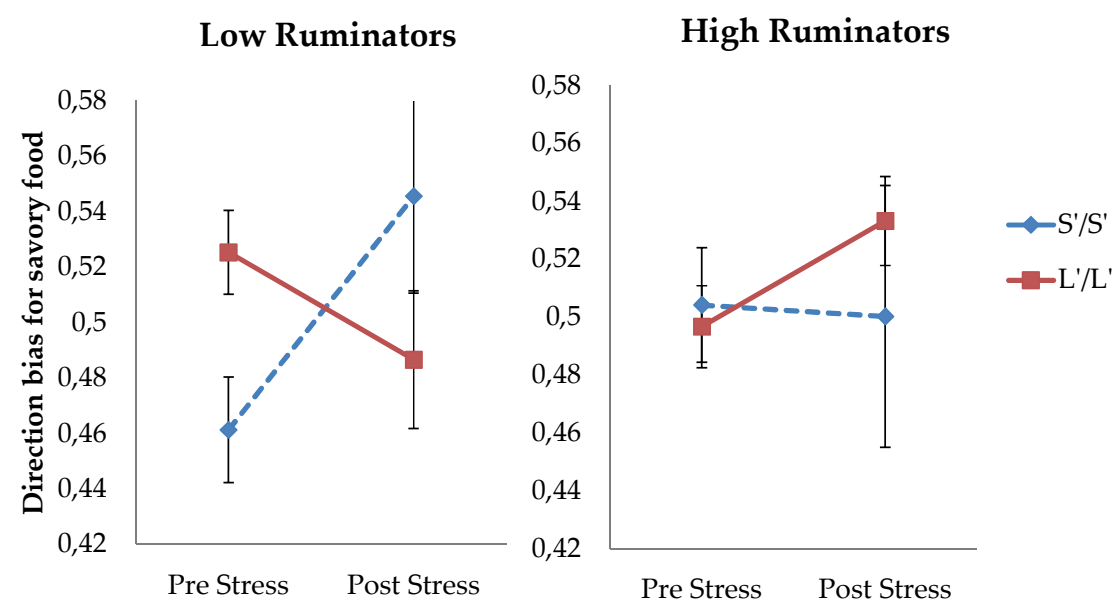

Figure 6 Eye-tracking data regarding mean direction bias for savoury high caloric foods as a function of Genotype ( $\left.\mathrm{S}^{\prime} / \mathrm{S}^{\prime}, \mathrm{L}^{\prime} / \mathrm{L}^{\prime}\right)$, Rumination (High, Low) and Stress (pre, post-stress induction). A three-way interaction between Genotype, Rumination and Stress was found $(p=0.013)$ in which a greater post-versus pre stress direction bias in $S^{\prime} / S^{\prime}$-over $L^{\prime} / L^{\prime}$-carriers was exclusively seen among low ruminators $(\mathrm{p}=0.008)$.

\section{Direction biases (eye-tracking data)}

Savoury food cues. Repeated Measures ANOVA with Genotype $\left(S^{\prime} / S^{\prime}, L^{\prime} / L^{\prime}\right)$ and Rumination (High, Low) as between and Stress (Pre, Post-Stress induction) as within-subjects factors on Direction Bias for savoury food cues revealed a three-way Genotype X Rumination X Stress -interaction, $\mathrm{F}(1,83)=6.494, p=0.013$. Further analysis showed that this interaction was caused by a two-way Genotype X Stress-interaction on direction bias scores, $\mathrm{F}(1,41)=7.815, p=0.008$ specifically in the low ruminators group. Within this group direction bias scores only increased as a function of Stress in the $S^{\prime} / S^{\prime}$-group, $F(1,22)=7.089$, $p=0.014$ as opposed to the $L^{\prime} / L^{\prime}-$ group, $F(1,25)=3.111, p=0.900$. See Figure 6 .

Sweet \& Low caloric food cues. Repeated Measures ANOVA with Genotype $\left(S^{\prime} / S^{\prime}, L^{\prime} / L^{\prime}\right)$ and Rumination (High, Low) as between and Stress (Pre, Post -Stress induction) as within-subjects factors on Direction Bias for sweet foods (and a separate analysis on low caloric foods) did not reveal any main or interaction-effects. 


\section{Discussion}

The aim of this study was to examine whether a combined genetic (S-allele, 5-HTTLPR) and cognitive (ruminative thinking) stress vulnerability may lead to an increased attention bias for palatable foods during stress. In support of the hypothesis group differences were exclusively found for the high caloric savoury food items. Against expectations, only in the absence of a ruminative thinking style did the $S^{\prime} / S^{\prime}$-allele carriers show a greater stress induced attention for savoury foods than $\mathrm{L}^{\prime} / \mathrm{L}^{\prime}$-allele carriers suggesting, that both a cognitive or biological stress vulnerability may mutually increase attention bias for high palatable food during acute stress.

\section{Stress Induction}

At baseline (when participants just arrived at the lab) there were no effects of genotype on salivary cortisol levels, this was expected as 5-HTTLPR's effect on the HPA-axis is usually found in response to an acute stressor (see: Miller et al., 2013). Interestingly, at baseline, high ruminating individuals already reported higher levels of negative affect (Total Mood Disturbance \& PANAS) and lower levels of positive affect (PANAS), validating the operationalization of rumination as form of chronic stress.

Overall increased levels of salivary cortisol and negative disturbances in mood after stress induction (MAST) proved its effectiveness in elucidating a biological and affective stress response, corresponding to previously reported work on the effects of the MAST (Smeets et al., 2012). Contrary to expectations $S^{\prime} / S^{\prime}$-allele carriers did not show a heightened cortisol stress responsiveness. However, difficulties in finding this association have been reported before and might be attributable to low effect sizes (see Miller et al., 2013 for a meta-analysis). Similarly genotype had no effect on stress induced changes in Total Mood Disturbance or Positive Affect. This absence of a significant association between stress related mood changes and 5-HTTLPR genotype might be attributable to the nature of the stressor. Studies using 
artificial acute stressors in the lab were also not always able to find this association (Capello and Markus, 2014b; Markus and Firk, 2009), although it was observed while studying natural real life stressors (Verschoor and Markus, 2011), suggesting that personal real life stress might be better at revealing genotype related effects on affective stress responsiveness.

Further, as expected, ruminative thinking style mediated stress induced increases of negative affect (PANAS). This corresponds with earlier research that found ruminative thinking to be a mechanism linking stressful life events to depressive symptoms (Michl et al., 2013). Stress induced mood changes measured by the POMS however did not show a mediating effect of rumination. This discrepancy between the POMS and PANAS have been reported before and are probably caused by subtle differences between the two scales (Rossi and Pourtois, 2012), thereby causing different sensitivities to changes in mood caused by ruminative thinking.

\section{Effect of stress on visual attention for food}

All subjects showed increased attention biases for all types of food after stress induction. This association was expected as subjects were not allowed to eat during the experiment and hunger has been found to be associated with increased attention for food cues (Castellanos et al., 2009; Mogg et al., 1998). Interestingly, differences in stress vulnerabilities (5-HTTLRP genotype, ruminative thinking) exclusively influenced stress induced attention for high caloric savoury foods. This corresponds with the notion that emotional eating increases the preference for high palatable sweet and/ or fat food (for a review see; Schepers \& Markus, 2015). The direction of the three way interaction between genotype, ruminative thinking and stress was slightly different than expected. The high ruminative $S^{\prime} / S^{\prime}$-carriers were expected to show the biggest attention bias for high palatable foods as they have a combined stress vulnerability. However, specifically low ruminative $\mathrm{L}^{\prime} / \mathrm{L}^{\prime}$-carriers were the only group not to show stress-induced visual attention biases (duration and direction) for high caloric savoury 
foods. One explanation for these findings might be that the presence of a stress vulnerability (biological or cognitive) will increase attention bias for high palatable foods, but the presence of a second vulnerability will not further increase this effect. A recent study (Tryon et al., 2013) showed that people who experience chronic stress show heightened brain responses when seeing pictures of high caloric foods. Ruminative thinking can prolong stress responses and in this experiment high ruminating participants already showed more negative affect at baseline. Therefore rumination might serve as a form of chronic stress, increasing attention bias for high caloric food and refuting the influence of a second stress vulnerability (5-HTTLPR S-allele). Additionally the stress induction task might have been too inefficient in revealing genotype related stress responsiveness as there also were no genotype differences on affect or cortisol responses. This could explain why carrying an S-allele does not add increased attention for high palatable foods after stress for high ruminative individuals but does show an effect in the absence of a more pronounced stress vulnerability, as ruminat

ive thinking did show increased negative affect responses and baselines. A second explanation for only finding an increased attention bias for high caloric savory food for $S^{\prime} / S^{\prime}$-carriers in the absence of a ruminative thinking style, might be the duration of the experiment. The hypothesis was that rumination would exacerbate the effect of carrying an S-allele by prolonging the stress response; while our experiment lasted around 90 minutes we were only able to measure the acute effects of stress. Maybe the effects of rumination become more pronounced over time showing genotype differences better when measured longer after the stressor and/or in a more natural environment (as opposed to the lab).

\section{Strengths and limitations}

A noteworthy strength of this study, the use of eye-tracking equipment provided an accurate objective measure of visual attention for food in direct relation to stress. Additionally our main findings were consistently observed 
for both duration and direction biases. A limitation in our design is that we cannot discern the effect of our stress induction from the effect of time as our design did not include a non-stress control condition. Additionally we cannot control for order effects, therefore visual attention in the post stress condition might partly be influenced by participants becoming hungrier over time. A second limitation is the relatively short duration of the experiment (90 min.) limiting us from exploring the long term effects of rumination.

\section{Conclusion}

Both a genetic (5-HTTLPR genotype) and a cognitive (ruminative thinking) stress vulnerability may mutually influence the effect of stress on food attention. Contrary to expectations; current results suggest that only in the absence of an additional cognitive stress-vulnerability (rumination) the possession of a genetic (S-allele 5-HTTLPR) stress-vulnerability increases attention biases for high caloric savoury food. These data underscore the importance of accounting for both cognitive and biological stress factors when examining stress related (eating) behaviour. Whether these effects of genotype and rumination on attention for food will be different to a more personal stressor or over longer periods of time remain to be investigated. 



\section{Chapter 4}

The effect of 5-HTTLPR genotype and cognitive rumination on long term cortisol reactivity measured in human hair.

(To be) submitted as:

Schepers, R., Keulers, E.H.H. \& Markus, C. R. (2018a). The effect of 5-HTTLPR genotype and cognitive rumination on long term cortisol reactivity measured in human hair. 


\section{Abstract}

Over the last decade numerous meta-analyses including ample experimental and associative studies have shown that a short allele (S-allele) of the serotonin transporter gene (5-HTTLPR) is linked to increased psychological and biological stress responsivity and affective disorders. Recent insights suggest that this association is even more pronounced in combination with a highly negative ruminative (stress-related) thinking style. However, past studies on the association between 5-HTTLPR and stress experience and/or rumination on biological stress-responsiveness almost exclusively measured responsiveness through acute salivary cortisol (HPA) changes under acute stress exposure. Measuring accumulated levels of cortisol over longer periods of time might better reflect (chronic) genotype by HPA stress responsiveness associations. With assessment of cortisol levels in scalp hair it is now possible to measure the accumulation of cortisol secretion of 1 month per every centimeter of hair. In this study we measured associations between 3-months accumulated cortisol concentrations and the tendency to ruminate about negative events in $27 \mathrm{~S} / \mathrm{S}$ and $27 \mathrm{~L} / \mathrm{L}$ 5-HTTLPR- carriers (screened from a large $n=827$ DNA database). A hierarchical regression analysis revealed a clear significant interaction between Genotype and Rumination $(p<0.01$, $\mathrm{f}^{2}=0.26$ ) indicating the highest accumulation of hair cortisol concentrations in high ruminating S/S-allele carriers. Concluding, this significant increased long term accumulation of cortisol secretion measured in scalp hair may be a most valuable additional measure to detect chronic stress vulnerabilities caused by a Gene X Environment interaction. 


\section{Introduction}

Repeated or chronic experience of stress is well-known to be associated with numerous negative physical and mental aspects of health, for instance: high blood pressure, a weakened immune system, anxiety, insomnia, depression and obesity (Baum \& Posluszny, 1999). The brain serotonin (5HT) system is critical in the regulation of mood and stress resilience (Pinel, 2006), therefore individual differences in this system's efficiency might be an important underlying factor in the experience of chronic stress. The serotonin transporter gene (5-HTTLPR) is polymorphic as it consists of 2 distinct functional promoter lengths: short (S) or long (L). The short allele is associated with lower transcriptional efficiency leading to lower 5-HTT availability among S-allele carriers than among L-allele carriers (Heils et al., 1996). Consistent with these findings S-allele carriers show multiple forms of stress vulnerability through: increased amygdala reactivity in relation to fearful stimuli (Hariri and Holmes, 2006; Munafò et al., 2008; Murphy et al., 2013), an attention bias towards negative emotional stimuli (Beevers et al., 2009; Firk and Markus, 2009; Markus and De Raedt, 2011) and most importantly show an increased risk to develop depression after the occurrence of stressful life events (Clarke et al., 2010; Karg et al., 2011; Sharpley et al., 2014). The exact mechanism(s) through which carrying an S-allele of 5-HTTLPR will lead to a higher stress vulnerability are not completely understood yet although it has been hypothesized that the hypothalamic-pituitary-adrenal (HPA)-axis plays an important part.

The HPA-axis is the main neural circuit that integrates the perception of (potential) stressors into a complex pattern of (neuro)-endocrine and autonomic responses serving as biological stress adaption (Ursin and Olff, 1993). The complex inter-relationship of the HPA-axis and the serotonergic system and their involvements in biological and psychological stress resilience (for a review see: Porter et al. (2004)) may serve as a good explanation for higher stress sensitivity among S-allele carriers of the 
5-HTTLPR gene. Increased HPA-reactivity among S-allele carriers has been reported in relation to acute, stress-inducing laboratory tasks, although these findings are not always replicated. The most recent meta-analysis concludes this association to be small but significant (Miller et al., 2013). The occasional acute rise of cortisol may not be notably problematic but, as the effect of 5-HTTLPR genotype on the 5-HT-system is constant (rather than acute) its interaction with the HPA-axis might lead to a chronic stress sensitivity and especially this cumulative strain of frequent HPA-axis activation seems to be important in the development of affective disorders (Chrousos, 2009). Ancillary to genes, cognitive factors can also influence cortisol reactivity. Recent findings show that ruminative thinking which is often defined as (uncontrollable) perseverative thinking about past or present negative events (Nolen-Hoeksema et al., 2008), prolongs cortisol secretion long after the stressor disappeared (Zoccola and Dickerson, 2012). We propose that ruminative thinking can exacerbate the stress vulnerability of carrying an S-allele by prolonging the already increased stress response. Interestingly, a greater incidence of depressive symptoms has been reported among specifically S-allele carriers with a tendency to ruminate (Schepers \& Markus, 2017b). In the current study we were interested if this interaction between 5-HTTLPR genotype and cognitive rumination could be caused by long term increased activation of the HPA-axis.

HPA-axis reactivity is usually measured through assessing cortisol levels in blood plasma, saliva or urine. In these bodily fluids cortisol levels can fluctuate in the matter of minutes in the case of blood and saliva or up to 24 hours in the case of urine. The HPA-axis is a highly reactive system effected by numerous factors including circadian rhythmicity (Kudielka et al., 2004; Weitzman et al., 1971), making analyses of cortisol in these bodily fluids far from the ideal assessment of chronic stress. Both carrying an S-allele of 5-HTTLPR and cognitive rumination can separately but even more so in combination potentially serve as a chronic, rather than an acute form of stress vulnerability (Clarke et al., 2010; Karg et al., 2011; Miller et al., 2013; 
Roelofs et al., 2008; Rood et al., 2010; Sharpley et al., 2014). Therefore we conjecture that testing our hypothesis of a heightened HPA-axis reactivity among subjects with this distinct combination (S-allele and cognitive rumination), might be better implemented by measurements of cortisol accumulation over longer periods of time than the more traditional hourly or daily endocrine responses measured in bodily fluids. A relatively new method to measure accumulated levels of cortisol secretion is through analysis of scalp hair. As cortisol is incorporated in growing hair and scalp hair grows with an average of $1 \mathrm{~cm}$ per month (Wennig, 2000) it is possible to retrospectively measure accumulated cortisol secretion of multiple months, a time frame that is virtually impossible to measure by analysing cortisol levels in blood plasma, saliva or urine. Although the analysis of hair cortisol concentrations (HCC) is fairly new, the existing literature shows it to be a reliable, valid method (Stalder et al., 2012; Wippert et al., 2014). For instance higher HCC's have been found in people suffering from affective disorders, chronic stress, PTSD, alcoholism or Cushing syndrome, while on the other hand lower levels of HCC were found in Addison's disease patients. Additionality, on a sub-clinical level, higher HCC's are reported among shift workers, unemployed people, women in the third trimester of pregnancy and people who have recently experienced stressful life events (for a review see: Stalder and Kirschbaum (2012) or Staufenbiel et al. (2013)). To the authors best knowledge, research regarding genetic influences on HCC's in humans has not been conducted yet. Interestingly though, a recent study showed increased HCC's in homozygotic S-allele macaque's compared to homozygotic L-allele macaque's, but only among those that that lived in a socially stressful environment (Qin et al., 2015).

The aim of the current study was to investigate if a distinct combination of a biological (S-allele of 5-HTTLPR) and cognitive (ruminative thinking) stress vulnerability will lead to significant higher concentrations of accumulated cortisol in scalp hair (conceivably as a result of chronic heightened stress HPA-axis responsiveness). 


\section{Methods}

\section{Participants}

Participants of this study were a sub-sample of individuals who were visiting our lab for a different study. For this different study, potential participants were selected from an existing DNA database (see: Schepers \& Markus, 2017b) containing 827 university students from Maastricht University, genotyped for 5-HTTLPR. Only homozygous carriers of 5-HTTLPR were invited, because differences in stress responses are more pronounced within these groups then within heterogynous groups (Way \& Taylor, 2010). Out of the 69 participants that visited the lab, all participants consented to donate hair for this study although 15 participants were excluded because their hair was of insufficient length $(<3 \mathrm{~cm})$ at the posterior vertex. The final sample $(\mathrm{N}=54)$ consisted of $27 \mathrm{~S} / \mathrm{S}$-carriers and $27 \mathrm{~L} / \mathrm{L}$-carriers of which 50 participants were female. The average age was $23.52(\mathrm{SD}=2.34)$.

\section{Assessment of rumination}

Participants filled in the Dutch translation of the Ruminative Response Scale (Nolen-Hoeksema and Morrow, 1991; Raes and Hermans, 2007; Treynor et al., 2003), this questionnaire has been proven to be a reliable and valid method to assess ruminative thinking. This assessment tool consists of 2 separate scales: brooding (negative rumination) and reflection (constructive introspection). We exclusively used the Brooding scale in our analysis as we were interested in the negative form of ruminative thinking.

\section{Hair sampling \& assessment of hair cortisol concentrations}

For each participant 2 strands of hair of approximately $3 \mathrm{~mm}$ thickness were cut as close to the scalp as possible at the posterior vertex. For the assessment of cortisol concentrations only the first $3 \mathrm{~cm}$ of hair were used, corresponding to accumulated cortisol secretion of approximately 3 months. Washing and steroid extraction procedures were followed as described in (Kirschbaum et al., 2009). Cortisol determination in these samples was achieved by using a commercially available immunoassay with chemiluminescence. The 
intraassay and interassay coefficient of variance of this assay is below $8 \%$.

\section{Hair dye}

As two recent studies (Manenschijn et al., 2011; Sauvé et al., 2007) found an association between dyed hair and lower HCC's we asked our participants to report (Yes/No) if they used any form of (semi)-permanent hair colouring in the past three months.

\section{Data Analysis}

Data were first examined for accuracy of data entry, missing values and normal distributions. HCC values were log transformed to create a more normal distribution, before transformation (Skewness=5.35, Kurtosis=33.82), after transformation (Skewness=-0.27, Kurtosis=2.33).

To test for independence of demographics over genotypes, separate independent samples T-test or Fisher's exact tests were run (proportions could not be tested using $\chi^{2}$ as some expected cells contained frequencies lower than 5). An independent samples T-test was run to compare HCC's for the use of hair dye in the past three months (Yes/No). All statistics were conducted at a two-tailed significance level and were Bonferroni corrected where needed.

The main analysis was conducted by means of Multiple Regression Analysis (using IBM SPSS 24 for Windows). The analysis was conducted with Genotype (S/S vs L/L), Rumination and their interaction as predictors for Hair Cortisol Concentrations (HCC). Additionally this model was tested again while controlling for the use of hair dye and once solely on women. 5-HTTLPR was coded as: $0=\mathrm{S} / \mathrm{S}, 1=\mathrm{L} / \mathrm{L}$, Sex was coded as: $0=$ Male, $1=$ Female, Dyed Hair was coded as $0=\mathrm{No}, 1=$ Yes.

Multicollinearity was no concern as all VIF values were below 10 and all Tolerance values were above 0.1. The errors appeared to be independent (Durbin-Watson value=1.81). Sensitivity analysis (using $\mathrm{G}^{*}$ Power 3.1.9.2 for Windows) showed this test could detect effect sizes of 
minimally Cohen's F ${ }^{2}=0.22(\alpha=0.05$, Power $=0.80, N=54$, Predictors $=3)$.

\section{Results}

\section{Demographics}

See table 7 for demographics, among these variables there were no a priori Genotype differences.

Table 7. Demographics and mean Hair Cortisol Concentrations by 5-HTTLPR genotype

\begin{tabular}{|c|c|c|c|c|c|c|}
\hline & \multicolumn{2}{|c|}{$\mathrm{S} / \mathrm{S}$} & \multicolumn{2}{|c|}{$\mathrm{L} / \mathrm{L}$} & \multirow[b]{2}{*}{$\mathbf{t}$} & \multirow[b]{2}{*}{$\mathrm{p}$} \\
\hline & Mean & SD & Mean & SD & & \\
\hline Age & 20.30 & 2.11 & 20.74 & 2.57 & 0.695 & 0.49 \\
\hline Rumination (Brooding) & 8.59 & 3.07 & 8.63 & 3.36 & 0.042 & 0.97 \\
\hline Hair Cortisol Concentration (nmol/1) & 10.64 & 15.71 & 7.24 & 5.35 & -1.07 & 0.29 \\
\hline Hair Cortisol Concentration (nmol/1) Log10 & 0.82 & 0.44 & 0.76 & 0.30 & -0.52 & 0.61 \\
\hline
\end{tabular}

\begin{tabular}{lcccccc}
\hline & \multicolumn{3}{c}{ S/S } & L/L \\
\cline { 2 - 6 } Sex & Male & Female & Male & Female & p \\
& 3 & 24 & 1 & 26 & 0.61 \\
\cline { 2 - 6 } Dyed hair in past 3 months & Yes & No & Yes & No & \\
\hline Note. N=54. There were no a priori Genotype differences in means or proportions.
\end{tabular}

Note. $\mathrm{N}=54$. There were no a priori Genotype differences in means or proportions.

\section{Dyed Hair on Hair Cortisol Concentrations}

There was no significant effect of Dyed Hair on Hair Cortisol Concentrations $(t=0.27, p=0.79)$.

\section{Genotype and Rumination on Hair Cortisol Concentrations}

Table 8 reports the unstandardized (B) and standardized $(\beta)$ regression coefficients for the multiple linear regression model. An interaction between Genotype and Rumination significantly predicted variance in HCC's ( $\beta=-$ 1.326, $\mathrm{p}=0.001, \mathrm{f}^{2}=0.26$ ) as the association of Rumination with higher $H C C^{\prime} s$ was greater among $\mathrm{S} / \mathrm{S}$-carriers than among L/L-carriers. 
Table 8. Summary of Multiple Linear Regression Analysis for (Logarithmized) Hair Cortisol Concentration $(\mathrm{N}=54)$

\begin{tabular}{|c|c|c|c|c|c|}
\hline & B & SE (B) & $\beta$ & $\mathrm{t}$ & $\mathrm{p}$ \\
\hline Constant & ,205 & 198 & & 1,034 & ,306 \\
\hline Genotype & ,802 & ,270 & 1,091 & 2,972 & ,005 \\
\hline Rumination &, 071 & ,022 & ,610 & 3,261 & ,002 \\
\hline Genotype $x$ Rumination &,- 099 & ,029 & $-1,326$ & $-3,374$ & ,001 \\
\hline
\end{tabular}

Note. $\mathrm{N}=54$, Genotype was represented as $\left(\mathrm{S} / \mathrm{S}=0, \mathrm{~L} / \mathrm{L}\right.$-carrier=1). $\mathrm{R}^{2}=0.206$

Additional Analysis

\section{Tests of potential confounding effects of Dyed Hair or Sex}

To control for the potential confounding effect of using hair colouration products or an effect of Sex, the main analysis was rerun once with Dyed Hair added as a factor and another time on solely the female subjects. Both tests did not alter the conclusion of the initial findings. 


\section{Discussion}

The aim of the current study was to explore whether the combined possession of a genetic (S-allele 5-HTTLPR) and a cognitive (Rumination) vulnerability for stress is reflected in (3 months) accumulation of cortisol in scalp hair (as a reflection of chronic HPA-axis stress-responsiveness). In line with our hypothesis, significantly higher concentrations of hair cortisol (HCC) were found in S/S-carriers with the highest high ruminative thinking styles.

Although previous findings have shown an increased susceptibility to develop depressive symptoms caused by an interaction between 5-HTTLPR genotype and ruminative negative (stress-related) thinking (Schepers \& Markus, 2017b); the mechanism behind this association was unknown. A plausible explanation for this effect might be that, ruminative thinking leads to repeated subjective experiences of stress and activations of the HPA-axis leading to a state of chronic psychological and biological stress. Conceivably this effect will more pronounced among people with a hyper stress reactive HPA-axis (S-allele-carriers of 5-HTTLPR). Regarding the subjective experience of stress, numerous studies have shown the long term negative effects of rumination on mood among clinically depressed (Mckim, 2008; Papageorgiou and Wells, 2003; Robinson and Alloy, 2003) as well as in the healthy population (Schepers and Markus, 2017a; Segerstrom et al., 2000; Thomsen et al., 2003; Verhaeghen et al., 2005). On the topic of biological stress responsivity it was shown that ruminative thinking can prolong cortisol stress responsiveness after an acute stressor (for a review see: Zoccola and Dickerson (2012)), however the long term effect of rumination on HPA-axis responsivity was not reported before. In regard to the effect of carrying an S-allele of 5-HTTLPR similar results were reported before. On a general or chronic level numerous studies reported a link between an S-allele and depressive symptoms (Clarke et al., 2010; Karg et al., 2011; Sharpley et al., 2014). On a biological level however, multiple studies reported increased activation of the HPA-axis in response to stress (Miller et al., 2013) but 
exclusively to acute stressors. The current study was the first to examine long term accumulated cortisol secretion as a function of ruminative thinking and 5-HTTLPR. In our data the highest HCC's were found in specifically in the high ruminating S/S-carriers. These data correspond well to earlier studies where carrying an S-allele of 5-HTTLPR in combination with a cognitive stress vulnerability led to lowered mood or more depressive symptoms (Capello and Markus, 2016; Markus, 2013; Schepers and Markus, 2017b).

Due to the observational/associative nature of the current study differences in cortisol accumulation in hair could be caused by several reasons. Fluctuations of serum cortisol levels have found to be caused by for instance, sleep-wake cycles (Czeisler and Klerman, 1999; Leproult et al., 1997), food intake (Delarue et al., 2003; Lovallo et al., 2006) and physical exercise (Bloom et al., 1976; Davies and Few, 1973). However, in our sample we found clear differences of accumulated cortisol levels based on prominently the stress proneness of our subjects, namely higher HCC's in S/S-carriers with a tendency to ruminate. Both ruminative thinking and carrying an S-allele of 5-HTTLPR have been linked to increased and/or prolonged HPA-axis stress reactivity (for a review see Zoccola and Dickerson (2012) and Miller et al. (2013)). Therefore we think it most likely that the group differences in HCC's in our study were caused by repeated/prolonged increased (subjective and) HPA-axis stress reactivity caused by the specific combination of carrying an S-allele and having a ruminative thinking style. The observation of this effect suggests a chronic biological stress vulnerability for everyday stressful events specifically for high ruminative S/S-carriers.

To the authors knowledge this is the first study to examine a 5-HTTLPR gene $x$ environment effect on cortisol reactivity measured in scalp hair in healthy human subjects. Interestingly, our data corresponds well to a study that found higher HCC's in S-carrying macaques, but specifically among those that lived in a socially stressful environment (Qin et al., 2015). High HCC's have been found in humans with different forms of chronic/long 
term stress both on a clinical and sub-clinical level (for a review see: Stalder and Kirschbaum (2012) or Staufenbiel et al. (2013)), further validating our hypothesis that carrying an S-allele in combination with having a ruminative thinking style can serve as a form of chronic stress vulnerability.

The innovative nature of measuring cortisol levels in hair over the more established methods of measuring in saliva, blood and urine is the long term retrospective possibilities. Because this method is able to detect the accumulation of cortisol over months it might prove to be a superior method to measure long term (chronic) stress responsivity than by using the more conventional methods of (repeatedly) measuring cortisol acutely in blood or saliva. This could also explain why we found such a robust effect (medium to large effect size) while the findings of acute effects of 5-HTTLPR on cortisol reactivity are sometimes insignificant or show only small effect sizes (Miller et al., 2013).

Corresponding to earlier studies (Dowlati et al., 2010; Stalder et al., 2012), the use of hair colouring products did not have any significant effect on HCC's or the main findings in the current study. It might still be important to check for this potential confounding effect in future studies as the frequency of participants with dyed hair in our sample might have been too low to validly compare to the rest of the sample ( 9 out of 54 participants) and we were not able to discern different types of hair colouring products. Additionally, in the past there have been reports of lower HCC's in dyed hair (Manenschijn et al., 2011; Sauvé et al., 2007).

\section{Strengths and Limitations}

This was the first study to show increased chronic/long term cortisol secretion among 5-HTTLPR S-allele carriers with a high ruminative thinking style. This effect was of moderate to large size $\left(\mathrm{f}^{2}=0.26\right)$ and was not confounded by sex differences or by use of hair colouring products. A limitation of this study was the relatively modest sample size $(\mathrm{N}=54)$, making replication of 
our results essential to validate our conclusions. Additionally due to the non-experimental nature of this study differences in HCC's could have been caused by other factors than 5-HTTLPR genotype or ruminative thinking. However, considering the formerly known effects of 5-HTTLPR and rumination on cortisol reactivity, it is highly likely that higher HCC's in high ruminative $\mathrm{S} / \mathrm{S}$-allele carriers were a result of a higher sensitivity to daily stress. Future studies could investigate this likely effect of higher stress sensitivity in high ruminative S-carriers more directly by for instance, measuring experiences of stress over a set time and relating these to HCC's corresponding to this period.

\section{Conclusion}

Carrying an S/S-genotype of 5-HTTLPR in combination with having a negative ruminative thinking style leads to an increased accumulation of hair cortisol concentrations; most likely due to more frequent long term stress experiences and consequently HPA-axis stress responsiveness potentially leading to form of chronic stress. Additionally this was the first study to show that assessment of hair cortisol concentrations is able to detect stress vulnerabilities caused by a Gene X Environment interaction. 



\section{Chapter 5}

The interaction between 5-HTTLPR genotype and Ruminative Thinking on Daily Stress and Food Intake - a multilevel approach

(To be) submitted as:

Schepers, R., Keulers, E.H.H. \& Markus, C. R. (2018b). The interaction between 5-HTTLPR genotype and Ruminative Thinking on Daily Stress and Food Intake - a multilevel approach 


\section{Abstract}

In certain individuals, stress and negative affect can lead to an increased consumption of high caloric palatable foods. Susceptibility to experience stress might be an important factor in the individual differences of developing this emotional eating behaviour. The brain serotonin system is known to play a crucial role in stress resilience as well as in eating behaviour. Genetic variation can influence this system, as a short allele (S-allele) of the serotonin transporter gene (5-HTTLPR) has been associated with a less efficient functioning brain serotonin system leading to increased biological and affective stress responsiveness. Numerous studies have shown that the effect of this genotype is however most pronounced while being moderated by an environmental or cognitive factor. The objective of the current study was to investigate whether S/S-allele carriers with a tendency to ruminate about negative events eat more palatable foods when stressed, measured in a natural daily setting. Using digital diaries for 6 weeks, we measured daily food intake and experience of stress of 69 homozygotic 5-HTTLPR carriers. In line with our hypothesis a multilevel analysis showed that the association between daily stress and increased intake of calories was highest among high ruminative S/S-carriers. Concluding, carrying a specific combination of cognitive and biological stress vulnerabilities (S-allele of 5-HTTLPR and ruminative thinking) can lead to increased caloric intake as a function of daily stress. 


\section{Introduction}

As the prevalence of obesity in the Western world is still on a steady and alarming increase (Berghöfer et al., 2008; Flegal et al., 2010; Wang and Beydoun, 2007), understanding (unhealthy) eating behaviours that can lead to this state of increased body mass are of great importance in today's healthcare. Emotional eating, which is consuming food to compensate for negative emotions rather than for its nutritional value, might be one of these behaviours contributing to weight gain as is not only increases overall intake of food but also shifts preference towards palatable (high fat, high sweet) foods (for a review see: (Schepers and Markus, 2015)). Numerous studies in different scientific fields have been aimed at finding deterministic factors of developing an emotional eating style, however results were often heterogeneous and a clear cause of developing this eating style still remains debatable. As emotional eating exclusively occurs in relation to negative mood, it might be important to look at individual differences in emotion regulation/stress resilience when looking for explanations for emotional eating behaviour. The serotonin (5-HT) system is crucial in the neurological regulation of emotions and stress (Pinel, 2006). Variations in the serotonin transporter gene (5-HTTLPR) influence the efficiency of the 5-HT system, as the short allele (S-allele) of this gene is associated with less mRNA expression, less 5-HT binding and lower 5-HT availability (Heils et al., 1996). Consequently S-allele carrier's show increased endocrine and behavioural stress responsiveness (Markus and De Raedt, 2011; Markus and Firk, 2009; Miller et al., 2013) and an increased chance of developing symptoms of depression (Clarke et al., 2010; Karg et al., 2011; Sharpley et al., 2014). Additionally the S-allele is associated with increased bodyweight (Erritzoe et al., 2010; Sookoian et al., 2007) and eating disorders (Di Bella et al., 2000; Fumeron et al., 2001), although, while several other studies were not able to produce similar results (Hinney et al., 1997; Racine et al., 2009; Sundaramurthy et al., 2000), it is therefore probable that 5-HTTLPR genotype's influence on (emotional) eating behaviour is more contributing 
than deterministic. Confirmatory to this hypothesis, both in the context of negative mood/ depression and eating behaviour, studies show the effect of 5-HTTLPR to be most pronounced in interaction with an environmental or cognitive stress factor (Brown and Harris, 2008; Capello and Markus, 2014a, b; Gunthert et al., 2007; Markus and Capello, 2012; Pluess et al., 2010; Sharpley et al., 2014; van Strien et al., 2010; van Strien et al., 2016).

Ruminative thinking which is having perseverative thoughts about past negative events (Treynor et al., 2003) could prove to be a good example of such a moderator. Ruminative thinking effectively prolongs stress responses as can be seen in increased cortisol secretion long after the disappearance of a stressor (McCullough et al., 2007; Zoccola and Dickerson, 2012). Consequently ruminative thinking is a solid predictor for negative mood in healthy subjects (Rood et al., 2010; Segerstrom et al., 2000) as well as being an important factor in clinical depression (Roelofs et al., 2008) and eating disorders (Birmingham and Firoz, 2006). As previously proposed (Schepers and Markus, 2015), ruminative thinking might exacerbate the effect of carrying an S-allele of 5-HTTLPR by prolonging the already increased stress response, thereby potentially increasing the rewarding effect of stress compensating behaviours like emotional eating to occur. Confirmatory, higher concentrations of cortisol were found in scalp hair (reflecting long term activation of the HPA-axis) of homozygotic S-carriers with a high ruminative thinking style (Schepers et al., 2018a). Additionally in a sample of 800 healthy students, depressive symptoms and body mass was highest among S-allele carriers with a tendency to ruminate (Schepers and Markus, 2017b). A third finding confirming emotional eating might be influenced by this distinct combination of stress vulnerabilities was found in an eyetracking study were an interaction was found between 5-HTTLPR genotype and ruminative thinking on a stress induced attention bias for high caloric savoury food (Schepers and Markus, 2017a). The current study was aimed at exploring whether a genotype $x$ cognition interaction on daily caloric intake could be found in a real life setting. Assessing food intake and 
experience of stress through diaries we expected to see an increase of caloric intake on days were stressful events occurred, specifically for high ruminating S/S-carriers.

\section{Methods}

\section{Participants}

Potential participants were selected from an existing DNA database containing 827 university students from University Maastricht, genotyped for 5-HTTLPR and screened for factors including general health (weight and length, smoking and drinking habits, personal or family history of psychiatric disorders). For the current study only healthy homozygous carriers of 5-HTTLPR were invited, as differences in stress responses are more pronounced within these groups than within heterogynous groups (Way \& Taylor, 2010). The sample size was based on convenience sampling as power calculations in multilevel models are very complex and up to date there are no clear rules of thumb (Field, 2009; Kreft et al., 1998; Twisk, 2006). In total 69 people consented to participate in the current study, of which 34 participants were S/S-carriers and 35 were L/L-carriers, with a mean age of $23.86(\mathrm{SD}=3.74)$ and a mean $\mathrm{BMI}$ of 22.39 (SD=3.07), 50 participants were female. See table 1 for participant characteristics.

\section{Design and procedure}

Participants filled in an initial digital questionnaire followed by 6 weeks of daily diaries. After recruitment the participants visited the lab once to receive information about the study and procedure. All data collection was done using the online platform Qualtrics (www.qualtrics.com), giving the participants the freedom to fill in questionnaires on any smart device they preferred. Participant's compliance of filling in the diaries was monitored through Qualtrics. When participants failed to fill in a diary they were encouraged through email to keep filling in the diaries every day. Participants were asked to fill in the diary at the end of the day as close to their bedtime as possible. To prevent attrition of participation we aimed to keep the daily 
measures as short as possible, in general participants took less than $5 \mathrm{~min}$. to fill it in. We chose to use end of day diaries over event sampling (i.e. filling in diaries after every meal or snack) as it has been shown to decrease burden and improve compliance (Tennen et al., 2006).

\section{Daily Measures}

\section{Stress and mood}

Participants were asked on scale of 1 to 5 how they felled in general that day. Additionally they filled in how many stressful events they experienced that day and per event they rated how intense they experienced this stressor (on a scale of 1 to 10). Examples of the nature of the stressors were given in the form of the seven domains of primary appraisal as defined by Lazarus (1999), for instance disruption of daily routine, financial problems or the health of someone you care about.

\section{Meal and Snack intake}

Participants reported every meal they consumed. They described the dish and gave an approximation of size (for instance: one plate of spaghetti Bolognese with grated cheese, or 2 sandwiches with ham and a bowl of yoghurt). Everything else they ate (besides their meals) was recorded as snacks and described in a similar manner (i.e. one packet of crisps or 2 blocks of chocolate). Additionally everything they drank besides water and nonsugared tea or coffee was recorded. All descriptions of these 3 food types were later entered by the researchers into an online software (Eetmeter) of the Netherlands Nutrition Centre (http://mijn.voedingscentrum.nl/nl/eetmeter/) to calculate an approximation of daily intake of kilocalories, carbohydrates, fats and proteins.

\section{General Measures}

\section{Rumination}

To measure our participants' tendency to ruminate about negative events, we asked them to fill in the Dutch translation of the Ruminative Response Scale 
(Raes, 2007; Treynor et al., 2003) at the start of the study. This assessment tool consists of 2 separate scales: brooding (negative rumination) and reflection (constructive introspection). We exclusively used the Brooding scale in our analysis as we were interested in the negative aspect of ruminative thinking.

\section{Data analysis}

To test for between group differences of demographics, separate T-tests and $\chi 2$ - tests were run with a Bonferroni correction, all tests were conducted at a two-tailed significance level.

Because diary data are nested (repeated measures within an individual) and missing data often occurred (not all subjects were able to fill in the diary all 42 days of the study), the main analyses were conducted by means of multilevel analyses, also called mixed models or hierarchical linear models (using IBM SPSS 24 for Windows). The data had a 2 level structure, level 1 containing daily experiences of stress and level 2 containing between subjects factors: genotype, ruminative thinking style and sex. The level 1 factor (experience of stress) was dichotomized $(0=\mathrm{No}, 1=\mathrm{Yes})$ as there was only a small amount of days where subjects reported more than 1 stressful event to occur ( $<15 \%$ out of all days on which stressful events were reported), for the same reason intensity ratings for the experience of these stressors were not used. Level 2 factors were either dichotomous (Genotype ( $0=\mathrm{L} / \mathrm{L}, 1=\mathrm{S} / \mathrm{S}$ ) and Sex ( $0=$ Male, $1=$ Female) or centred around it's grand mean (Rumination). Using these fixed factors, a random intercept model was used on different measures of daily food intake and mood. The covariance structure was based on the lowest deviance score, a random intercept model (taking into account personal baselines) with scaled identity (assuming independence and a common variance of the repeated daily measures) showed to best fit the data. All main and second order interactions were added in this model as well as a three way interaction between genotype, rumination and daily stress. As we only wanted to include sex as a covariate it was added as a main effect and all of its possible 2 way interactions which, as recently proposed by 
Keller (2014), is the correct way of controlling for factors in a model including gene $\mathrm{x}$ environment interactions. Regarding daily food intake, at first, effects on daily total caloric intake were analysed, if significant effects were found, further analyses were conducted to see if the effects were caused by differences in intake in meals, snacks or drinks. If within these food types significant effects were found, further analyses were conducted on intake of specific macronutrients. If in any of these analyses there was a significant three way interaction, the data was split on genotype to further explore this effect, only significant main and interaction effects that were significantly interacting with genotype on a higher order before splitting were interpreted. Dependent variables related to food intake were log transformed to obtain more normally distributed residuals. 


\section{Results}

\section{Demographics and compliance}

Table 9 reports means and proportions of demographics, there were no significant a priori differences. The 69 participants provided a total of 2686 usable diary entries, 212 entries (7\%) were deleted because of completely of partly missing data.

Table 9. Demographics of level 2 variables by 5-HTTLPR genotype

\begin{tabular}{lcccc}
\hline & \multicolumn{2}{c}{ S/S } & \multicolumn{2}{c}{ /L } \\
\cline { 2 - 5 } Age & Mean & SD & Mean & SD \\
BMI & 23.46 & 2.28 & 24.26 & 4.72 \\
Rumination & 22.59 & 3.17 & 22.20 & 2.97 \\
& 8.65 & 2.94 & 8.89 & 3.13 \\
& \multicolumn{4}{c}{ S/S } \\
& Male & Female & Male & Female \\
Sex & 10 & 24 & 9 & 26 \\
& \multicolumn{4}{c}{ L/L } \\
\cline { 2 - 5 } Daily Stress & 183 & 1112 & 161 & 1219 \\
\hline
\end{tabular}

Note. $\mathrm{N}=69$. There were no a priori Genotype differences in means or proportions. Rumination reflects scores on the brooding scale of the Ruminative Response Scale (RRS). Daily Stress reflects the total number of days with reports of the occurrence of one or more stressful events (yes) vs the absence of stressful events (no).

\section{Daily Mood}

Table 10 reports the unstandardized (B) regression coefficients for the random intercept model. There was a main effect of Daily Stress on Daily Mood, $t(2639)=-9.234, p<0.001$ as the occurrence of stressful events led to lower reports of mood. There were no further main or interaction effects of Genotype or Rumination.

\section{Daily Total Caloric Intake}

Table 11a reports the unstandardized (B) regression coefficients for the random intercept model. There was a significant interaction between Genotype, Rumination and Daily Stress on Daily Total Caloric Intake, $\mathrm{t}$ $(2637)=2.101, p=0.036$. 
Table 10. Demographics of level 2 variables by 5-HTTLPR genotype

\begin{tabular}{lcc}
\hline & B & S.E. \\
\hline Random Intercept & $\mathbf{4 . 3 2 5 ^ { * }}$ & 0.130 \\
Level 1 & & \\
Daily Stress & $\mathbf{- 0 . 8 6 7 ^ { * }}$ & 0.094 \\
& & \\
Level 2 & & 0.181 \\
Genotype & -0.319 & 0.041 \\
Rumination & -0.053 & 0.149 \\
Sex & -0.247 & \\
(Cross level) Interactions & & 0.085 \\
Genotype X Daily Stress & & 0.031 \\
Genotype x Rumination & & 0.209 \\
Genotype x Sex & 0.165 & 0.099 \\
Sex x Daily Stress & -0.005 & 0.040 \\
Sex x Rumination & 0.245 & 0.019 \\
Rumination x Daily Stress & 0.044 & 0.026 \\
Genotype x Rumination x Daily Stress & -0.009 & 0.012 \\
\hline Note. *p.05 Dependent variablewas
\end{tabular}

Note. ${ }^{*} \mathrm{p}<0.05$ Dependent variable was log transformed, Rumination was centered around its grand mean. Daily Stress $(\mathrm{No}=0, \mathrm{Yes}=1)$, Genotype $(\mathrm{L} / \mathrm{L}=0, \mathrm{~S} / \mathrm{S}=1)$, Sex $($ Male $=0$, Female $=1)$.

Table 11a. Multi-level effects on daily total caloric intake

\begin{tabular}{lcc}
\hline & B & S.E. \\
\hline Random Intercept & $7.437^{*}$ & 0.045
\end{tabular}

Level 1

Daily Stress

0.009

0.026

Level 2

Genotype

$0.349 \quad 0.064$

Rumination

$0.175 \quad 0.014$

Sex

$0.150 \quad 0.085$

\section{(Cross level) Interactions}

Genotype X Daily Stress

$\begin{array}{cc}-0.041 & 0.038 \\ 0.024 & 0.019 \\ 0.020 & 0.108 \\ -0.051 & 0.044 \\ -0.011 & 0.021 \\ \mathbf{0 . 0 2 0} & 0.008 \\ \mathbf{0 . 0 2 5}^{*} & 0.017\end{array}$

Genotype x Rumination 0.017

Genotype $x$ Sex

Sex x Daily Stress

Sex $x$ Rumination

Rumination x Daily Stress

Genotype $x$ Rumination $x$ Daily Stress

Note. ${ }^{*} \mathrm{p}<0.05$. Dependent variable was log transformed, Rumination was centered around its grand mean. Daily Stress $(\mathrm{No}=0, \mathrm{Yes}=1)$, Genotype $(\mathrm{L} / \mathrm{L}=0, \mathrm{~S} / \mathrm{S}=1)$, Sex $($ Male $=0$, Female $=1)$. 
Table 11b. Multi-level effects on daily total caloric intake split by genotype.

\begin{tabular}{|c|c|c|c|c|}
\hline & \multicolumn{2}{|c|}{$\mathbf{L} / \mathbf{L}$} & \multicolumn{2}{|c|}{$\mathrm{S} / \mathrm{S}$} \\
\hline & B & S.E. & B & S.E. \\
\hline Random Intercept & $7.364^{*}$ & 0.041 & $7.464^{*}$ & 0.053 \\
\hline \multicolumn{5}{|l|}{ Level 1} \\
\hline Daily Stress & $-0.075^{*}$ & 0.033 & 0.041 & 0.272 \\
\hline \multicolumn{5}{|l|}{ Level 2} \\
\hline Rumination & -0.002 & 0.011 & 0.016 & 0.017 \\
\hline Sex & $-0.279 *$ & 0.792 & 0.014 & 0.108 \\
\hline \multicolumn{5}{|l|}{ (Cross level) Interactions } \\
\hline Sex $x$ Daily Stress & 0.100 & 0.059 & $0.241^{*}$ & 0.067 \\
\hline Sex $x$ Rumination & 0.013 & 0.025 & -0.311 & 0.032 \\
\hline Rumination $x$ Daily Stress & -0.003 & 0.008 & $0.024^{*}$ & 0.008 \\
\hline
\end{tabular}

As can be seen in table 11b, splitting the data on Genotype showed a significant interaction between Rumination and Daily Stress, $t(1265)=-2.883$, $\mathrm{p}=0.004$ exclusively in the $\mathrm{S} / \mathrm{S}$-subjects, reflecting in a higher amount of Daily Total Caloric Intake for high ruminative S/S-carriers on days that stressful events occurred. Additionally, L/L-carriers showed a decrease in Daily Total Caloric Intake on stressful days, $t(1365)=2.296, p=0.022$.

\section{Daily Caloric Intake through Drinks, Snacks and Meals}

Table 12a reports the unstandardized (B) regression coefficients for the random intercept models. A significant main effect of Sex, $t(123)=2.508$, $\mathrm{p}=0.050$ showed that women have a lower intake of calories through snacks than men. There were no further main or interactions effects on the Daily Caloric Intake through Drinks or Snacks. A significant interaction between Sex and Daily Stress on Daily Caloric Intake through Meals, t (2627) $=2.69$, $\mathrm{p}=0.007$ revealed that women have a higher intake of calories through meals exclusively on stressful days. Additionally there was a significant interaction between Genotype, Rumination and Daily Stress on Daily Caloric Intake through Meals, t (2635) $=2.161$, $\mathrm{p}=0.031$. 
As can be seen table 12b, splitting the data on Genotype showed a significant interaction between Rumination and Daily Stress, t (1265)=-2.147, p=0.032 exclusively in the S/S-subjects, reflecting in a higher amount of Daily Caloric Intake through Meals for high ruminative S/S-carriers on days that stressful events occurred. Additionally there was a Sex $x$ Daily Stress interaction exclusively among S/S-carriers, $t$ (1265) $=38.70$, $\mathrm{p}<0.001$; S/S-carrying women reported a higher amount of caloric intake through meals on stressful days.

Table 12a. Multi-level effects on daily caloric intake by foodtype.

\begin{tabular}{|c|c|c|c|c|c|c|}
\hline & \multicolumn{2}{|c|}{ Drinks } & \multicolumn{2}{|c|}{ Snacks } & \multicolumn{2}{|c|}{ Meals } \\
\hline & B & S.E. & B & S.E. & B & S.E. \\
\hline Random Intercept & $5.255^{*}$ & 0.124 & $5.607^{*}$ & 0.104 & $7.078^{*}$ & 0.045 \\
\hline \multicolumn{7}{|l|}{ Level 1} \\
\hline Daily Stress & 0.142 & 0.088 & 0.037 & 0.069 & -0.027 & 0.026 \\
\hline \multicolumn{7}{|l|}{ Level 2} \\
\hline Genotype & 0.143 & 0.184 & 0.027 & 0.148 & 0.011 & 0.064 \\
\hline Rumination & 0.031 & 0.039 & 0.048 & 0.034 & 0.013 & 0.014 \\
\hline Sex & -0.066 & 0.242 & $-0.494^{*}$ & 0.197 & -0.121 & 0.084 \\
\hline \multicolumn{7}{|l|}{ (Cross level) Interactions } \\
\hline Genotype X Daily Stress & -0.205 & 0.137 & -0.192 & 0.099 & 0.048 & 0.038 \\
\hline Genotype $x$ Rumination & -0.002 & 0.054 & 0.012 & 0.044 & $0.040^{*}$ & 0.019 \\
\hline Genotype $x$ Sex & -0.306 & 0.273 & 0.383 & 0.239 & 0.008 & 0.107 \\
\hline Sex $x$ Daily Stress & 0.025 & 0.876 & 0.106 & 0.118 & $0.119^{*}$ & 0.044 \\
\hline Sex $x$ Rumination & 0.013 & 0.053 & 0.025 & 0.046 & -0.016 & 0.021 \\
\hline Rumination $x$ Daily Stress & 0.021 & 0.028 & 0.037 & 0.022 & 0.016 & 0.008 \\
\hline Genotype x Rumination x Daily & -0.006 & 0.041 & -0.030 & 0.031 & $0.025^{*}$ & 0.012 \\
\hline Stress & & & & & & \\
\hline
\end{tabular}

Note. ${ }^{*} \mathrm{p}<0.05$ Dependent variables were log transformed, Rumination was centered around its grand mean. Daily Stress $(\mathrm{No}=0, \mathrm{Yes}=1)$, Genotype $(\mathrm{L} / \mathrm{L}=0, \mathrm{~S} / \mathrm{S}=1)$, Sex $($ Male $=0$, Female $=1)$. 
Table 12b. Multi-level effects on daily caloric intake through meals split by genotype.

\begin{tabular}{|c|c|c|c|c|}
\hline & \multicolumn{2}{|c|}{$\mathrm{L} / \mathrm{L}$} & \multicolumn{2}{|c|}{$\mathrm{S} / \mathrm{S}$} \\
\hline & B & S.E. & B & S.E. \\
\hline Random Intercept & $7.263^{*}$ & 0.074 & $7.100^{*}$ & 0.090 \\
\hline \multicolumn{5}{|l|}{ Level 1} \\
\hline Daily Stress & -0.018 & 0.049 & $-0.266^{*}$ & 0.062 \\
\hline \multicolumn{5}{|l|}{ Level 2} \\
\hline Rumination & -0.026 & 0.028 & 0.043 & 0.027 \\
\hline Sex & $0.223^{*}$ & 0.086 & -0.002 & 0.102 \\
\hline \multicolumn{5}{|l|}{ (Cross level) Interactions } \\
\hline Sex x Daily Stress & 0.007 & 0.058 & $0.262^{*}$ & 0.068 \\
\hline Sex $x$ Rumination & 0.002 & 0.028 & 0.030 & 0.030 \\
\hline Rumination $x$ Daily Stress & -0.009 & 0.008 & $0.018^{*}$ & 0.008 \\
\hline
\end{tabular}

Note. ${ }^{*} \mathrm{p}<0.05$ Dependent variables were log transformed, Rumination was centered around its grand mean. Daily Stress (No=0, Yes=1), Genotype $(\mathrm{L} / \mathrm{L}=0, \mathrm{~S} / \mathrm{S}=1)$, Sex $($ Male =0, Female=1).

\section{Daily Intake of Carbohydrates, Proteins, Fats and Saturated Fats through Meals}

Table 13a reports the unstandardized (B) regression coefficients for the random intercept models. There was a main effect of Daily Stress on Carbohydrate Intake through Meals, $\mathrm{t}(2623)=-2.662$, p=0.008, as intake of carbohydrates was lower on stressful days. There were main effects of Sex on Protein Intake, $t(63)=-3.210, \mathrm{p}=0.002$, Fat Intake, $\mathrm{t}(63)=-3.390, \mathrm{p}=0.001$ and Saturated Fat Intake, $t$ (63) $=-2.258, \mathrm{p}=0.027$, as in general men had a higher intake of these three macronutrients through their meals. Additionally there was an interaction between Sex and Daily Stress on Fat Intake, t (2642), $\mathrm{p}=0.042$, showing that women ate more fats through their meals on days that stressful events occurred. Furthermore there was a significant three way interaction between Genotype, Rumination and Daily Stress on Saturated Fats Intake through Meals, t (2649) $=2.451, \mathrm{p}=0.014$.

As can be seen table 13b, after splitting the data on Genotype there were no significant interpretable effects. There where however 2 opposite trends of a Rumination X Daily Stress interaction on Saturated Fats Intake through 
Meals, as on stressful days, there was a lower intake of saturated fats through meals for high ruminative L/L-carriers, $\mathrm{t}(1273)=1.761, \mathrm{p}=0.079$ while there was a higher intake among high ruminative S/S-carriers, t (1369) =-1.764, $\mathrm{p}=0.080$.

Table 13a. Multi-level effects on daily macronutrient intake through meals.

\begin{tabular}{|c|c|c|c|c|c|c|c|c|}
\hline & \multicolumn{2}{|c|}{ Carbohydrates } & \multicolumn{2}{|c|}{ Protein } & \multicolumn{2}{|c|}{ Fats } & \multicolumn{2}{|c|}{ Saturated Fats } \\
\hline & B & S.E. & B & S.E. & B & S.E. & B & S.E. \\
\hline Random Intercept & $2.351^{*}$ & 0.035 & $1.442^{*}$ & 0.018 & $4.032^{*}$ & 0.085 & $2.929^{*}$ & 0.096 \\
\hline \multicolumn{9}{|l|}{ Level 1} \\
\hline Daily Stress & $-0.053^{*}$ & 0.020 & -0.002 & 0.014 & -0.095 & 0.068 & -0.083 & 0.075 \\
\hline \multicolumn{9}{|l|}{ Level 2} \\
\hline Genotype & 0.009 & 0.048 & -0.003 & 0.026 & -0.061 & 0.118 & -0.055 & 0.135 \\
\hline Rumination & 0.006 & 0.011 & -0.001 & 0.006 & -0.011 & 0.027 & -0.014 & 0.030 \\
\hline Sex & -0.057 & 0.040 & $-0.068^{*}$ & 0.021 & $-0.330^{*}$ & 0.098 & $-0.251^{*}$ & 0.111 \\
\hline \multicolumn{9}{|l|}{ (Cross level) } \\
\hline \multicolumn{9}{|l|}{ Interactions } \\
\hline Genotype X Daily & 0.028 & 0.018 & -0.121 & 0.123 & -0.096 & 0.061 & -0.077 & 0.068 \\
\hline \multicolumn{9}{|l|}{ Stress } \\
\hline Genotype $x$ & 0.002 & 0.008 & 0.002 & 0.004 & 0.008 & 0.020 & -0.009 & 0.023 \\
\hline \multicolumn{9}{|l|}{ Rumination } \\
\hline Genotype $x$ Sex & -0.022 & 0.055 & 0.013 & 0.030 & 0.140 & 0.136 & 0.044 & 0.155 \\
\hline Sex $x$ Daily Stress & 0.041 & 0.021 & 0.004 & 0.014 & $0.145^{*}$ & 0.072 & -0.078 & 0.068 \\
\hline Sex $x$ Rumination & -0.007 & 0.011 & -0.004 & 0.006 & -0.005 & 0.026 & 0.001 & 0.029 \\
\hline Rumination $x$ Daily & -0.004 & 0.004 & -0.002 & 0.003 & -0.015 & 0.013 & -0.025 & 0.015 \\
\hline \multicolumn{9}{|l|}{ Stress } \\
\hline Genotype $x$ & 0.009 & 0.005 & 0.007 & 0.004 & 0.035 & 0.019 & $0.051^{*}$ & 0.021 \\
\hline \multicolumn{9}{|l|}{ Rumination x Daily } \\
\hline Stress & & & & & & & & \\
\hline
\end{tabular}

Note. ${ }^{*} \mathrm{p}<0.05$ Dependent variables were log transformed, Rumination was centered around its grand mean. Daily Stress $(\mathrm{No}=0$, Yes=1), Genotype $(\mathrm{L} / \mathrm{L}=0, \mathrm{~S} / \mathrm{S}=1)$, Sex $($ Male =0, Female =1). 
Table 13b. Multi-level effects on daily saturated fats intake through meals split by genotype.

\begin{tabular}{lcccccc}
\hline & \multicolumn{3}{c}{ L/L } & & \multicolumn{2}{c}{ S/S } \\
\cline { 3 - 4 } \cline { 5 - 6 } & B & S.E. & & B & S.E. \\
\hline Random Intercept & $2.939^{*}$ & & 0.099 & & $2.882^{*}$ & 0.094
\end{tabular}

\section{Level 1}

Daily Stress

$-0.067$

0.087

$-0.188$

0.114

Level 2

Rumination

$$
-0.028
$$

0.043

$-0.013$

0.035

Sex

$-0.268^{*}$

0.113

0.205

0.111

(Cross level) Interactions

Sex x Daily Stress

0.112

0.102

0.164

0.123

Sex $x$ Rumination

0.178

0.046

$-0.014$

0.040

Rumination $x$ Daily Stress

$-0.025 t$

0.014

$0.027+$

0.015

Note. ${ }^{*} \mathrm{p}<0.05,+\mathrm{P}<0.08$. Dependent variables were log transformed, Rumination was centered around its grand mean. Daily Stress $(\mathrm{No}=0$, Yes=1), Genotype $(\mathrm{L} / \mathrm{L}=0, \mathrm{~S} / \mathrm{S}=1)$, Sex $($ Male =0, Female $=1)$. 


\section{Discussion}

The present study investigated the influence of real-life daily stress on food intake in subjects differing in 5-HTTLPR genotype and ruminative thinking tendencies. It was hypothesized that stressful events would have a bigger effect on high ruminative S-allele carriers reflected in a lower mood and increased intake of high caloric foods. Analysis showed that although there were no group effects on stress induced shifts in mood, intake of calories was highest among high ruminative S-allele carriers on days where stressful events occurred.

\section{Daily Mood}

The S-allele of 5-HTTLPR and ruminative thinking have separately been associated with increased neuroendocrine (Miller et al., 2013; Zoccola and Dickerson, 2012) and behavioural (Beevers et al., 2009; Markus and De Raedt, 2011; Markus and Firk, 2009; Rood et al., 2010; Segerstrom et al., 2000) stress responsiveness. As described in the introduction, our hypothesis is that ruminative thinking can exacerbate the effect of carrying an S-allele by prolonging the already increased stress responses, leading to lowered mood caused by daily hassles. Surprisingly we only found an effect of the occurrence of stressful events on daily mood but no main or interaction effects of 5-HTTLPR or ruminative thinking. This finding does not correspond to previous (diary) studies that found daily stressors to have a larger negative effect on mood in S-allele carriers (Conway et al., 2014; Gunthert et al., 2007) or among people who tend to ruminate about negative events (Brinker and Dozois, 2009; Ciesla et al., 2012). An explanation why we did not find such effects or interactions between genotype, ruminative thinking and daily stress on mood might lay in our assessment method. To measure daily shifts in mood we asked participants to rate on a scale of 1-5 how they felt that day. Widely used and accepted mood assessment tools like the Profile of Mood States (Wald and Mellenbergh, 1990) or Positive and Negative Affect Scales (Crawford and Henry, 2004) use multiple items divided over multiple 
subscales to measure mood. The small scale and uni-dimensionality of our question might have prevented our data to become varied enough to detect small shifts in mood caused by genotypical or cognitive influences. A second explanation for the absence of effects of genotype and ruminative thinking on daily mood could lay in the effects on food intake that we found in our data. As will be discussed in the following paragraphs there was an increased intake of kilocalories through fats among the stress vulnerable subjects (high ruminative S/S-allele carriers) on stressful days, hypothetically this stress-related eating might have compensated their lowered mood, masking the potential interactions between daily stress, genotype and ruminative thinking on daily mood.

\section{Daily Caloric Intake}

In line with our hypothesis we found an interaction between genotype, rumination and stress on daily intake of calories. The association between rumination and total caloric intake was highest among S/S-allele carriers specifically on days that stressful events occurred. These results correspond well to previous studies that implicated a higher risk for emotional eating among high ruminative S/S-carriers through interactions between 5-HTTLPR genotype and ruminative thinking on body mass (Schepers and Markus, 2017b) and stress induced visual attention for food cues (Schepers and Markus, 2017a). Further analysis showed that this interaction came specifically through meals as opposed to snacks or drinks. Although emotional eating is usually associated with a higher intake of high caloric palatable foods, it is still unknown whether this occurs in general or is caused by shifts in intake through specifically snacks or meals as numerous studies have found effects for either as well as both (for a review see: Schepers and Markus (2015)). Additionally, the men in our sample had a significantly greater intake of calories through snacks than women; this might be explained by the fact that women in general show higher cognitive dietary restraint (Provencher et al., 2003) thereby potentially restricting their intake of calories more through snacks than meals. Lastly there was an interaction between sex and daily 
stress, in which the effect of daily stress on increased intake of calories through meals was higher among women than among men. This effect corresponds well to numerous studies that have shown emotional eating to occur predominantly in woman (Larsen et al., 2006; van Strien, 2004; Wardle, 1987).

\section{Daily Macronutrient Intake through Meals}

To check if this increased intake of calories in stress prone subjects was as hypothesized caused by shifts of preference to high palatable foods (high in carbohydrates and/or fats) we examined the macronutrient content of meals. As expected a three-way interaction was found between genotype, rumination and stress on daily intake of saturated fats through meals. This finding is line with the notion that emotional eating increases the intake of high palatable (sweet and/or fatty) foods (Schepers and Markus, 2015) and more specifically with an earlier study where high ruminative S/S-carriers showed a stress induced attention bias for high caloric savoury foods (Schepers and Markus, 2017a). After splitting the data on genotype, there was no longer a rumination by daily stress interaction, however there were two trends $(\mathrm{p}<0.08)$ in the expected direction as the interaction between rumination and daily stress led to an increase of saturated fats intake in S/Scarriers while it decreased intake among L/L-carriers. Possibly splitting the data on genotype and specific macronutrients caused a decrease of statistical power, making the interaction of daily stress and rumination lose its significance. Oddly, daily stress had a negative main effect on carbohydrate intake through meals. Earlier reports of emotional eating showed increased intake of not only fats but also carbohydrate rich foods. The taste of sucrose has clear effects on the activation of the reward system of the brain (Berridge et al., 2009), it is therefore very plausible that sucrose consumption can be a good compensation for negative mood. As snack foods are more likely to contain large quantities of sucrose than meals this could explain why earlier studies found an increased intake of carbohydrates by emotional eating as these studies also often found effects of increased intake of snack foods as opposed to our data where emotional eating only led to effects on intake of 
meals.

Additionally, men reported a greater intake of protein and fats through meals than women. As this did not lead to an increased intake of calories this cannot be explained by men's higher daily required energy intake but has to arise out of differences in diet choices. A good explanation for this effect might the fact that men are likely to eat more (red) meats (Beerman et al., 1990; Goldberg and Strycker, 2002; Kubberød et al., 2002; Prättälä et al., 2006), a food type that is usually rich in protein and fat. Finally there was an interaction between sex and daily stress on intake of saturated fats, where women ate more saturated fats on stressful days. This corresponds well to the other effect(s) in our data of women having a higher intake of calories on stressful days and the marginal significant effect of emotional eating among stress prone subjects to specifically affect the intake of saturated fats.

\section{Strengths and limitations}

A major strength of the current study was the ability to monitor daily changes in mood and eating behaviour over a long time (6 weeks) and using a Multilevel model to analyse all available data, not having to worry about missing observations. To prevent the study of becoming too big of a burden on participants, we did not include validated measures of mood or daily stress but incorporated our own developed short questionnaires, therefore comparisons with other studies on these measurements should be considered carefully. Additionally as in all food diary studies, our measurements of food intake were dependent on the diligence of the participants to fill them in correctly and the specificity of the software used to calculate calories and macronutrients based on these diary entries. However we had no reason to assume this specificity and diligence was unequal across groups or individuals.

\section{Conclusion}

The current study was the first to show that the combination of biological 
(5-HTTLR) and cognitive (ruminative thinking) stress vulnerabilities can lead to increased caloric intake after the occurrence of stressful events. Data suggests that this increased caloric intake is caused by a preference of saturated fats. 
111 



\section{Chapter 6}

General Discussion 
Although much research has been conducted regarding the interplay of stress and eating behaviour, the underlying mechanisms of emotional eating are still not fully determined. Numerous explanations for emotional eating have been published in various scientific fields. Individual differences at a genetic, behavioural, cognitive or neuronal level all have been proposed to influence emotional eating, however none of these hypotheses seem to fully explain why certain individuals tend to increase their intake of high caloric palatable foods during stress. While emotional eating almost exclusively occurs during/after the experience of stress or negative mood, individual differences in stress vulnerability seem to play a crucial part in the development of an emotional eating style. The serotonergic (5-HT) system in the brain is greatly involved in stress (Pinel, 2006) and the efficiency of this neurotransmitter is partly regulated by the serotonin transporter gene (5-HTTLPR). The low expressing variant of this gene (S-allele) is in comparison to the long expressing variant (L-allele), associated with lower serotonin transporters and related to an increased stress vulnerability (Heils et al., 1996). Consequently the S-allele has been linked to increased bodyweight (Erritzoe et al., 2010; Sookoian et al., 2007) and the risk for eating-related behavioural disturbances (Di Bella et al., 2000; Fumeron et al., 2001). However these results were not always replicated (Hinney et al., 1997; Racine et al., 2009; Sundaramurthy et al., 2000), leading to the hypothesis that 5-HTTLPR is a more contributing than deterministic factor in (emotional) eating behaviour. Recent insights show that the increased stress responsiveness often found in S-allele carriers becomes even more pronounced when combined with a cognitive stress vulnerability, for instance when experiencing stressful life events (Clarke et al., 2010; Karg et al., 2011; Sharpley et al., 2014) or when having a neurotic personality trait (Markus, 2013). Cognitive rumination, which is having uncontrollable perseverative thoughts about negative past or present events, could potentially be such a cognitive factor exacerbating the effects of an S-allele. Rumination leads to repeated experiences of stress and negative affect, resulting in long-lasting HPA-axis activation (Zoccola 
and Dickerson, 2012). Particularly when combined with a genetic (S-allele of the 5-HTTLPR) vulnerability factor, this thinking style can potentially increase the risk for stress-related mood disturbances and consequently stress relieving (unhealthy) behaviours, including emotional eating.

The first aim of this thesis was to examine whether the combination of a biological (S-allele of 5-HTTLPR) and cognitive (ruminative thinking) stress vulnerability potentiates stress responsiveness. It was hypothesized that the possession of a negative ruminating thinking style particularly in S-allele carriers will potentiate (further exacerbate) hormonal and/or emotionalbehavioural stress-responsiveness

The second aim of the thesis was to investigate whether high ruminating S-allele carriers compensate for their hypothesized increased stress responsiveness by increasing their intake of high caloric palatable foods particularly during stress and/or negative affect. 


\section{Summary of findings}

Chapter 2 describes an associative study investigating whether high ruminative S-allele carriers have an increased risk for overweight (higher body mass) and if this is mediated by emotional eating. As expected, data showed that body mass index (BMI) and negative mood (depressive symptoms) were highest among high ruminating S-allele carriers. Against expectations, a Moderated-Mediation analysis could not provide sound support that this higher BMI was indeed mediated by a higher emotional eating tendency. In Chapter 3 visual attention for high caloric palatable foods (as a measure for food preference/reward) was assessed before and after a stress inducing task. It was expected that the stress inducing task would have a larger negative effect among high ruminative S-allele carriers, thereby increasing their preferences for high rewarding palatable foods (measured by attention for pictures of high caloric palatable snacks). Potential participants were preselected based on their homozygous S- or L-allele 5-HTTLPR genotype and on their high or low scores on a ruminative thinking questionnaire. Using an eye-tracker, participants' visual attention for high palatable food (vs low caloric food or objects) was measured before and after administering the Maastricht Acute Stress Test (MAST). However, contrary to expectations, no effects were found in S-allele genotypes but, low ruminative L-carriers were found to have a smaller stress induced attention bias for palatable savoury food. Salivary cortisol and mood assessments proved that the MAST was successful in inducing stress, however there were also no differences in stress responsivity caused by genotype or ruminative thinking. Chapter 4 describes a study in which analysis of accumulated cortisol in scalp hair was used as a measure to search for differences in chronic HPA stress responsiveness in high ruminative S-allele carriers. In line with expectations, highest levels of cortisol were found in the hair samples of high ruminating S/S-carriers; supporting the hypothesis that the combined possession a S-allele and a ruminative thinking style can lead to long term stress vulnerability. Chapter 5 concerns a study investigating whether an interaction between carrying an 
S-allele and having a high ruminative thinking style can lead to increased food intake in a natural daily setting. Sixty-nine homozygous 5-HTTLPR carriers reported their daily food intake and experiences of stress for six weeks. These diaries were later entered into software of the Netherlands Nutrition Centre to calculate intake of kilocalories and macronutrients. Interestingly, total caloric intake was highest among high ruminative S/S-carriers, but only on days that stressful events occurred. A trend in the data suggested that this increased caloric intake among high ruminative S/S-carriers was caused by an increased intake of saturated fats. 


\section{Discussion of the main research questions}

Does a combination of a biological (S-allele of 5-HTTLPR) and cognitive (ruminative thinking) stress vulnerability lead to increased hormonal and affective-behavioural stress responsivity?

In the first study of this thesis (chapter 2), among 795 healthy subjects the highest number of depressive symptoms was reported by high ruminative S-allele carriers. These data indirectly supports the hypothesis that a combined genetic (5HT) and cognitive (rumination) stress vulnerability might profoundly potentiate stress and/or negative affect. Additionally in chapter 4, the largest quantities of cortisol were found in scalp hair samples of high ruminating S/S-carriers. Since these scalp hair cortisol concentrations represent past months activation of the hypothalamic-pituitary-adrenal (HPA) axis, this is further support for the hypothesis that the simultaneous possession of 5-HT genetic and cognitive stress vulnerability might potentiate everyday life stress experiences and/or responsiveness.

The other studies described in this thesis showed conflicting results regarding the first main question. In chapter 3, mood and salivary cortisol were measured before and after stress exposure. At baseline there were no differences in cortisol levels based on genotype or ruminative thinking. Interestingly, ruminative thinking was associated with lower mood at baseline, suggesting a general (chronic) lowered mood for high ruminative thinkers. The stress induction task that followed appeared to be successful since it caused higher levels of cortisol and negative mood. However these effects of stress did not differ between genotypes. There were only different effects of stress based on ruminative thinking tendencies; revealing greater decline in mood after stress induction in high compared to low ruminative thinkers. In the last study (Chapter 5), food intake diaries were collected over 42 days. Analysis showed that the effects of stressful events on daily mood were comparable across genotype and ruminative thinking tendency. 
The inconsistent results in the described studies could be explained by the time level at which mood or cortisol was measured. The significant interacting effects of 5-HTTLPR and rumination were exclusively found in the studies that tested for differences on mood and cortisol secretion on a long term: chapters 2 and 4 . In chapter 2 depressive symptoms were measured over the past week are assessed whereas HPA cortisol secretion in chapter 4 was assessed for the past 3 months. The studies where no significant interaction was found measured changes in cortisol and/or mood within minutes (chapter 3) or one day (chapter 5). Conceivably, the interaction between 5-HTTLPR genotype and rumination on mood or cortisol secretion is of modest size, making it harder to detect changes within small measurements of time than through measuring on longer term encapsulating an accumulation of this effect. An alternative explanation for the absence of an expected interaction could be a combination of two methodological matters in chapters 3 and 5. The study described in chapter 3 was the only study in this thesis that examined the effects of an artificial (lab induced) stressor. Previous studies on 5-HTTLPR have shown that real life (personal) stressors have often more pronounced effects than laboratory stressors (Capello and Markus, 2014b; Markus and Firk, 2009; Verschoor and Markus, 2011). As described in chapter 5, the measure of mood used in that study was not validated, unidimensional and had a small scale (1-5). Perhaps the absence of the expected genotype by rumination effect on mood in chapters 3 and 5 are caused by the artificial nature of the stressor in chapter 3 and the unidimensional small scaled measure of daily mood in chapter 5 .

\section{Conclusion}

Although previous studies have examined the interaction between 5-HTTLPR genotype and other environmental or cognitive stress vulnerabilities on mood or depressive symptoms, this thesis was the first to investigate the interaction between 5-HTTLPR and negative rumination. When answering the question whether high ruminative S-carriers are more affected by stress 
on a endocrinological and affective level, some incongruities were found within the four main chapters of this thesis. Nonetheless, these results seem to confirm this hypothesis, especially when measuring mood and HPA-axis reactivity on a long term scale.

Does a combination of a biological (S-allele of 5-HTTLPR) and cognitive (ruminative thinking) stress vulnerability increase the risk of developing an emotional eating style?

The first study described in this thesis (chapter 2) investigated differences in 5-HTTLPR genotype, ruminative thinking, emotional eating, and body mass among 795 healthy students. It was hypothesized that the tendency to eat in response to stress (emotional eating) will be higher among individuals with higher stress responsivity as they will relatively benefit more from the rewarding effect of food. As the combination of an S-allele of 5-HTTLPR and ruminative thinking led to increased stress responsivity, it was expected to find the highest incidence of emotional eating and consequently a higher body mass among individuals with these combined stress vulnerabilities. In line with the hypothesis the highest BMI (Body Mass Index) scores were found among high ruminative S-allele carriers. Surprisingly a moderated mediation analysis did not show this increased body mass among stress prone subjects to relate to emotional eating. Possibly emotional eating was not measured adequately as described in the chapter; the questionnaire used to asses emotional eating behaviour only contained 3 questions. Additionally assessing emotional eating behaviour through self-reports has been critiqued in the current literature and often shows conflicting results with behavioural data. A second explanation for higher body mass in stress prone subjects without a mediating effect of emotional eating might be that other physiological effects of stress instead of eating behaviour could lead to an increase in body mass, for instance endocrine or metabolic changes. This latter explanation is less probable in the context of the other chapters though as they describe data suggesting that a combination of 5-HTTLPR 
and ruminative thinking does lead to emotional eating when measured on a (pre)behavioural level.

In chapter 3 visual attention for food cues was measured before and after a stress induction task. It was expected to see a stress induced visual attention bias for palatable foods among high ruminative S-carriers. Oddly, high ruminative $S$ /S-carriers did not show the highest stress induced attention bias for food cues, though the inverse effect was found, as low ruminative L/Lcarriers showed the lowest increase in visual attention for high caloric savoury foods after stress. As described in the chapter, this effect might be caused by a ceiling effect where the stress vulnerabilities of carrying an S-allele or ruminative thinking both lead to increased stress responsiveness but do not exacerbate each's effect as a certain limit of stressfulness is already reached. A second explanation could lie in the time aspect, as the whole experiment lasted only about 90 minutes, this might be too short to assess the full effect of ruminative thinking. Thirdly, the absence of a significant interaction between 5-HTTLPR and ruminative thinking on stress induced changes in cortisol secretion and mood, might also have prevented the expected stress induced increased attention bias for high palatable foods. Nonetheless as the least stress vulnerable group (low ruminative L/L-carriers) showed the lowest stress induced attention bias it is viable to conclude that both 5-HTTLPR genotype and ruminative thinking can independently influence visual attention for high caloric savoury foods during stress.

In the last study (chapter 5) daily food intake was measured through the use of digital diaries. In line with the hypothesis, high ruminative S/S-carriers had a greater intake of calories on days that stressful events occurred. Data suggested that this increased intake of calories was caused by a greater preference for saturated fats, corresponding to the stress induced attention bias for specifically high caloric savoury foods described in chapter 3 . 


\section{Conclusion}

Based on the studies described in the current thesis it is feasible to conclude that a combination of carrying an S-allele of 5-HTTLPR and having a ruminative thinking style increases the risk to develop an emotional eating style and consequently gain body weight. These results support the hypothesis that high ruminative S-allele carriers are at risk to overeat high caloric palatable foods during stress to compensate for their increased stress responsivity. 


\section{Conclusion and future directions}

From the work presented in this thesis it becomes apparent that a distinct combination of carrying an S-allele of 5-HTTLPR and having a ruminative thinking style leads to increased cognitive and biological stress reactivity and consequently increases the risk to develop an emotional eating style and hence, increased body mass.

The focus of the current thesis was to explore whether this stress prone subgroup is at higher risk to develop an emotional eating pattern. An interesting next step could be to examine whether this risk can be decreased by for instance administering tryptophan or increasing carbohydrate consumption to potentially negate the effect of carrying an S-allele or by using forms of cognitive therapy to change ruminative thinking patterns.

The participants for the studies of the current thesis were all recruited among healthy university students. As the relevance of discovering the mechanism behind emotional eating is largely to prevent weight problems, it would be very interesting to see if the genetic and cognitive factors involved as described in the current thesis are also found significantly influencing (emotional) eating behaviour in (sub)populations where weight gain is a pressing health concern. Possibly among the clinically obese or even on a sub

clinical level, among people with a lower socio economic status, the effects of 5-HTTLPR and cognitive factors on eating behaviour could prove to be more relevant than among healthy young students.

The current thesis showed the importance of exploring both cognitive and biological stress vulnerabilities in the incidence of emotional eating, however these are probably not the only stress vulnerabilities that have an influence on emotional eating behaviour. It could be interesting for future research to focus on interactions between for instance: other genes related to serotonin functioning (e.g., TPH or 5HT2s), genes related to dopaminergic functioning (e.g., DAT1 or DRD4), other cognitive factors (e.g., anxiety, perfectionism, 
catastrophizing or mindfulness) or environmental factors (e.g., work stress or social support).

In sum, the findings reported in this thesis show that S-allele carriers of the 5-HTTLPR gene who also have the tendency to ruminate about negative events are more negatively affected by stress on a biological and emotional level. Additionally, this combination of stress vulnerabilities was shown to be associated with higher bodyweight and increased caloric intake as function of the experience of stress. Independently these stress vulnerabilities also influence visual attention for high palatable foods during stress. The findings presented in the current thesis underline both the importance of interpersonal differences in stress resilience and the interplay of cognitive and biological factors in the aetiology of emotional eating. 



\section{References}


Affleck, G., Tennen, H., Urrows, S., \& Higgins, P. (1994). Person and contextual features of daily stress reactivity: individual differences in relations of undesirable daily events with mood disturbance and chronic pain intensity. Journal of personality and social psychology, 66(2), 329.

Allbaugh, L. J. (2013). Rumination in the context of the centrality of stressful events. Miami University.

Anglé, S., Engblom, J., Eriksson, T., Kautiainen, S., Saha, M.-T., Lindfors, P., . . . Rimpelä, A. (2009). Three factor eating questionnaire-R18 as a measure of cognitive restraint, uncontrolled eating and emotional eating in a sample of young Finnish females. International Journal of Behavioral Nutrition and Physical Activity, 6(1), 41.

Anschutz, D. J., Van Strien, T., Van De Ven, M. O. M., \& Engels, R. C. M. E. (2009). Eating styles and energy intake in young women. Appetite, 53(1), 119-122. doi: 10.1016/j.appet.2009.03.016

Arborelius, L. (1999). The role of corticotropin-releasing factor in depression and anxiety disorders. Journal of Endocrinology, 160(1), 1-12. doi: 10.1677/ joe.0.1600001

Beck, A. T., Steer, R. A., \& Carbin, M. G. (1988). Psychometric properties of the Beck Depression Inventory: Twenty-five years of evaluation. Clinical psychology review, 8(1), 77-100.

Beck, A. T., Ward, C., Menselson, M., Mock, J., \& Ebauch, J. (1961). An inventory for measuring depression.

Beerman, K. A., Jennings, G., \& Crawford, S. (1990). The effect of student residence on food choice. Journal of American College Health, 38(5), 215-220.

Beevers, C. G., Wells, T. T., \& McGeary, J. E. (2009). The BDNF Val66Met polymorphism is associated with rumination in healthy adults. Emotion, 9(4), 579-584. doi: 10.1037/a0016189

Bellisle, F., Louis-Sylvestre, J., Linet, N., Rocaboy, B., Dalle, B., Cheneau, F., . . . Guyot, L. (1990). Anxiety and food intake in men. Psychosomatic Medicine, 52(4), 452-457. doi: 10.1097/00006842-199007000-00007

Berghöfer, A., Pischon, T., Reinhold, T., Apovian, C. M., Sharma, A. M., \& Willich, S. N. (2008a). Obesity prevalence from a European perspective: a systematic review. BMC Public Health, 8(1). doi: 10.1186/1471-2458-8-200

Berridge, K. C. (1996). Food reward: brain substrates of wanting and liking. Neuroscience \& Biobehavioral Reviews, 20(1), 1-25.

Berridge, K. C., Robinson, T. E., \& Aldridge, J. W. (2009). Dissecting components of reward:'liking','wanting', and learning. Current opinion in pharmacology, 9(1), 65-73.

Birmingham, C., \& Firoz, T. (2006). Rumination in eating disorders: literature review. Eating and Weight Disorders-Studies on Anorexia, Bulimia and Obesity, 11(3), e85-e89.

Bjorntorp, P. (2001). Do stress reactions cause abdominal obesity and comorbidities? Obesity Reviews, 2(2), 73-86. doi: 10.1046/j.1467-789x.2001.00027.x

Blair, A., Lewis, V., \& Booth, D. A. (1990). Does emotional eating interfere with success in attempts at weight control? Appetite, 15(2), 151-157. 
Bloom, S., Johnson, R., Park, D., Rennie, M., \& Sulaiman, W. (1976). Differences in the metabolic and hormonal response to exercise between racing cyclists and untrained individuals. The Journal of physiology, 258(1), 1-18.

Bohon, C., Stice, E., \& Spoor, S. (2009). Female emotional eaters show abnormalities in consummatory and anticipatory food reward: A functional magnetic resonance imaging study. International Journal of Eating Disorders, 42(3), 210221. doi: 10.1002/eat.20615

Bolger, N., \& Schilling, E. A. (1991). Personality and the problems of everyday life: The role of neuroticism in exposure and reactivity to daily stressors. Journal of personality, 59(3), 355-386.

Bolger, N., \& Zuckerman, A. (1995). A framework for studying personality in the stress process. Journal of personality and social psychology, 69(5), 890.

Born, J. M., Lemmens, S. G. T., Rutters, F., Nieuwenhuizen, A. G., Formisano, E., Goebel, R., \& Westerterp-Plantenga, M. S. (2009). Acute stress and foodrelated reward activation in the brain during food choice during eating in the absence of hunger. International Journal of Obesity, 34(1), 172-181. doi: 10.1038/ijo.2009.221

Bradley, B. P., Garner, M., Hudson, L., \& Mogg, K. (2007). Influence of negative affect on selective attention to smoking-related cues and urge to smoke in cigarette smokers. Behavioural pharmacology, 18(4), 255-263.

Brinker, J. K., \& Dozois, D. J. (2009). Ruminative thought style and depressed mood. Journal of clinical psychology, 65(1), 1-19.

Brosschot, J. F., Gerin, W., \& Thayer, J. F. (2006). The perseverative cognition hypothesis: A review of worry, prolonged stress-related physiological activation, and health. Journal of Psychosomatic Research, 60(2), 113-124. doi: 10.1016/j.jpsychores.2005.06.074

Brown, G. W., \& Harris, T. O. (2008). Depression and the serotonin transporter 5-HTTLPR polymorphism: a review and a hypothesis concerning geneenvironment interaction. Journal of affective disorders, 111(1), 1-12.

Canli, T., Qiu, M., Omura, K., Congdon, E., Haas, B. W., Amin, Z., . . . Lesch, K. P. (2006). Neural correlates of epigenesis. Proceedings of the National Academy of Sciences, 103(43), 16033-16038. doi: 10.1073/pnas.0601674103

Cann, A., Calhoun, L. G., Tedeschi, R. G., Triplett, K. N., Vishnevsky, T., \& Lindstrom, C. M. (2011). Assessing posttraumatic cognitive processes: The event related rumination inventory. Anxiety, Stress, E Coping, 24(2), 137-156.

Capello, A. E., \& Markus, C. R. (2014a). Differential influence of the 5-HTTLPR genotype, neuroticism and real-life acute stress exposure on appetite and energy intake. Appetite, 77, 85-95.

Capello, A. E., \& Markus, C. R. (2014b). Effect of sub chronic tryptophan supplementation on stress-induced cortisol and appetite in subjects differing in 5-HTTLPR genotype and trait neuroticism. Psychoneuroendocrinology, 45, 96-107.

Capello, A. E., \& Markus, C. R. (2016). Daily hassles and energy intake: Influence of the 5-HTTLPR genotype, neuroticism and dietary tryptophan. Unpublished work.

Carter, B. L., \& Tiffany, S. T. (1999). Meta-analysis of cue-reactivity in addiction research. Addiction, 94(3), 327-340. 
Cartwright, M., Wardle, J., Steggles, N., Simon, A. E., Croker, H., \& Jarvis, M. J. (2003). Stress and dietary practices in adolescents. Health Psychology, 22(4), 362-369. doi: 10.1037/0278-6133.22.4.362

Caspi, A., Gorsky, P., \& Chajut, E. (2003). The influence of group size on nonmandatory asynchronous instructional discussion groups. The Internet and Higher Education, 6(3), 227-240. doi: 10.1016/s1096-7516(03)00043-5

Castellanos, E. H., Charboneau, E., Dietrich, M. S., Park, S., Bradley, B. P., Mogg, K., \& Cowan, R. L. (2009). Obese adults have visual attention bias for food cue images: evidence for altered reward system function. International Journal of Obesity, 33(9), 1063-1073.

Ciesla, J. A., Reilly, L. C., Dickson, K. S., Emanuel, A. S., \& Updegraff, J. A. (2012). Dispositional mindfulness moderates the effects of stress among adolescents: rumination as a mediator. Journal of Clinical Child \& Adolescent Psychology, 41(6), 760-770.

Chrousos, G. P. (2009). Stress and disorders of the stress system. Nature Reviews Endocrinology, 5(7), 374-381.

Clarke, H., Flint, J., Attwood, A. S., \& Munafò, M. R. (2010). Association of the 5HTTLPR genotype and unipolar depression: a meta-analysis. Psychological Medicine, 40(11), 1767-1778. doi: 10.1017/s0033291710000516

Clasen, P. C., Wells, T. T., Knopik, V. S., McGeary, J. E., \& Beevers, C. G. (2011). 5-HTTLPR and BDNF Val66Met polymorphisms moderate effects of stress on rumination. Genes, Brain and Behavior, 10(7), 740-746. doi: 10.1111/j.1601183x.2011.00715.x

Collier, D., Stöber, G., Li, T., Heils, A., Catalano, M., Di Bella, D., . . Bengel, D. (1996). A novel functional polymorphism within the promoter of the serotonin transporter gene: possible role in susceptibility to affective disorders. Molecular Psychiatry, 1(6), 453-460.

Conway, C. C., Slavich, G. M., \& Hammen, C. (2014). Daily stress reactivity and serotonin transporter gene (5-HTTLPR) variation: Internalizing responses to everyday stress as a possible transdiagnostic phenotype. Biology of mood $\mathcal{E}$ anxiety disorders, $4(1), 2$.

Cota, D., Tschöp, M. H., Horvath, T. L., \& Levine, A. S. (2006). Cannabinoids, opioids and eating behavior: The molecular face of hedonism? Brain Research Reviews, 51(1), 85-107. doi: 10.1016/j.brainresrev.2005.10.004

Crawford, J. R., \& Henry, J. D. (2004). The Positive and Negative Affect Schedule (PANAS): Construct validity, measurement properties and normative data in a large non-clinical sample. British journal of clinical psychology, 43(3), 245265.

Culverhouse, R., Saccone, N., Horton, A., Ma, Y., Anstey, K., Banaschewski, T., . . . Fisher, H. (2017). Collaborative meta-analysis finds no evidence of a strong interaction between stress and 5-HTTLPR genotype contributing to the development of depression. Molecular Psychiatry.

Czeisler, C. A., \& Klerman, E. B. (1999). Circadian and sleep-dependent regulation of hormone release in humans. Recent progress in hormone research, 54, 97-130; discussion 130-132.

Dallman, M. F., Pecoraro, N., Akana, S. F., la Fleur, S. E., Gomez, F., Houshyar, H., ... Manalo, S. (2003). Chronic stress and obesity: A new view of "comfort 
food". Proceedings of the National Academy of Sciences, 100(20), 11696-11701. doi: 10.1073/pnas.1934666100

David, J. P., \& Suls, J. (1999). Coping efforts in daily life: Role of Big Five traits and problem appraisals. Journal of personality, 67(2), 265-294.

David, S. P. (2005). A Functional Genetic Variation of the Serotonin (5-HT) Transporter Affects 5-HT1A Receptor Binding in Humans. Journal of Neuroscience, 25(10), 2586-2590. doi: 10.1523/jneurosci.3769-04.2005

David, S. P., Murthy, N. V., Rabiner, E. A., Munafó, M. R., Johnstone, E. C., Jacob, R., . . G Grasby, P. M. (2005). A functional genetic variation of the serotonin (5-HT) transporter affects 5-HT1A receptor binding in humans. The Journal of neuroscience, 25(10), 2586-2590.

Davies, C., \& Few, J. (1973). Effects of exercise on adrenocortical function. Journal of Applied Physiology, 35(6), 887-891.

Delarue, J., Matzinger, O., Binnert, C., Schneiter, P., Chiolero, R., \& Tappy, L. (2003). Fish oil prevents the adrenal activation elicited by mental stress in healthy men. Diabetes \& metabolism, 29(3), 289-295.

de Lauzon-Guillain, B., Basdevant, A., Romon, M., Karlsson, J., Borys, J.-M., Charles, M. A., \& Group, F. S. (2006). Is restrained eating a risk factor for weight gain in a general population? The American journal of clinical nutrition, 83(1), 132138.

de Lauzon, B., Romon, M., Deschamps, V., Lafay, L., Borys, J.-M., Karlsson, J., . . . Charles, M. A. (2004). Three-Factor Eating Questionnaire--Revised 18-item Version. Retrieved from: http://dx.doi.org/10.1037/t44324-000

Deakin, J. F. W. (2013). The origins of '5-HT and mechanisms of defence' by Deakin and Graeff: A personal perspective. Journal of Psychopharmacology, 27(12), 1084-1089. doi: 10.1177/0269881113503508

Di Bella, D., Catalano, M., Cavallini, M. C., Riboldi, C., \& Bellodi, L. (2000). Serotonin transporter linked polymorphic region in anorexia nervosa and bulimia nervosa. Molecular Psychiatry, 5(3), 233-234. doi: 10.1038/sj.mp.4000689

Dick, D. M., Agrawal, A., Keller, M. C., Adkins, A., Aliev, F., Monroe, S., . . Sher, K. J. (2015). Candidate gene-environment interaction research: Reflections and recommendations. Perspectives on Psychological Science, 10(1), 37-59.

Dickerson, S. S., \& Kemeny, M. E. (2004). Acute stressors and cortisol responses: a theoretical integration and synthesis of laboratory research. Psychological bulletin, 130(3), 355.

Dong, C., Sanchez, L. E., \& Price, R. A. (2004). Relationship of obesity to depression: a family-based study. International Journal of Obesity, 28(6), 790-795. doi: 10.1038/sj.ijo.0802626

Dowlati, Y., Herrmann, N., Swardfager, W., Thomson, S., Oh, P. I., Van Uum, S., Lanctôt, K. L. (2010). Relationship between hair cortisol concentrations and depressive symptoms in patients with coronary artery disease. Neuropsychiatric disease and treatment, 6, 393.

Elfhag, K., Tholin, S., \& Rasmussen, F. (2008). Consumption of fruit, vegetables, sweets and soft drinks are associated with psychological dimensions of eating behaviour in parents and their 12-year-old children. Public Health Nutrition, 11(09). doi: 10.1017/s1368980008002371

Epel, E., Jimenez, S., Brownell, K., Stroud, L., Stoney, C., \& Niaura, R. A. Y. (2004). 
Are Stress Eaters at Risk for the Metabolic Syndrome? Annals of the New York Academy of Sciences, 1032(1), 208-210. doi: 10.1196/annals.1314.022

Epel, E., Lapidus, R., McEwen, B., \& Brownell, K. (2001). Stress may add bite to appetite in women: a laboratory study of stress-induced cortisol and eating behavior. Psychoneuroendocrinology, 26(1), 37-49. doi: 10.1016/s03064530(00)00035-4

Eriksson, M., Rasmussen, F., \& Tynelius, P. (2006). Genetic Factors in Physical Activity and the Equal Environment Assumption - the Swedish Young Male Twins Study. Behavior Genetics, 36(2), 238-247. doi: 10.1007/s10519-005-90187

Erritzoe, D., Frokjaer, V. G., Haahr, M. T., Kalbitzer, J., Svarer, C., Holst, K. K., . . . Knudsen, G. M. (2010). Cerebral serotonin transporter binding is inversely related to body mass index. Neuroimage, 52(1), 284-289.

Faith, M. S., Berkowitz, R. I., Stallings, V. A., Kerns, J., Storey, M., \& Stunkard, A. J. (2006). Eating in the Absence of Hunger: A Genetic Marker for Childhood Obesity in Prepubertal Boys?*. Obesity, 14(1), 131-138. doi: 10.1038/ oby.2006.16

Fernstrom, J. D., Larin, F., \& Wurtman, R. J. (1973). Correlation between brain tryptophan and plasma neutral amino acid levels following food consumption in rats. Life Sciences, 13(5), 517-524. doi: 10.1016/0024-3205(73)90044-1

Fernstrom, J. D., \& Wurtman, R. J. (1971). Brain Serotonin Content: Increase Following Ingestion of Carbohydrate Diet. Science, 174(4013), 1023-1025. doi: 10.1126/ science.174.4013.1023

Field, A. (2009). Discovering statistics using SPSS: Sage publications.

Field, M., Eastwood, B., Bradley, B. P., \& Mogg, K. (2006). Selective processing of cannabis cues in regular cannabis users. Drug and alcohol dependence, 85(1), 75-82.

Field, M., Mogg, K., \& Bradley, B. P. (2004). Eye movements to smoking-related cues: effects of nicotine deprivation. Psychopharmacology, 173(1-2), 116-123.

Firk, C., \& Markus, C. R. (2009). Differential effects of 5-HTTLPR genotypes on mood, memory, and attention bias following acute tryptophan depletion and stress exposure. Psychopharmacology, 203(4), 805-818.

Fisher, J. O., Cai, G., Jaramillo, S. J., Cole, S. A., Comuzzie, A. G., \& Butte, N. F. (2007). Heritability of Hyperphagic Eating Behavior and Appetite-Related Hormones among Hispanic Children*. Obesity, 15(6), 1484-1495. doi: 10.1038/oby.2007.177

Flegal, K. M. (2010). Prevalence and Trends in Obesity Among US Adults, 1999-2008. JAMA, 303(3), 235. doi: 10.1001/jama.2009.2014

Flegal, K. M., Carroll, M. D., Ogden, C. L., \& Curtin, L. R. (2010). Prevalence and trends in obesity among US adults, 1999-2008. Jama, 303(3), 235-241.

Folkman, S., \& Lazarus, R. S. (1988). Coping as a mediator of emotion. Journal of Personality and Social Psychology, 54(3), 466.

Fuemmeler, B. F., Agurs-Collins, T. D., Mcclernon, F. J., Kollins, S. H., Kail, M. E., Bergen, A. W., \& Ashley-Koch, A. E. (2008). Genes implicated in serotonergic and dopaminergic functioning predict BMI categories. Obesity, 16(2), 348355.

Fumeron, F., Betoulle, D., Aubert, R., Herbeth, B., Siest, G., \& Rigaud, D. (2000). 
Association of a functional 5-HT transporter gene polymorphism with anorexia nervosa and food intake. Molecular Psychiatry, 6(1), 9-10. doi: 10.1038/sj.mp.4000824

Fumeron, F., Betoulle, D., Aubert, R., Herbeth, B., Siest, G., \& Rigaud, D. (2001). Association of a functional 5-HT transporter gene polymorphism with anorexia nervosa and food intake.

Gibson, E. L. (2012). The psychobiology of comfort eating. Behavioural Pharmacology, 23(5 and 6), 442-460. doi: 10.1097/fbp.0b013e328357bd4e

Goldberg, L. R., \& Strycker, L. A. (2002). Personality traits and eating habits: The assessment of food preferences in a large community sample. Personality and Individual Differences, 32(1), 49-65.

Gotlib, I. H., Joormann, J., Minor, K. L., \& Hallmayer, J. (2008). HPA axis reactivity: a mechanism underlying the associations among 5-HTTLPR, stress, and depression. Biol Psychiatry, 63(9), 847-851. doi: 10.1016/j.biopsych.2007.10.008

Gotlib, I. H., Joormann, J., Minor, K. L., \& Hallmayer, J. (2008). HPA axis reactivity: a mechanism underlying the associations among 5-HTTLPR, stress, and depression. Biological psychiatry, 63(9), 847-851.

Grady, M. M., \& Stahl, S. M. (2014). Antidepressants: Recent Developments Encyclopedia of Psychopharmacology (pp. 1-9): Springer Berlin Heidelberg.

Graeff, F. G., Guimarães, F. S., De Andrade, T. G., \& Deakin, J. F. (1996). Role of 5-HT in stress, anxiety, and depression. Pharmacology Biochemistry and Behavior, 54(1), 129-141.

Graeff, F. G., Guimarães, F. S., De Andrade, T. G. C. S., \& Deakin, J. F. W. (1996). Role of 5-HT in stress, anxiety, and depression. Pharmacology Biochemistry and Behavior, 54(1), 129-141. doi: 10.1016/0091-3057(95)02135-3

Greeno, C. G., \& Wing, R. R. (1994). Stress-induced eating. Psychological Bulletin, 115(3), 444-464. doi: 10.1037/0033-2909.115.3.444

Groesz, L. M., McCoy, S., Carl, J., Saslow, L., Stewart, J., Adler, N., . . Epel, E. (2012). What is eating you? Stress and the drive to eat. Appetite, 58(2), 717-721. doi: 10.1016/j.appet.2011.11.028

Grunberg, N. E., \& Straub, R. O. (1992). The role of gender and taste class in the effects of stress on eating. Health Psychology, 11(2), 97-100. doi: 10.1037/02786133.11.2.97

Guerrieri, R., Nederkoorn, C., Schrooten, M., Martijn, C., \& Jansen, A. (2009). Inducing impulsivity leads high and low restrained eaters into overeating, whereas current dieters stick to their diet. Appetite, 53(1), 93-100. doi: 10.1016/j.appet.2009.05.013

Guerrieri, R., Nederkoorn, C., Stankiewicz, K., Alberts, H., Geschwind, N., Martijn, C., \& Jansen, A. (2007). The influence of trait and induced state impulsivity on food intake in normal-weight healthy women. Appetite, 49(1), 66-73. doi: 10.1016/j.appet.2006.11.008

Gunthert, K. C., Cohen, L. H., \& Armeli, S. (1999). The role of neuroticism in daily stress and coping. Journal of Personality and Social Psychology, 77(5), 1087.

Habhab, S., Sheldon, J. P., \& Loeb, R. C. (2009). The relationship between stress, dietary restraint, and food preferences in women. Appetite, 52(2), 437-444. doi: 10.1016/j.appet.2008.12.006

Hariri, A. R., \& Holmes, A. (2006). Genetics of emotional regulation: the role of the 
serotonin transporter in neural function. Trends in cognitive sciences, 10(4), 182-191.

Hayes, A. F. (2013). Introduction to mediation, moderation, and conditional process analysis: A regression-based approach: Guilford Press.

Heatherton, T. F., \& Baumeister, R. F. (1991). Binge eating as escape from selfawareness. Psychological Bulletin, 110(1), 86.

Heils, A., Teufel, A., Petri, S., Stöber, G., Riederer, P., Bengel, D., \& Lesch, K. P. (1996). Allelic variation of human serotonin transporter gene expression. Journal of neurochemistry, 66(6), 2621-2624.

Heils, A., Teufel, A., Petri, S., Stöber, G., Riederer, P., Bengel, D., \& Lesch, K. P. (2002). Allelic Variation of Human Serotonin Transporter Gene Expression. Journal of Neurochemistry, 66(6), 2621-2624. doi: 10.1046/j.1471-4159.1996.66062621.x

Hepworth, R., Mogg, K., Brignell, C., \& Bradley, B. P. (2010). Negative mood increases selective attention to food cues and subjective appetite. Appetite, 54(1), 134-142.

Hinney, A., Barth, N., Ziegler, A., Von Prittwitz, S., Hamann, A., Hennighausen, K., . . Hebebrand, J. (1997). Serotonin transporter gene-linked polymorphic region: Allele distributions in relationship to body weight and in anorexia nervosa. Life Sciences, 61(21), PL295-PL303. doi: 10.1016/s0024-3205(97)008886

Hoefgen, B., Schulze, T. G., Ohlraun, S., von Widdern, O., Höfels, S., Gross, M., . . . Kölsch, H. (2005). The power of sample size and homogenous sampling: association between the 5-HTTLPR serotonin transporter polymorphism and major depressive disorder. Biological psychiatry, 57(3), 247-251.

Homberg, J. R., \& Lesch, K.-P. (2011). Looking on the Bright Side of Serotonin Transporter Gene Variation. Biological Psychiatry, 69(6), 513-519. doi: 10.1016/j.biopsych.2010.09.024

Iordanidou, M., Tavridou, A., Petridis, I., Arvanitidis, K. I., Christakidis, D., Vargemezis, V., \& Manolopoulos, V. G. (2010). The serotonin transporter promoter polymorphism (5-HTTLPR) is associated with type 2 diabetes. Clinica Chimica Acta, 411(3), 167-171.

Jans, L. A. W., Riedel, W. J., Markus, C. R., \& Blokland, A. (2006). Serotonergic vulnerability and depression: assumptions, experimental evidence and implications. Molecular Psychiatry, 12(6), 522-543. doi: 10.1038/sj.mp.4001920

Joiner, T. E., Johnson, F., Soderstrom, K., \& Brown, J. S. (2003). Is there an association between serotonin transporter gene polymorphism and family history of depression? Journal of affective disorders, 77(3), 273-275.

Kandiah, J., Yake, M., Jones, J., \& Meyer, M. (2006). Stress influences appetite and comfort food preferences in college women. Nutrition Research, 26(3), 118123. doi: 10.1016/j.nutres.2005.11.010

Karg, K., Burmeister, M., Shedden, K., \& Sen, S. (2011). The Serotonin Transporter Promoter Variant (5-HTTLPR), Stress, and Depression Meta-analysis Revisited. Archives of General Psychiatry, 68(5), 444. doi: 10.1001/ archgenpsychiatry.2010.189

Karlsson, J., Persson, L., Sjöström, L., \& Sullivan, M. (2000). Psychometric properties and factor structure of the Three-Factor Eating Questionnaire (TFEQ) in obese men and women. Results from the Swedish Obese Subjects (SOS) 
study. International journal of obesity and related metabolic disorders: journal of the International Association for the Study of Obesity, 24(12), 1715-1725.

Keller, M. C. (2014). Genex environment interaction studies have not properly controlled for potential confounders: the problem and the (simple) solution. Biological psychiatry, 75(1), 18-24.

Kendler, K. S., Kuhn, J., \& Prescott, C. A. (2004). The interrelationship of neuroticism, sex, and stressful life events in the prediction of episodes of major depression. American Journal of Psychiatry.

Keskitalo, K., Tuorila, H., Spector, T. D., Cherkas, L. F., Knaapila, A., Kaprio, J., . . . Perola, M. (2008). The Three-Factor Eating Questionnaire, body mass index, and responses to sweet and salty fatty foods: a twin study of genetic and environmental associations. The American journal of clinical nutrition, 88(2), 263-271.

Kirkegaard Thomsen, D. (2006). The association between rumination and negative affect: A review. Cognition \& Emotion, 20(8), 1216-1235. doi: 10.1080/02699930500473533

Kirschbaum, C., Tietze, A., Skoluda, N., \& Dettenborn, L. (2009). Hair as a retrospective calendar of cortisol production - increased cortisol incorporation into hair in the third trimester of pregnancy. Psychoneuroendocrinology, 34(1), 32-37.

Kivimäki, M., Head, J., Ferrie, J. E., Shipley, M. J., Brunner, E., Vahtera, J., \& Marmot, M. G. (2006). Work stress, weight gain and weight loss: evidence for bidirectional effects of job strain on body mass index in the Whitehall II study. International Journal of Obesity, 30(6), 982-987. doi: 10.1038/sj.ijo.0803229

Konttinen, H., Männistö, S., Sarlio-Lähteenkorva, S., Silventoinen, K., \& Haukkala, A. (2010). Emotional eating, depressive symptoms and self-reported food consumption. A population-based study. Appetite, 54(3), 473-479. doi: 10.1016/j.appet.2010.01.014

Kreft, I. G., Kreft, I., \& de Leeuw, J. (1998). Introducing multilevel modeling: Sage.

Kubberød, E., Ueland, Ø., Tronstad, Å., \& Risvik, E. (2002). Attitudes towards meat and meat-eating among adolescents in Norway: a qualitative study. Appetite, 38(1), 53-62.

Kubiak, T., Vögele, C., Siering, M., Schiel, R., \& Weber, H. (2008). Daily hassles and emotional eating in obese adolescents under restricted dietary conditions The role of ruminative thinking. Appetite, 51(1), 206-209. doi: 10.1016/j. appet.2008.01.008

Kudielka, B. M., Schommer, N. C., Hellhammer, D. H., \& Kirschbaum, C. (2004). Acute HPA axis responses, heart rate, and mood changes to psychosocial stress (TSST) in humans at different times of day. Psychoneuroendocrinology, 29(8), 983-992.

Laitinen, J., Ek, E., \& Sovio, U. (2002). Stress-Related Eating and Drinking Behavior and Body Mass Index and Predictors of This Behavior. Preventive Medicine, 34(1), 29-39. doi: 10.1006/pmed.2001.0948

Lam, D., Smith, N., Checkley, S., Rijsdijk, F., \& Sham, P. (2003). Effect of neuroticism, response style and information processing on depression severity in a clinically depressed sample. Psychological medicine, 33(03), 469-479.

Lan, M., Chang, Y., Chen, W., Kao, Y., Lin, H., \& Liu, J. (2009). Serotonin transporter gene promoter polymorphism is associated with body mass index and 
obesity in non-elderly stroke patients. Journal of endocrinological investigation, 32(2), 119-122.

Larsen, R. J., \& Ketelaar, T. (1991). Personality and susceptibility to positive and negative emotional states. Journal of personality and social psychology, 61(1), 132.

Larsen, J. K., van Strien, T., Eisinga, R., \& Engels, R. C. (2006). Gender differences in the association between alexithymia and emotional eating in obese individuals. Journal of psychosomatic research, 60(3), 237-243.

Leibowitz, S. F., \& Alexander, J. T. (1998). Hypothalamic serotonin in control of eating behavior, meal size, and body weight. Biological Psychiatry, 44(9), 851864. doi: 10.1016/s0006-3223(98)00186-3

Leproult, R., Copinschi, G., Buxton, O., \& Van Cauter, E. (1997). Sleep loss results in an elevation of cortisol levels the next evening. Sleep, 20(10), 865-870.

Lesch, K. P., Bengel, D., Heils, A., Sabol, S. Z., Greenberg, B. D., Petri, S., . . Murphy, D. L. (1996). Association of Anxiety-Related Traits with a Polymorphism in the Serotonin Transporter Gene Regulatory Region. Science, 274(5292), 1527 1531. doi: $10.1126 /$ science.274.5292.1527

Lesch, K. P., Meyer, J., Glatz, K., Flugge, G., Hinney, A., Hebebrand, J., . . Heils, A. (1997). The 5-HT transporter gene-linked polymorphic region (5-HTTLPR) in evolutionary perspective: Alternative biallelic variation in rhesus monkeys. Journal of Neural Transmission, 104(11-12), 1259-1266. doi: 10.1007/bf01294726

Liu, C., Xie, B., Chou, C.-P., Koprowski, C., Zhou, D., Palmer, P., . . . Anderson Johnson, C. (2007). Perceived stress, depression and food consumption frequency in the college students of China seven cities. Physiology E Behavior, 92(4), 748-754. doi: 10.1016/j.physbeh.2007.05.068

Lluch, A., Herbeth, B., Méjean, L., \& Siest, G. (2000). Dietary intakes, eating style and overweight in the Stanislas Family Study. International Journal of Obesity, 24(11), 1493-1499. doi: 10.1038/sj.ijo.0801425

Lovallo, W. R., Farag, N. H., Vincent, A. S., Thomas, T. L., \& Wilson, M. F. (2006). Cortisol responses to mental stress, exercise, and meals following caffeine intake in men and women. Pharmacology Biochemistry and Behavior, 83(3), 441-447.

Lubman, D., Peters, L., Mogg, K., Bradley, B., \& Deakin, J. (2000). Attentional bias for drug cues in opiate dependence. Psychological Medicine, 30(01), 169-175.

Luteijn, F., \& Bouman, T. K. (1988). The concepts of depression, anxiety, and neuroticism in questionnaires. European Journal of Personality, 2(2), 113-120.

Maes, M. (1995). Evidence for an immune response in major depression: A review and hypothesis. Progress in Neuro-Psychopharmacology and Biological Psychiatry, 19(1), 11-38. doi: 10.1016/0278-5846(94)00101-m

Manenschijn, L., Koper, J. W., Lamberts, S. W., \& van Rossum, E. F. (2011). Evaluation of a method to measure long term cortisol levels. Steroids, 76(10), 1032-1036.

Markus, C. R. (2008). Dietary amino acids and brain serotonin function; implications for stress-related affective changes. Neuromolecular medicine, 10(4), 247-258.

Markus, C. R. (2013). Interaction between the 5-HTTLPR genotype, impact of stressful life events, and trait neuroticism on depressive symptoms in healthy volunteers. Psychiatric Genetics, 23(3), 108-116.

Markus, C. R., \& Capello, A. E. M. (2012). Contribution of the 5-HTTLPR gene by 
neuroticism on weight gain in male and female participants. Psychiatric Genetics, 22(6), 279-285. doi: 10.1097/ypg.0b013e328358632a

Markus, C. R., \& De Raedt, R. (2010). Differential Effects of 5-HTTLPR Genotypes on Inhibition of Negative Emotional Information Following Acute Stress Exposure and Tryptophan Challenge. Neuropsychopharmacology, 36(4), 819826. doi: 10.1038/npp.2010.

Markus, C. R., \& Firk, C. (2009). Differential effects of tri-allelic 5-HTTLPR polymorphisms in healthy subjects on mood and stress performance after tryptophan challenge. Neuropsychopharmacology, 34(13), 2667-2674. doi: 10.1038/npp.2009.92

Martí, O., Martí, J., \& Armario, A. (1994). Effects of chronic stress on food intake in rats: Influence of stressor intensity and duration of daily exposure. Physiology $\mathcal{E}$ Behavior, 55(4), 747-753. doi: 10.1016/0031-9384(94)90055-8

Martin, L. L., \& Tesser, A. (1996). Some ruminative thoughts. Advances in social cognition, 9, 1-47.

McCann, B. S., Warnick, G. R., \& Knopp, R. H. (1990). Changes in plasma lipids and dietary intake accompanying shifts in perceived workload and stress. Psychosomatic Medicine, 52(1), 97-108. doi: 10.1097/00006842-199001000-00008

McCullough, M. E., Orsulak, P., Brandon, A., \& Akers, L. (2007). Rumination, fear, and cortisol: An in vivo study of interpersonal transgressions. Health Psychology, 26(1), 126-132. doi: 10.1037/0278-6133.26.1.126

Mckim, R. D. (2008). Rumination as a mediator of the effects of mindfulness: Mindfulnessbased stress reduction (MBSR) with a heterogeneous community sample experiencing anxiety, depression, and/or chronic pain. ProQuest Information \& Learning.

Mellbin, T., \& Vuille, J. C. (1989). Rapidly Developing Overweight in School Children as an Indicator of Psychosocial Stress. Acta Paediatrica, 78(4), 568-575. doi: 10.1111/j.1651-2227.1989.tb17938.x

Michaud, C., Kahn, J. P., Musse, N., Burlet, C., Nicolas, J. P., \& Mejean, L. (1990). Relationships between a critical life event and eating behaviour in highschool students. Stress Medicine, 6(1), 57-64. doi: 10.1002/smi.2460060112

Michl, L. C., McLaughlin, K. A., Shepherd, K., \& Nolen-Hoeksema, S. (2013). Rumination as a mechanism linking stressful life events to symptoms of depression and anxiety: longitudinal evidence in early adolescents and adults. Journal of abnormal psychology, 122(2), 339.

Middeldorp, C. M., de Geus, E. J., Beem, A. L., Lakenberg, N., Hottenga, J. J., Slagboom, P. E., \& Boomsma, D. I. (2007). Family based association analyses between the serotonin transporter gene polymorphism (5-HTTLPR) and neuroticism, anxiety and depression. Behav Genet, 37(2), 294-301. doi: 10.1007/s10519-006-9139-7

Middeldorp, C. M., de Geus, E. J. C., Beem, A. L., Lakenberg, N., Hottenga, J.-J., Slagboom, P. E., \& Boomsma, D. I. (2007). Family Based Association Analyses between the Serotonin Transporter Gene Polymorphism (5-HTTLPR) and Neuroticism, Anxiety and Depression. Behavior Genetics, 37(2), 294-301. doi: 10.1007/s10519-006-9139-7

Miller, R., Wankerl, M., Stalder, T., Kirschbaum, C., \& Alexander, N. (2012). The serotonin transporter gene-linked polymorphic region (5-HTTLPR) and 
cortisol stress reactivity: a meta-analysis. Molecular Psychiatry, 18(9), 10181024. doi: 10.1038/mp.2012.124

Mogg, K., Bradley, B. P., Hyare, H., \& Lee, S. (1998). Selective attention to foodrelated stimuli in hunger: are attentional biases specific to emotional and psychopathological states, or are they also found in normal drive states? Behaviour Research and Therapy, 36(2), 227-237.

Mokdad, A. H., Ford, E. S., Bowman, B. A., Dietz, W. H., Vinicor, F., Bales, V. S., \& Marks, J. S. (2003). Prevalence of Obesity, Diabetes, and Obesity-Related Health Risk Factors, 2001. JAMA, 289(1). doi: 10.1001/jama.289.1.76

Mueller, A., Brocke, B., Fries, E., Lesch, K. P., \& Kirschbaum, C. (2010). The role of the serotonin transporter polymorphism for the endocrine stress response in newborns. Psychoneuroendocrinology, 35(2), 289-296. doi: 10.1016/j. psyneuen.2009.07.002

Munafò, M. R., Brown, S. M., \& Hariri, A. R. (2008). Serotonin Transporter (5-HTTLPR) Genotype and Amygdala Activation: A Meta-Analysis. Biological Psychiatry, 63(9), 852-857. doi: 10.1016/j.biopsych.2007.08.016

Munafò, M. R., Clark, T., \& Flint, J. (2004). Does measurement instrument moderate the association between the serotonin transporter gene and anxiety-related personality traits? A meta-analysis. Molecular Psychiatry, 10(4), 415-419. doi: 10.1038/sj.mp.4001627

Munafò, M. R., Clark, T. G., Moore, L. R., Payne, E., Walton, R., \& Flint, J. (2003). Genetic Polymorphisms and Personality in Healthy Adults: A systematic review and meta-analysis. Molecular Psychiatry, 8(5), 471-484. doi: 10.1038/ sj.mp.4001326

Munafò, M. R., Freimer, N. B., Ng, W., Ophoff, R., Veijola, J., Miettunen, J., . . . Flint, J. (2009). 5-HTTLPR genotype and anxiety-related personality traits: A meta-analysis and new data. American Journal of Medical Genetics Part B: Neuropsychiatric Genetics, 150B(2), 271-281. doi: 10.1002/ajmg.b.30808

Murphy, S. E., Norbury, R., Godlewska, B. R., Cowen, P. J., Mannie, Z. M., Harmer, C. J., \& Munafò, M. R. (2012). The effect of the serotonin transporter polymorphism (5-HTTLPR) on amygdala function: a meta-analysis. Molecular Psychiatry, 18(4), 512-520. doi: 10.1038/mp.2012.19

Nederkoorn, C., Houben, K., Hofmann, W., Roefs, A., \& Jansen, A. (2010). Control yourself or just eat what you like? Weight gain over a year is predicted by an interactive effect of response inhibition and implicit preference for snack foods. Health Psychology, 29(4), 389-393. doi: 10.1037/a0019921

Neumeister, A. (1997). Effects of Tryptophan Depletion on Drug-Free Patients With Seasonal Affective Disorder During a Stable Response to Bright Light Therapy. Archives of General Psychiatry, 54(2), 133. doi: 10.1001/ archpsyc.1997.01830140043008

Newman, E., O'Connor, D. B., \& Conner, M. (2007). Daily hassles and eating behaviour: The role of cortisol reactivity status. Psychoneuroendocrinology, 32(2), 125-132. doi: 10.1016/j.psyneuen.2006.11.006

Ng, D. M., \& Jeffery, R. W. (2003). Relationships Between Perceived Stress and Health Behaviors in a Sample of Working Adults. Health Psychology, 22(6), 638-642. doi: 10.1037/0278-6133.22.6.638

Nguyen-Michel, S. T., Unger, J. B., \& Spruijt-Metz, D. (2007). Dietary correlates of 
emotional eating in adolescence. Appetite, 49(2), 494-499. doi: 10.1016/j. appet.2007.03.005

Nolen-Hoeksema, S. (2000). The role of rumination in depressive disorders and mixed anxiety/depressive symptoms. Journal of Abnormal Psychology, 109(3), 504-511. doi: 10.1037//0021-843x.109.3.504

Nolen-Hoeksema, S., \& Morrow, J. (1991). A prospective study of depression and posttraumatic stress symptoms after a natural disaster: the 1989 Loma Prieta Earthquake. Journal of personality and social psychology, 61(1), 115.

Nolen-Hoeksema, S., Wisco, B. E., \& Lyubomirsky, S. (2008). Rethinking rumination. Perspectives on psychological science, 3(5), 400-424.

O'Connor, D. B., \& O'Connor, R. C. (2004). Perceived changes in food intake in response to stress: the role of conscientiousness. Stress and Health, 20(5), 279291. doi: $10.1002 / \mathrm{smi} .1028$

Oliver, G., \& Wardle, J. (1999). Perceived Effects of Stress on Food Choice. Physiology $\mathcal{E}$ Behavior, 66(3), 511-515. doi: 10.1016/s0031-9384(98)00322-9

Oliver, G., Wardle, J., \& Gibson, E. L. (2000). Stress and Food Choice: A Laboratory Study. Psychosomatic Medicine, 62(6), 853-865. doi: 10.1097/00006842200011000-00016

Papageorgiou, C., \& Wells, A. (2004). Depressive rumination: Nature, theory and treatment: John Wiley \& Sons.

Peeters, F., Ponds, R., Boon-Vermeeren, M., Hoorweg, M., Kraan, H., \& Meertens, L. (1999). Handleiding bij de Nederlandse vertaling van de Positive and Negative Affect Schedule (PANAS). Maastricht: Universiteit Maastricht, Vakgroep Psychiatrie en Neuropsychologie.

Peralta-Leal, V., Leal-Ugarte, E., Meza-Espinoza, J. P., Dávalos-Rodríguez, I. P., Bocanegra-Alonso, A., Acosta-González, R. I., . . . Durán-González, J. (2012). Association of a serotonin transporter gene (SLC6A4) 5-HTTLPR polymorphism with body mass index categories but not type 2 diabetes mellitus in Mexicans. Genetics and molecular biology, 35(3), 589-593.

Pinel, J. P. (2006). Biopsychology. 6th: Allyn \& Bacon, Boston.

Pluess, M., Belsky, J., Way, B. M., \& Taylor, S. E. (2010). 5-HTTLPR moderates effects of current life events on neuroticism: Differential susceptibility to environmental influences. Progress in Neuro-Psychopharmacology and Biological Psychiatry, 34(6), 1070-1074. doi: 10.1016/j.pnpbp.2010.05.028

Pollard, T. M., Steptoe, A., Canaan, L., Davies, G. J., \& Wardle, J. (1995). Effects of academic examination stress on eating behavior and blood lipid levels. International Journal of Behavioral Medicine, 2(4), 299-320. doi: 10.1207/ s15327558ijbm0204_2

Porter, R. J., Gallagher, P., Watson, S., \& Young, A. H. (2004). Corticosteroidserotonin interactions in depression: a review of the human evidence. Psychopharmacology, 173(1-2), 1-17.

Prättälä, R., Paalanen, L., Grinberga, D., Helasoja, V., Kasmel, A., \& Petkeviciene, J. (2006). Gender differences in the consumption of meat, fruit and vegetables are similar in Finland and the Baltic countries. European Journal of Public Health, 17(5), 520-525.

Provencher, V., Drapeau, V., Tremblay, A., Després, J. P., \& Lemieux, S. (2003). Eating behaviors and indexes of body composition in men and women from 
the Quebec family study. Obesity, 11(6), 783-792.

Pyszczynski, T., \& Greenberg, J. (1987). Self-regulatory perseveration and the depressive self-focusing style: A self-awareness theory of reactive depression. Psychological Bulletin, 102(1), 122-138. doi: 10.1037/0033-2909.102.1.122

Qin, D., Rizak, J., Feng, X., Yang, S., Yang, L., Fan, X., ... Hu, X. (2015). Cortisol responses to chronic stress in adult macaques: Moderation by a polymorphism in the serotonin transporter gene. Behavioural brain research, 278, 280-285.

Racine, S. E., Culbert, K. M., Larson, C. L., \& Klump, K. L. (2009). The possible influence of impulsivity and dietary restraint on associations between serotonin genes and binge eating. Journal of Psychiatric Research, 43(16), 12781286. doi: 10.1016/j.jpsychires.2009.05.002

Raes, F., \& Hermans, D. (2007). RRS-NL-EXT. Internet Document. Retrieved from http://www.ekgp.ugent.be/pages/nl/vragenlijsten/RRS-NL.pdf

Risch, N., Herrell, R., Lehner, T., Liang, K.-Y., Eaves, L., Hoh, J., .. Merikangas, K. R. (2009a). Interaction Between the Serotonin Transporter Gene (5-HTTLPR), Stressful Life Events, and Risk of Depression. JAMA, 301(23), 2462. doi: 10.1001/jama.2009.878

Roberts, C. J., Campbell, I. C., \& Troop, N. (2013). Increases in Weight during Chronic Stress are Partially Associated with a Switch in Food Choice towards Increased Carbohydrate and Saturated Fat Intake. European Eating Disorders Review, 22(1), 77-82. doi: 10.1002/erv.2264

Robinson, M. S., \& Alloy, L. B. (2003). Negative cognitive styles and stress-reactive rumination interact to predict depression: A prospective study. Cognitive Therapy and Research, 27(3), 275-291.

Roelofs, J., Huibers, M., Peeters, F., Arntz, A., \& van Os, J. (2008). Rumination and worrying as possible mediators in the relation between neuroticism and symptoms of depression and anxiety in clinically depressed individuals. Behaviour Research and Therapy, 46(12), 1283-1289.

Rood, L., Roelofs, J., Bögels, S. M., \& Alloy, L. B. (2010). Dimensions of negative thinking and the relations with symptoms of depression and anxiety in children and adolescents. Cognitive therapy and research, 34(4), 333-342.

Rossi, V., \& Pourtois, G. (2012). Transient state-dependent fluctuations in anxiety measured using STAI, POMS, PANAS or VAS: a comparative review. Anxiety, Stress \& Coping, 25(6), 603-645.

Rutters, F., Nieuwenhuizen, A. G., Lemmens, S. G. T., Born, J. M., \& WesterterpPlantenga, M. S. (2009). Acute Stress-related Changes in Eating in the Absence of Hunger. Obesity, 17(1), 72-77. doi: 10.1038/oby.2008.493

Schachter, S., Goldman, R., \& Gordon, A. (1968). Effects of fear, food deprivation, and obesity on eating. Journal of Personality and Social Psychology, 10(2), 91-97. doi: 10.1037/h0026284

Sauvé, B., Koren, G., Walsh, G., Tokmakejian, S., \& Van Uum, S. H. (2007). Measurement of cortisol in human hair as a biomarker of systemic exposure. Clinical \& Investigative Medicine, 30(5), 183-191.

Schepers, R., Keulers, E.H.H. \& Markus, C. R. (2018a). The effect of 5-HTTLPR genotype and cognitive rumination on long term cortisol reactivity measured in human hair. To be published

Schepers, R., \& Markus, C. R. (2015). Gene x Cognition interaction on stress-induced 
eating; effect of rumination. Psychoneuroendocrinology, 54, 41-53.

Schepers, R., \& Markus, C. R. (2017b). The interaction between 5-HTTLPR genotype and ruminative thinking on BMI. British Journal of Nutrition, 118, 629-637.

Schepers, R., \& Markus, C. R. (2017a). Gene by Cognition interaction on stressinduced attention bias for food: effects of 5-HTTLPR and Ruminative Thinking. Biological Psychology, 128, 21-28.

Schinka, J. A., Busch, R. M., \& Robichaux-Keene, N. (2004). A meta-analysis of the association between the serotonin transporter gene polymorphism (5-HTTLPR) and train anxiety. Molecular Psychiatry, 9, 197-202.

Schinka, J. A., Busch, R. M., \& Robichaux-Keene, N. (2004). A meta-analysis of the association between the serotonin transporter gene polymorphism (5-HTTLPR) and trait anxiety. Molecular Psychiatry, 9(2), 197-202. doi: 10.1038/sj.mp.4001405

Segerstrom, S. C., Tsao, J. C., Alden, L. E., \& Craske, M. G. (2000). Worry and rumination: Repetitive thought as a concomitant and predictor of negative mood. Cognitive therapy and research, 24(6), 671-688.

Sen, S., Burmeister, M., \& Ghosh, D. (2004). Meta-analysis of the association between a serotonin transporter promoter polymorphism (5-HTTLPR) and anxietyrelated personality traits. American Journal of Medical Genetics, 127B(1), 85-89. doi: 10.1002/ajmg.b.20158

Shafran, R., Lee, M., Cooper, Z., Palmer, R. L., \& Fairburn, C. G. (2007). Attentional bias in eating disorders. International Journal of Eating Disorders, 40(4), 369380.

Sharpley, C. F., Palanisamy, S. K., Glyde, N. S., Dillingham, P. W., \& Agnew, L. L. (2014). An update on the interaction between the serotonin transporter promoter variant (5-HTTLPR), stress and depression, plus an exploration of non-confirming findings. Behavioural brain research, 273, 89-105.

Shoji, K., Harrigan, J. A., Woll, S. B., \& Miller, S. A. (2010). Interactions among situations, neuroticism, and appraisals in coping strategy choice. Personality and Individual Differences, 48(3), 270-276. doi: 10.1016/j.paid.2009.10.009

Silverstone, T., \& Goodall, E. (1986). Serotoninergic mechanisms in human feeding: The pharmacological evidence. Appetite, 7, 85-97. doi: 10.1016/s01956663(86)80054-x

Small, D. M., Jones-Gotman, M., \& Dagher, A. (2003). Feeding-induced dopamine release in dorsal striatum correlates with meal pleasantness ratings in healthy human volunteers. Neuroimage, 19(4), 1709-1715.

Smeets, T., Cornelisse, S., Quaedflieg, C. W., Meyer, T., Jelicic, M., \& Merckelbach, H. (2012). Introducing the Maastricht Acute Stress Test (MAST): A quick and non-invasive approach to elicit robust autonomic and glucocorticoid stress responses. Psychoneuroendocrinology, 37(12), 1998-2008.

Smith, J. M., \& Alloy, L. B. (2009). A roadmap to rumination: A review of the definition, assessment, and conceptualization of this multifaceted construct. Clinical psychology review, 29(2), 116-128.

Sookoian, S., Gemma, C., García, S. I., Fernández Gianotti, T., Dieuzeide, G., Roussos, A., . . Pirola, C. J. (2007). Short Allele of Serotonin Transporter Gene Promoter Is a Risk Factor for Obesity in Adolescents*. Obesity, 15(2), 271-276. doi: 10.1038/oby.2007.519 
Sookoian, S., Gianotti, T. F., Gemma, C., Burgueño, A., \& Pirola, C. J. (2008). Contribution of the Functional 5-HTTLPR Variant of the SLC6A4 Gene to Obesity Risk in Male Adults. Obesity, 16(2), 488-491.

Spoor, S. T. P., Bekker, M. H. J., Van Strien, T., \& van Heck, G. L. (2007). Relations between negative affect, coping, and emotional eating. Appetite, 48(3), 368376. doi: 10.1016/j.appet.2006.10.005

Stalder, T., \& Kirschbaum, C. (2012). Analysis of cortisol in hair-state of the art and future directions. Brain, behavior, and immunity, 26(7), 1019-1029.

Stalder, T., Steudte, S., Miller, R., Skoluda, N., Dettenborn, L., \& Kirschbaum, C. (2012). Intraindividual stability of hair cortisol concentrations. Psychoneuroendocrinology, 37(5), 602-610.

Staufenbiel, S. M., Penninx, B. W., Spijker, A. T., Elzinga, B. M., \& van Rossum, E. F. (2013). Hair cortisol, stress exposure, and mental health in humans: a systematic review. Psychoneuroendocrinology, 38(8), 1220-1235.

Steptoe, A., Lipsey, Z., \& Wardle, J. (1998). Stress, hassles and variations in alcohol consumption, food choice and physical exercise: A diary study. British Journal of Health Psychology, 3(1), 51-63. doi: 10.1111/j.2044-8287.1998.tb00555.x

Stoltenberg, S. F., Anderson, C., Nag, P., \& Anagnopoulos, C. (2012). Association between the serotonin transporter triallelic genotype and eating problems is moderated by the experience of childhood trauma in women. Int J Eat Disord, 45(4), 492-500. doi: 10.1002/eat.20976

Sundaramurthy, D., Pieri, L. F., Gape, H., Markham, A. F., \& Campbell, D. A. (2000). Analysis of the serotonin transporter gene linked polymorphism (5-HTTLPR) in anorexia nervosa. American Journal of Medical Genetics, 96(1), 53-55. doi: 10.1002/(sici)1096-8628(20000207)96:1

Sung, J., Lee, K., Song, Y.-M., Lee, M. K., \& Lee, D.-H. (2009). Heritability of Eating Behavior Assessed Using the DEBQ (Dutch Eating Behavior Questionnaire) and Weight-related Traits: The Healthy Twin Study. Obesity, 18(5), 10001005. doi: 10.1038/oby.2009.389

Takeda, E., Terao, J., Nakaya, Y., Miyamoto, K.-i., Baba, Y., Chuman, H., . . Rokutan, K. (2004). Stress control and human nutrition. The Journal of Medical Investigation, 51(3,4), 139-145. doi: 10.2152/jmi.51.139

Tennen, H., Affleck, G., Coyne, J. C., Larsen, R. J., \& DeLongis, A. (2006). Paper and plastic in daily diary research: Comment on Green, Rafaeli, Bolger, Shrout, and Reis (2006).

Tholin, S., Rasmussen, F., Tynelius, P., \& Karlsson, J. (2005). Genetic and environmental influences on eating behavior: the Swedish Young Male Twins Study. The American journal of clinical nutrition, 81(3), 564-569.

Thomsen, D. K., Mehlsen, M. Y., Christensen, S., \& Zachariae, R. (2003). Ruminationrelationship with negative mood and sleep quality. Personality and Individual Differences, 34(7), 1293-1301.

Torres, S. J., \& Nowson, C. A. (2007). Relationship between stress, eating behavior, and obesity. Nutrition, 23(11-12), 887-894. doi: 10.1016/j.nut.2007.08.008

Townshend, J., \& Duka, T. (2001). Attentional bias associated with alcohol cues: differences between heavy and occasional social drinkers. Psychopharmacology, 157(1), 67-74.

Treynor, W. (2003). Cognitive Therapy and Research, 27(3), 247-259. doi: 


\subsection{3/a:1023910315561}

Triplett, K. N., Tedeschi, R. G., Cann, A., Calhoun, L. G., \& Reeve, C. L. (2012). Posttraumatic growth, meaning in life, and life satisfaction in response to trauma. Psychological Trauma: Theory, Research, Practice, and Policy, 4(4), 400.

Twisk, J. W. (2006). Applied multilevel analysis: a practical guide for medical researchers: Cambridge University Press.

Uher, R., \& McGuffin, P. (2010). The moderation by the serotonin transporter gene of environmental adversity in the etiology of depression: 2009 update. Molecular Psychiatry, 15(1), 18-22. doi: 10.1038/mp.2009.123

Ursin, H., \& Olff, M. (1993). Psychobiology of coping and defence strategies. Neuropsychobiology, 28(1-2), 66-71.

Vallès, A., Martí, O., García, A., \& Armario, A. (2000). Single exposure to stressors causes long-lasting, stress-dependent reduction of food intake in rats. American Journal of Physiology-Regulatory, Integrative and Comparative Physiology, 279(3), R1138-R1144.

van Praag, H. M. (2004). Can stress cause depression? Progress in NeuroPsychopharmacology and Biological Psychiatry, 28(5), 891-907. doi: 10.1016/j. pnpbp.2004.05.031

van Strien, T. (2004). Nederlandse Vragenlijst voor Eetgedrag 2005: Boom Test Publ.

van Strien, Frijters, J. E., Roosen, R. F., Knuiman-Hijl, W. J., \& Defares, P. B. (1985). Eating behavior, personality traits and body mass in women. Addictive Behaviors, 10(4), 333-343.

van Strien, Rookus, M., Bergers, G., Frijters, J., \& Defares, P. (1985). Life events, emotional eating and change in body mass index. International journal of obesity, 10(1), 29-35.

van Strien, T., Konttinen, H., Homberg, J. R., Engels, R. C., \& Winkens, L. H. (2016). Emotional eating as a mediator between depression and weight gain. Appetite, 100, 216-224.

van Strien, T., van der Zwaluw, C. S., \& Engels, R. C. (2010). Emotional eating in adolescents: A gene (SLC6A4/5-HTT)-Depressive feelings interaction analysis. Journal of psychiatric research, 44(15), 1035-1042.

van Strien, T., Winkens, L., Toft, M. B., Pedersen, S., Brouwer, I., Visser, M., \& Lähteenmäki, L. (2016). The mediation effect of emotional eating between depression and body mass index in the two European countries Denmark and Spain. Appetite, 105, 500-508.

Verschoor, E., \& Markus, C. R. (2011). Effects of acute psychosocial stress exposure on endocrine and affective reactivity in college students differing in the 5-HTTLPR genotype and trait neuroticism. Stress, 14(4), 407-419.

Verhaeghen, P., Joorman, J., \& Khan, R. (2005). Why we sing the blues: the relation between self-reflective rumination, mood, and creativity. Emotion, 5(2), 226.

Wald, F., \& Mellenbergh, G. (1990). De verkorte versie van de Nederlandse vertaling van de Profile of Mood States (POMS). Nederlands Tijdschrift voor de Psychologie en haar Grensgebieden.

Wallis, D. J., \& Hetherington, M. M. (2004). Stress and eating: the effects of ego-threat and cognitive demand on food intake in restrained and emotional eaters. Appetite, 43(1), 39-46. doi: 10.1016/j.appet.2004.02.001

Wang, Y., \& Beydoun, M. A. (2007). The obesity epidemic in the United States- 
gender, age, socioeconomic, racial/ethnic, and geographic characteristics: a systematic review and meta-regression analysis. Epidemiologic reviews, 29(1), 6-28.

Wardle, J., Steptoe, A., Oliver, G., \& Lipsey, Z. (2000). Stress, dietary restraint and food intake. Journal of Psychosomatic Research, 48(2), 195-202. doi: 10.1016/ s0022-3999(00)00076-3

Watkins, E. R. (2008). Constructive and unconstructive repetitive thought. Psychological Bulletin, 134(2), 163-206. doi: 10.1037/0033-2909.134.2.163

Watson, D., Clark, L. A., \& Tellegen, A. (1988). Development and validation of brief measures of positive and negative affect: the PANAS scales. Journal of personality and social psychology, 54(6), 1063.

Way, B. M., \& Taylor, S. E. (2010). The serotonin transporter promoter polymorphism is associated with cortisol response to psychosocial stress. Biological psychiatry, 67(5), 487-492.

Weitzman, E. D., Fukushima, D., Nogeire, C., Roffwarg, H., Gallagher, T., \& Hellman, L. (1971). Twenty-four hour pattern of the episodic secretion of cortisol in normal subjects. The Journal of Clinical Endocrinology \& Metabolism, 33(1), 1422.

Wendland, J., Martin, B., Kruse, M., Lesch, K.-P., \& Murphy, D. (2006). Simultaneous genotyping of four functional loci of human SLC6A4, with a reappraisal of 5-HTTLPR and rs25531. Molecular Psychiatry.

Wennig, R. (2000). Potential problems with the interpretation of hair analysis results. Forensic science international, 107(1), 5-12.

Werthmann, J., Roefs, A., Nederkoorn, C., Mogg, K., Bradley, B. P., \& Jansen, A. (2011). Can (not) take my eyes off it: Attention bias for food in overweight participants. Health Psychology, 30(5), 561.

Willis-Owen, S. A. G., Turri, M. G., Munafò, M. R., Surtees, P. G., Wainwright, N. W. J., Brixey, R. D., \& Flint, J. (2005). The Serotonin Transporter Length Polymorphism, Neuroticism, and Depression: A Comprehensive Assessment of Association. Biological Psychiatry, 58(6), 451-456. doi: 10.1016/j. biopsych.2005.04.050

Wippert, P.-M., Honold, J., Wang, V., \& Kirschbaum, C. (2014). Assessment of chronic stress: comparison of hair biomarkers and allostatic load indices. Psychology Research, 4(7).

Wing, R. R., Goldstein, M. G., Acton, K. J., Birch, L. L., Jakicic, J. M., Sallis, J. F., . . . Surwit, R. S. (2001). Behavioral Science Research in Diabetes: Lifestyle changes related to obesity, eating behavior, and physical activity. Diabetes Care, 24(1), 117-123. doi: 10.2337/diacare.24.1.117

Wurtman, R. J., \& Wurtman, J. J. (1986). Carbohydrate craving, obesity and brain serotonin. Appetite, 7, 99-103. doi: 10.1016/s0195-6663(86)80055-1

Yang, W., Kelly, T., \& He, J. (2007). Genetic Epidemiology of Obesity. Epidemiologic Reviews, 29(1), 49-61. doi: 10.1093/epirev/mxm004

Yeomans, M. R., Javaherian, S., Tovey, H. M., \& Stafford, L. D. (2005). Attentional bias for caffeine-related stimuli in high but not moderate or non-caffeine consumers. Psychopharmacology, 181(3), 477-485.

Zellner, D. A., Loaiza, S., Gonzalez, Z., Pita, J., Morales, J., Pecora, D., \& Wolf, A. (2006). Food selection changes under stress. Physiology \& Behavior, 87(4), 
789-793. doi: 10.1016/j.physbeh.2006.01.014

Zoccola, P. M., \& Dickerson, S. S. (2012). Assessing the relationship between rumination and cortisol: A review. Journal of psychosomatic research, 73(1), $1-9$. 

Summary 
In this dissertation it was investigated whether carrying an S-allele of the 5 -HTTLPR gene in combination with a tendency to ruminate about negative events leads to an increased chance of developing an emotional eating style.

People often crave for high-caloric sweet/fat foods when facing stress; this 'emotional eating' could potentially lead to weight gain or even obesity. Eating under stress contrasts with the normally expected response of a loss of appetite, yet in spite of intensive research within the field of biological and cognitive disciplines, it is still unknown why stress or negative affect triggers overeating in such a large portion of the population. Since the prevalence of overweight and obesity still rises, the discovery of its crucial risk factors is a most desirable goal of today's research on sub-optimal eating habits. Chapter 1 summarizes current knowledge from scientific literature regarding cognitive and biological vulnerabilities for stress-induced emotional eating. This review reveals that most studies contemplate a rather one-directional way of focusing on either cognitive or biological factors, while the interaction between biology and cognition could be essential in emotional eating behaviour. The chapter further elaborates and/or integrates these findings into a biological-cognitive interaction model in which a specific combination of genetic (5-HTTLPR) and cognitive (ruminative thinking) stress vulnerabilities are thought to increase bio-behavioural responsiveness to stress, critically increasing the rewarding value of pleasant foods and thereby promotes emotional eating.

In chapter 2 this model was tested among 827 healthy university students. These students were assessed for 5-HTTLPR genotype, ruminative thinking style, body mass index and emotional eating behaviour. As expected there was a greater association between ruminative thinking and an increased body mass among S-allele carriers than among homozygotic L-allele carriers of 5-HTTLPR. Oddly, a moderated mediation analysis did not show this 
increased BMI among stress vulnerable subjects to be mediated by emotional eating. As explained in this chapter the absence of this mediation effect of emotional eating might have been caused by the tool that was used to asses emotional eating style.

In chapter 3 an infrared eye tracker was used to measure visual attention for different food types before and after a stress induction. Participants were pre-screened for a homozygotic 5-HTTLPR genotype and having a low or high ruminative thinking style. It was expected that the high stress prone participants (high ruminative S/S-carriers) would show a heightened attention for palatable foods after stress induction. Contrary to expectations, the high ruminative S/S-carriers did not show the highest attention bias for high caloric food after stress, although the low ruminative L/L-carriers (the most stress resilient group) did show the lowest stress induced attention bias for high caloric food. Several explanations for this effect are discussed in chapter 3.

Chapter 4 describes a study in which the biological stress sensitivity of high ruminative S/S-carriers was measured on a long term scale. Through analysis of scalp hair, accumulated cortisol (stress hormone) secretion of 1 month per centimetre of hair could be determined. In this study 54 homozygotic 5-HTTLPR carriers donated a 3 centimetre hair sample and were assessed for their tendency to ruminate about negative events. In line with the hypothesis, the highest concentrations of hair cortisol were found in high ruminative S/Scarriers. These results support the hypothesis that a combination of carrying an S-allele of 5-HTTLPR and having a ruminative thinking style leads to a long term/chronic stress vulnerability.

Chapter 5 concerns a study investigating whether the combination of carrying an S/S-genotype and having a ruminative thinking style leads to increased intake of palatable foods after experiencing real life daily stress. For six weeks, 70 participants preselected for a homozygotic 5-HTTLPR genotype, filled in diaries about their food intake and their daily mood/experiences of stress. 
These diaries were later entered in software by the Netherlands Nutrition Centre, transforming these data in estimation of daily macronutrient and calorie intake. In line with expectations, total caloric intake was higher among high ruminative S/S-carriers but interestingly, only on days where they experienced stress. Further examination of the data suggested that this increased caloric intake among stress prone subjects was caused by a greater preference for saturated fats on stressful days.

In chapter 6 the results of the preceding chapters are used to discuss the hypotheses that the combined possession of an S-allele and a ruminative thinking style leads toincreased stress vulnerability and through this, increases the risk to develop an emotional eating style. Different methodological considerations and inconsistencies in the results are discussed. The overall conclusion is that there is enough evidence from different approaches to assume there is a (modest) increased risk for high ruminative S-carriers to develop an emotional eating style. 
151 

Samenvatting 
In deze dissertatie werd onderzocht of het dragen van een S-allel van het 5-HTTLPR genotype in combinatie met de neiging om vaak te rumineren (piekeren) leidt tot een verhoogde kans op het ontwikkelen van een emotionele eetstijl.

Tijdens of na stressvolle momenten verlangen mensen vaak naar hoog calorische vette/zoete etenswaren; dit 'emotioneel eten' kan potentieel leiden tot overgewicht of obesitas. Ondanks veel onderzoek binnen de biologische en cognitieve wetenschappen blijft het grotendeels onbekend waarom er zoveel mensen zijn die meer eten als ze stress ervaren. Aangezien de prevalenties van obesitas en overgewicht nog steeds stijgen, is het ontdekken van risicofactoren voor het ontwikkelen van ongezonde eetpatronen van cruciaal belang. Hoofdstuk 1 geeft een overzicht van de huidige kennis over emotioneel eetgedrag bekeken vanuit de biologische en cognitieve wetenschappen. Een literatuurstudie van relevante onderzoeken laat zien dat de meeste wetenschappelijke studies het onderwerp emotioneel eten benaderen vanuit een puur biologische of cognitieve richting, terwijl juist de interactie tussen biologie en cognitie essentieel zou kunnen zijn in emotioneel eetgedrag. De rest van dit hoofdstuk integreert huidige wetenschappelijke kennis in een bio-cognitief model waarin een combinatie van genetische (5-HTTLPR) en cognitieve (ruminatie) invloeden leidt tot een verhoogde stressrespons. Deze verhoogde stressrespons leidt potentieel tot het relatief groter belonend effect van lekker eten, en daarmee dus ook tot een groter risico op het ontwikkelen van een emotioneel eetpatroon.

Hoofdstuk 2 beschrijft een eerste toetsing van dit model onder 827 gezonde universiteitsstudenten. Onder deze studenten werd er bepaald welke variant zij hadden van het 5-HTTLPR genotype (namelijk S/S, S/L, of L/L), in hoeverre zij een geneigd zijn tot rumineren (piekeren), emotioneel eten en wat hun gewicht (BMI) was. Zoals verwacht, was het verband tussen rumineren en een hoger BMI groter onder S-allel-dragers dan onder homozygote L-allel- 
dragers. Tegen verwachting in kon op basis van een moderated mediation analyse niet worden geconcludeerd dat dit hoger BMI onder stressgevoelige mensen veroorzaakt werd door emotioneel eetgedrag. Zoals uitgebreider uitgelegd in dit hoofdstuk komt de afwezig van dit mediërende effect wellicht door de wijze waarop emotioneel eetgedrag in deze studie is gemeten.

Hoofdstuk 3 beschrijft een experiment waarin een eye-tracker is gebruikt om visuele aandacht voor verschillende voedingstypes te meten, voor en na stressinductie. Deelnemers waren uitgenodigd op basis van hun hoge dan wel lage geneigdheid tot rumineren en het hebben van een homozygoot 5-HTTLPR-genotype. De hypothese was dat stressgevoelige deelnemers (tot ruminatie geneigde S-allel-dragers) meer visueel gericht zouden zijn op plaatjes van hoog calorisch vet/zoet voedsel, na het ervaren van acute stress. Tegen verwachting in hadden niet de hoog ruminerende S/S-alleldragers de meeste stress geïnduceerde visuele aandacht voor hoog calorisch voedsel, maar hadden wel de laag ruminerende L-allel-dragers (de meest stressbestendige groep) de minste aandacht voor hoog calorisch voedsel na stress. In dit hoofdstuk worden enkele verklaringen voor dit effect verder uitgelicht.

Hoofdstuk 4 beslaat een studie waarin de biologische stressgevoeligheid van hoog ruminerende $S / S$-allel-dragers werd gemeten op een lange termijn schaal. Door middel van het analyseren van hoofdhaar is het mogelijk om retrospectief te zien hoeveel cortisol (stresshormoon) actief was in het lichaam. Iedere centimeter haar komt hier overeen met één maand cortisol afscheiding. In deze studie werden 54 mensen uitgenodigd op basis van een homozygoot 5-HTTLPR genotype, daarbij werd hun neiging tot rumineren gemeten. Zoals verwacht werden de hoogste concentraties cortisol gemeten in de $3 \mathrm{~cm}$ lange haarmonsters van hoog ruminerende S/S-allel-dragers. Deze resultaten ondersteunen de hypothese dat de combinatie van het dragen van een S-allel met de neiging om te rumineren leidt tot een hogere stressgevoeligheid op een chronische schaal. 
In hoofdstuk 5 wordt een studie beschreven waarin werd onderzocht of de combinatie van het dragen van een S-allel en het hebben van een ruminerend denkpatroon leidt tot verhoogde inname van hoog calorisch voedsel na het ervaren van stress in het dagelijks leven. Gedurende zes weken hielden 69 homozygote 5-HTTLPR-dragers een dagboek bij over hun voedingsinname en hun dagelijkse ervaring van stress. Deze (voedings)dagboeken zijn ingevoerd in de 'Eetmeter' van het Voedingscentrum om een beeld te krijgen van de dagelijkse inname van calorieën en specifieke macronutriënten. In overeenstemming met de hypothese bleek dat hoog ruminerende S/Sdragers een hogere calorie inname hadden, maar enkel op dagen dat zij stress hadden ervaren. Trends in de data suggereerden dat deze verhoogde energetische inname onder stressgevoelige deelnemers werd veroorzaakt door een grotere inname van verzadigde vetten op stressvolle dagen.

Afsluitend worden in hoofdstuk 6 alle voorgaande hoofstukken samen bediscussieerd om een conclusie te trekken over de hypothese dat de combinatie van het dragen van een S-allel van het 5-HTTLPR genotype in combinatie met de neiging vaak te rumineren (piekeren), leidt tot een verhoogde stressgevoeligheid en daarmee ook een verhoogde kans op het ontwikkelen van een emotionele eetstijl. Enkele methodologische kwesties en inconsistente resultaten worden bediscussieerd. De algemene conclusie van deze dissertatie luidt dat er voldoende bewijs is om aan te nemen dat er een (bescheiden doch significant) verhoogd risico is voor hoog ruminerende S-allel-dragers om een emotioneel eetpatroon te ontwikkelen. 

Valorization Addendum 


\section{Relevance of the studies}

Presently one of the most alarming health issues is obesity. Especially in the western world this problem is becoming more and more apparent as for instance in the USA approximately $70 \%$ of its inhabitants is overweight and in the Netherlands this number lies close to $50 \%$. As overweight and obesity are associated with serious physical and psychological health concerns and even a higher mortality rate it is imperative to the scientific community to gain more insight in the aetiology of weight gain and pave the way to the development of more efficient treatment and prevention programs.

One of the most simple but true benefactors to weight gain in a healthy population is having a diet with a caloric content that exceeds energy expenditure. Often this "overeating" is caused by eating without hunger, meaning that other factors (than the need to replenish nutrients) in people's lives makes them eat. A good example of one of these factors is emotions. Emotions can influence peoples eating behaviour, when feeling happy or sad some people restrict their food intake while others eat more. Especially this latter group is important in the context of obesity as this behavioural pattern could potentially lead to overeating and hence, weight gain. Not only does this behaviour (potentially) lead to increased intake of total calories it also often coincides with a preference for high fat and/or sweet food. While these high fat/sweet foods are usually dense in energy, this increases the risk to overeat even more. The current thesis explored a possible healthy subpopulation (high ruminative S/S-allele carriers) with an increased risk to develop an emotional eating style. By identifying these high risk subgroups, better programs can be developed to prevent or treat emotional eating and thereby prevent unhealthy weight gain.

\section{Target groups}

First and foremost this dissertation is of relevance for researchers who are interested in emotional eating behaviour and/or stress sensitivity. The 
current thesis gives new insights in how the interplay between cognitive and biological stress vulnerabilities can exacerbate each other's effects and increases the negative consequences of stress within in a clinically healthy population. Researchers in related fields can use these new insights to further develop new paradigms and better understand the complex aetiology of emotional eating behaviour. Additionally, the findings in this dissertation can be important for healthcare professionals treating or preventing emotional eating, for instance clinical psychologists, dieticians, general practitioners or policy makers.

\section{Activities and products}

The main focus of the dissertation was to gain more knowledge about the influence of the serotonergic system and ruminative thinking in the context of eating behaviour. In theory these new insights can be used in the clinical context of prevention and treatment of obesity. If only used to screen for people who are prone to develop an emotional eating style, genotyping for 5-HTTLPR genotype is (currently) too expensive. However this genotyping could be used more selectively among (sub) populations or families where obesity is prevalent. To screen for ruminative thinking patters is much easier than genotyping as there are several well validated questionnaires that can be taken through online surveys. If individuals are screened for a vulnerability to develop an emotional eating style (high ruminative S/Scarriers), prevention programs can be setup to coach those individuals in developing/maintaining a healthy eating style.

The amino-acid tryptophan can also be potentially used in the treatment of these stress prone (S/S-carrying) individuals. Tryptophan is a large amino acid which serves as a precursor for serotonin. Several studies have shown that tryptophan can a have a beneficial effect on the mood of individuals with an S/S-5-HTTLPR genotype. A few studies have shown that through (sub) chronic intake of tryptophan supplements (which have virtually no negative side effects) the negative effects on mood and stress induced appetite caused 
by an S-allele of 5-HTTLPR can be countered. Ancillary, certain diets can also improve tryptophan availability in the brain. For instance carbohydrate consumption can make tryptophan pass the blood brain barrier easier, thereby theoretically having similar effects as taking tryptophan supplements among S-allele carriers. If people are screened for ruminative thinking, this can be treated in the form of cognitive therapy. However as the effects of carrying an S-allele and/or having a ruminative thinking style on emotional eating (described in the current thesis) are of modest size these prevention methods might be too costly (in effort of the patient and financial costs for the healthcare system) for the benefits they might provide.

\section{Innovation}

Where a lot a former studies regarding emotional eating mostly looked at either biological or psychological factors, the innovation in the current dissertation was to look at theinterplay between thesefactors. As hypothesized it was found that this combination of biological and psychological stress vulnerabilities in the context of emotional eating is far more explanatory than simply looking at either factor separately. A second innovative approach of the current research line was to look for vulnerabilities to develop an emotional eating style within a healthy population rather than looking for associations among individuals pre-screened for having an emotional eating style, eating disorder or obesity.

\section{Dissemination}

The new insights as described in this dissertation have been disseminated in the academic community through publications in leading international scientific journals and presentations at international conferences. These new findings have also been incorporated in courses of the research master curriculum at the faculty of psychology and neuroscience at Maastricht University. As described under the previous headings, at the moment, these findings aren't immediately applicable for clinicians or the general public, therefor they will mostly serve an academic purpose to further our 
knowledge about emotional eating and give way to develop better models/ paradigms explaining emotional eating behaviour. 



\section{Dankwoord}


"And now, the end is near and so I face the final curtain. My friend, I'll say it clear I'll state my case, of which I'm certain. Regrets, I've had a few, but then again, too few to mention. I did what I had to do and saw it through without exemption. I planned each charted course, each careful step along the byway. And more, much more than this, I did it my way"

Maar... alleen had ik het zeker niet gekund, dus:

Allereerst, Rob bedankt dat jij mij de kans gegeven hebt om aan dit project te mogen werken! De zelfstandigheid die je mij toevertrouwde (zeker op het vlak van statistiek!) heb ik altijd zeer gewaardeerd. Ik heb vanaf het begin het gevoel gehad dat jouw deur altijd voor me open stond. De interesse die jij toont, niet alleen in het academische/professionele leven van jouw studenten/ collega's maar ook hun leven buiten de universiteit siert je. Bedankt voor al dat ik van jou heb mogen leren!

Esther, mijn academische carrière begon met een stage bij jou en nu ben je ook nog mijn co-promotor geworden! Tijdens mijn stage bij jou en Petra heb ik mogen ontdekken hoe mooi ik wetenschappelijk onderzoek doen vind. Ik vond het dan ook heel fijn dat je betrokken bent geweest bij mijn promotieonderzoek. Ik heb altijd heel graag met jou samen gewerkt en heb heel veel geleerd van jouw kritische en ervaren blik op mijn schrijven, dank je wel!

Graag bedank ik Prof. dr. Ramaekers, Dr. Roefs, Dr. Nederkoorn, Prof. dr. van Elburg, en Prof. dr. Smeets voor het beoordelen van deze dissertatie en aanwezig zijn bij mijn verdediging.

Heren van de techniek: Ron, Jacco, Erik en Johan, zonder jullie was de eyetracking studie nooit gelukt. Ontzettend bedankt voor het ontwikkelen van de taak en het veelvuldig debuggen van de eye-tracking apparatuur! 
Zonder de stagiaires en assistenten die geholpen hebben bij mijn projecten had ik lang niet zo'n mooie, grote steekproeven kunnen includeren. Sarah, Gulizar, Mariah, Leonie, Jet, Fabiona, Aimee, Romain, Bo en natuurlijk Michelle, ontzettend bedankt voor al jullie inzet! Over die grote steekproeven gesproken, alle mensen die (vaak herhaaldelijk) hebben deelgenomen aan onze studies, bedankt! Ook zonder jullie was dit boek er nooit geweest.

Mede PhD-studenten en 'post-doccers', wat hebben wij het gezellig gehad de afgelopen jaren. Ik heb altijd erg genoten van de tijd samen tijdens lunches, congressen, borrels, uitjes en zelfs een weekendje samen naar de Ardennen! Franziska, Stéphanie, Eliza, Nick, Stefan, Anne, Joep, Frederick, Jens, Natasha, Des, Ben, Rachel, Jessica, Ieke, Joseph, Lisa, Nadia en Lilian enorm bedankt, jullie zijn top!

Arjan en Annemie, bedankt voor alles wat jullie doen om de afdeling draaiende te houden! Ik ben waarschijnlijk verpest voor het leven, zo'n fijne afdeling als deze ga ik elders niet meer vinden.

Eri, de grootste proportie onverklaarde variantie die ik ooit heb mogen meemaken. We hebben elkaar al leren kennen tijdens mijn studie en uiteraard maakte toen je al een enorme indruk. Dank je wel voor al het rondfladderen op de afdeling de afgelopen jaren, de sfeer die jij bracht zal ik zeker gaan missen.

Kamergenootjes (en buurvrouw) Laura, Christine en Melloney, wat een fantastische tijd hebben wij gehad. De onderonsjes op 2.753 en daarbuiten waren voor mij enorm waardevol, de prachtige band die wij hebben opgebouwd is niet in woorden te vatten, bedankt voor alles!

Jeroen en Patrick, wij hebben flink wat slechte films gekeken de afgelopen jaren, al dan niet gevolgd door een flinke portie Buurman \& Buurman. Eén van de mooiste filmavonden van de afgelopen jaren was voor mij: 31 maart 2017. Ik was toen de hele dag bezig geweest met het vervoeren van meerdere vaten limonade, van Enschede naar het lab in Maastricht. s' Avonds kon ik 
toen moe maar voldaan bij Jeroen thuis aanschuiven voor een stukje vlaai (greumelen pudding!) terwijl wij vol verbazing en plezier de "topper" 'Birdemic' hebben gekeken, wat een draak van een film was dat. Mannen, bedankt voor deze avondjes! Dat er nog velen mogen volgen!

(Zuster) Ankie, dankzij jou heb ik de afgelopen jaren in ieder geval geen honger hoeven te lijden. Bedankt voor alle lekkere maaltijden die vaak in overvloede geserveerd werden en meestal gepaard gingen met een tweede maaltijd om mee naar huis te nemen! Kevin, enorm bedankt voor alle hulp de afgelopen jaren! Of het nou om autoproblemen gaat, verhuizen of wat dan ook, jij schroomt nooit om hulp aan te bieden, dank je wel!

Pap en mam, jullie hebben mij van jongs af aan al altijd de ruimte en het vertrouwen gegeven om zelf mijn plek in deze wereld te ontdekken. Bedankt dat jullie altijd achter mij staan bij al mijn ondernemingen!

Lieve Floor, de Blues Brothers zeiden het al: 'everybody needs somebody to love!' en voor mij ben jij dat! Dank je wel voor het opfleuren van dit boekje en de rest van mijn leven! 



\section{Curriculum Vitae}


Robbie Schepers was born on the $21^{\text {st }}$ of October 1988 in Stein. After completing secondary school (HAVO, Groenewald college Stein) in 2005 he obtained a bachelor's degree in Social Work (Hogeschool Zuyd in Maastricht) in 2009 and a bachelor's degree in Psychology and Neuroscience (University Maastricht) in 2012. Robbie attained a master's degree in Neuropsychology in 2013, during his time at university Maastricht he conducted a research internship at the department of Neuropsychology and Psychopharmacology with dr. Petra Hurks and dr. Esther Keulers. In this internship, where he tested the effectiveness of a computer game that was designed to improve working memory in young children, he discovered his love for doing research. After graduating, Robbie combined teaching at the university with doing research at Statistics Netherlands (CBS) for a short time. In 2014 he was given the opportunity to start a PhD project with prof. dr. Markus which resulted in this dissertation. During this project he also obtained his University Teaching Qualification (BKO). After obtaining his PhD Robbie followed his passion for statistics and is currently continuing his career as a data analist. 



\section{Publications}




\section{Published:}

Schepers, R., \& Markus, C. R. (2017b). The interaction between 5-HTTLPR genotype and ruminative thinking on BMI. British Journal of Nutrition, 118, 629-637.

Schepers, R., \& Markus, C. R. (2017a). Gene by Cognition interaction on stress-induced attention bias for food: effects of 5-HTTLPR and Ruminative Thinking. Biological Psychology, 128, 21-28.

Markus, C. R., Rogers, P. J., Brouns, F., \& Schepers, R. (2017). Eating dependence and weightgain;nohuman evidencefor a'sugar-addiction'model of overweight. Appetite, 114, 64-72.

Schepers, R., \& Markus, C. R. (2015). Gene $\times$ cognition interaction on stressinduced eating: Effect of rumination. Psychoneuroendocrinology, 54, 41-53.

\section{(To be) submitted:}

Schepers, R., Keulers, E.H.H. \& Markus, C. R. (2018a). The effect of 5-HTTLPR genotype and cognitive rumination on long term cortisol reactivity measured in human hair.

Schepers, R., Keulers, E.H.H. \& Markus, C. R. (2018b). The interaction between 5-HTTLPR genotype and Ruminative Thinking on Daily Stress and Food Intake - a multilevel approach.

\section{Conference presentations}

Schepers, R., \& Markus, C. R. (2017). The effect of 5-HTTLPR genotype and cognitive rumination on cortisol reactivity measured in human hair. Dutch Neuroscience Meeting, Lunteren, the Netherlands

Schepers, R., \& Markus, C. R. (2016). Gene by cognition interaction on stress- 
induced attention for food. Stress and Behavior, Miami (FL), USA

Schepers, R., \& Markus, C. R. (2016). Gene by cognition interaction on stressinduced attention for food. Dutch Neuroscience Meeting, Lunteren, the Netherlands

Schepers, R., \& Markus, C. R. (2015). The interaction between 5-HTTLPR and rumination on emotional eating. Dutch Neuroscience Meeting, Lunteren, the Netherlands 